Portland State University

PDXScholar

\title{
Experimental determination of post-buckling performance of steel angles
}

\author{
Rupasiri Purasinghe \\ Portland State University
}

Follow this and additional works at: https://pdxscholar.library.pdx.edu/open_access_etds

Part of the Mechanical Engineering Commons, and the Structural Engineering Commons Let us know how access to this document benefits you.

\section{Recommended Citation}

Purasinghe, Rupasiri, "Experimental determination of post-buckling performance of steel angles" (1981). Dissertations and Theses. Paper 3165.

https://doi.org/10.15760/etd.3156

This Thesis is brought to you for free and open access. It has been accepted for inclusion in Dissertations and Theses by an authorized administrator of PDXScholar. Please contact us if we can make this document more accessible: pdxscholar@pdx.edu. 
AN ABSTRACT OF THE THESIS OF RUpasiri Purasinghe for the Master of Science in Applied Science presented September 24, 1981.

Title: Experimental Determination of Post-Buckling Performance of Steel Angles

APPROVED BY MEMBERS OF THESIS COMMITTEE:

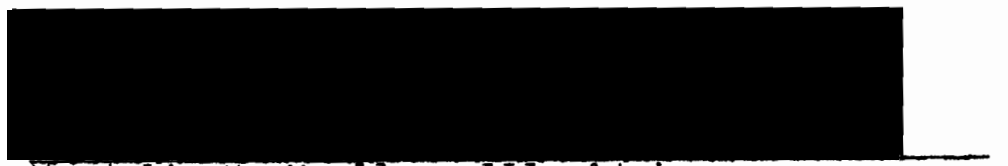

$$
\text { Wendelin H. Mueller, III, Advisor }
$$
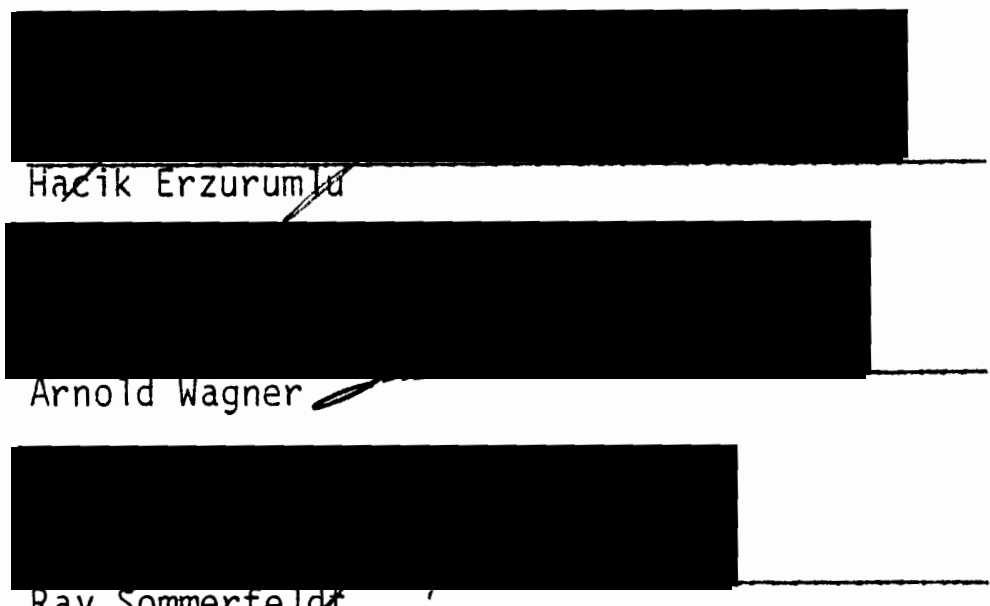

Ray sommerfeldt

An experimental testing program was conducted to determine the compression member performance in post-buckling region. These results are compared with an analytical computer program developed by Portland State University under Bonneville Power Administration Contract 79-80BP 24005. The paper presents the sensitivity of the performance of single angle compression members to various parameters such as length to radius of gyration ratio, eccentricity, end conditions and yield stress. The effect of local buckling on long member performance is also documented. Data is presented as axial load vs axial displacement. Dial gages were used to measure translation and rotation of the member ends. Computer 
programs documented in this paper calculate the axial displacement using these dial readings. Preliminary study of load transfer characteristics of an indeterminate truss is also documented.

These results are needed as a foundation to verify member performance in a Limit State Analys is of transmission towers. 
EXPERIMENTAL DETERMINATION OF POST-BUCKLING PERFORMANCE OF STEEL ANGLES

by

RUPASIRI PURASINGHE

A thesis submitted in partial fulfillment of the requirements for the degree of

\author{
MASTER OF SCIENCE \\ in \\ APPLIED SCIENCE
}

Portland State University

1981 
TO THE OFFICE OF GRADUATE STUDIES AND RESEARCH:

The members of the Committee approve the thesis of Rupasiri Purasinghe presented September 24, 1981.

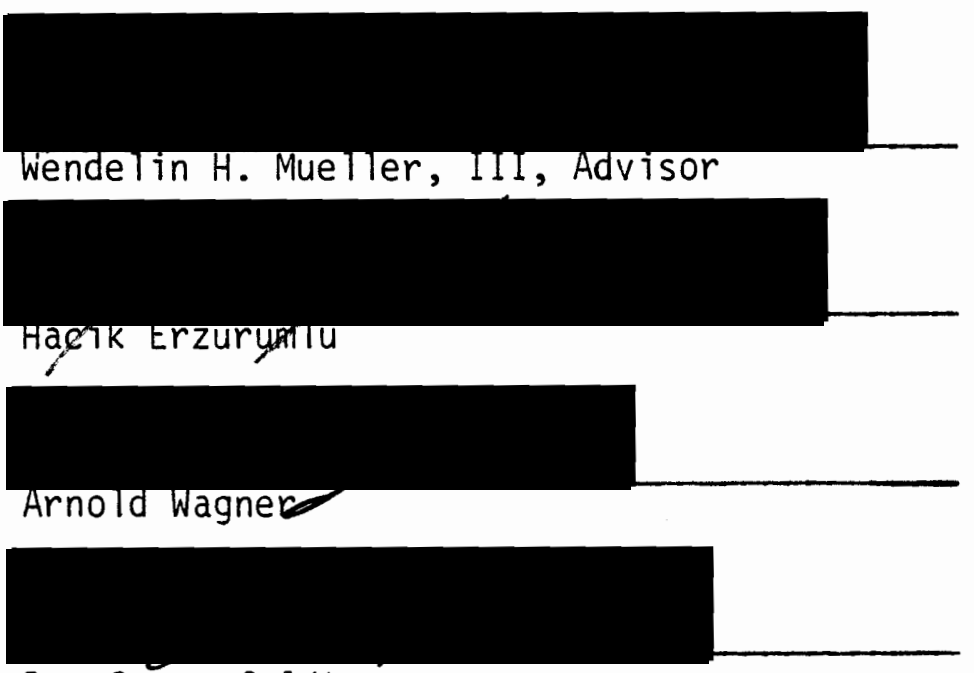

Ray Sommerfeldt

APPROVED :

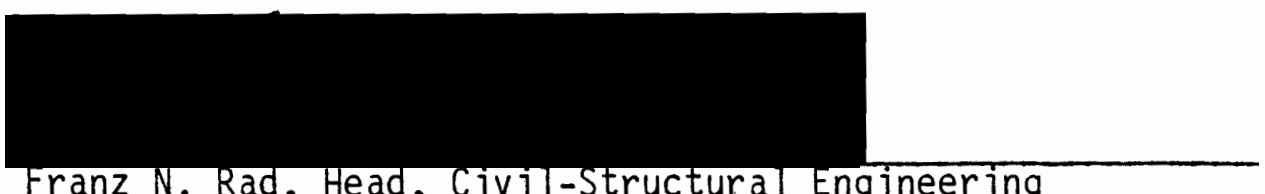

Franz N. Rad, Head, Civil-Structural Engineering

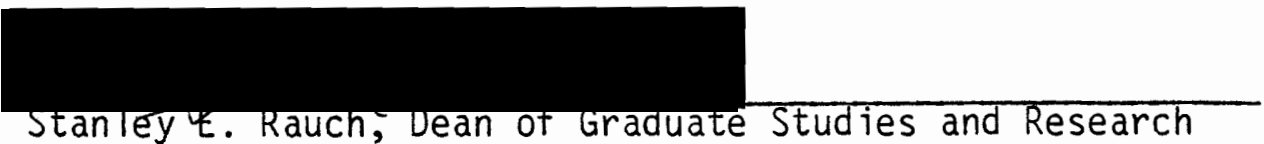


TO MY LOVING MOTHER 
The author is deeply grateful to Dr. Wendelin H. Mueller for his guidance, help, encouragement and patience throughout this investigation. Gratitude is aiso expressed to Dr. H. Erzurumlu for his advice and comments during my stay at Portland State University. The author is thankful to Mr. Arnold Wagner and Or. Ray Sommerfeldt for their comments and criticism.

Financial assistance in the form of a research grant from the Bonneville Power Administration is gratefully appreciated.

Appreciation is also due to Mr. Steve Speer for the help in the experimental work and to Mr. Bahman Daniali and Mr. David Reiser for their assistance in drawing the figures. Last but not least to Ms. Donna Mikulic for the fine job she did in typing this thesis. 
TABLE OF CONTENTS

PAGE

ACKNOWLEDGMENTS iv

LIST OF TABLES vii

LIST OF FIGURES

viii

CHAPTER

I INTRODUCTION

1.1 Background and Review of Literature 1

1.2 Objective of this Investigation 5

II EXPERIMENTAL PROGRAM FOR SINGLE ANGLE MEMBERS 7

2.1 Overview 9

2.2 Experimental Setup for Single Angle Member Tests

2.3 Instrumentation

2.4 Test Procedure 23

2.5 Computation of Axial Displacement 24

2.6 Steel Properties and Coupon Tests 24

2.7 Comparison of Experimental and Analytical Results for Single Angle Member Tests 25

II PREL IMINARY EXPERIMENTAL PROGRAM FOR INDETERMINATE TRUSS TESTS

3.1 Overview

3.2 Experimental Setup 61

3.3 Instrumentation 
CHAPTER

3.4 Test Procedure $\quad 64$

3.5 Steel Properties and Coupon Tests 65

3.6 Discussion of Results 65

IV CONCLUSIONS AND RECOMMENDATIONS 80

$\begin{array}{ll}\text { REFERENCES } & 83\end{array}$

$\begin{array}{ll}\text { APPENDIX A } & 84\end{array}$

$\begin{array}{ll}\text { APPENDIX B } & 95\end{array}$ 


\section{LIST OF TABLES}

TABLE

PAGE

I Test Configuration for Single Members 16

II Results of Coupon Tests for Single Member Tests 27

II Failure Load Comparison for Single Member Tests 55

IVA Diagonal Member Configuration in Preliminary Truss Tests $\quad 66$

IVB Comparison of Results in Preliminary Truss Tests 67

V Steel Properties of Indeterminate Truss Tests 68 
LIST OF FIGURES

FIGURE

PAGE

1. Bilinear load vs displacement curve 3

2. Indeterminate truss 8

3. Experimental setup for single angle test member 10

4. Details of end connections for single member tests 12

5. Experimental setup for single member tests 13

6. Experimental setup for single member tests 13

7. Loading configuration for single member tests 14

8. Hinged joint 15

9. Bolted member end connection attached to the ball joint 15

10. Bolted connections for single member tests 18

11. Dial gage setup for measuring displacements 20

12. Gage layout to measure rotation about the axis of the member

13. Gage layout for single member tests including the rotational gages

14. Typical stress strain curve 26

15. Test S2 HH 50-2 29

16. Test $\mathrm{S} 2 \mathrm{HH} 36-1 \quad 30$

17. Test $\mathrm{S} 2 \mathrm{HH} 36-2 \quad 31$

18. Test SI HH 50-1 32

19. Test SI HH 36-2 33

20. Test S3 BB 36-1 34 
FIGURE

PAGE

21. Test S3 BB 36-2

35

22. Test S1 BB 36-2

36

23. Test S2 BB 36-3

24. Test T2 BB 50-1

25. Test T2 BB 36-1

39

26. Test $T 1$ BB 36-1

27. Test $T 1$ BB 50-1

28. Test T3 BB 50-1

29. Test T3 BB 36-1

43

30. Test S3 BB 50-1

31. Test $S \emptyset$ BB 50-1

45

32. Test T2 BF 50-1

46

33. Test T2 BF 36-1

34. Test SR3 BB 36-1

35. Test TR3 BB 50-1 (1) 49

36. Test TR3 BB 50-1

50

37. Test TR2 BB 50-1

38. Test TR1 36-1

39. Test TA BB 36-1

40. Test T4 BB 36-2

41. Setup of truss without diagonal bracing

42. Indeterminate truss with diagonal bracing

43. Indeterminate truss

44. Test FX1

45. Test $F \times 2$ 
F IGURE

PAGE

46. Test $F \times 3$ and $F \times 3 A$

47. Test Fx4 and Fx4A 72

48. Test Fx5, F $\times 5 A$ and Fx5B 73

49. Test Fx6 74

50. Test Fx7, Fx7A and Fx7B 75

51. Test Fx8 and Fx8A 76

52. Test Fx9 and Fx9A 77

53. The end plate and gage layout at one end of the test member

54. Translation of the end plate and rotation about the $y$ axis for the hinged-hinged configuration

55. Gage layout for single member tests including the rotational gages

56. Translation of the end plate with rotation about the $x$ axis

57. Rotation of the end plate about the $z$ axis

58. Rotation of the end plate about the $x$ axis 100

59. Rotation of the end plate about the $y$ axis 100 


\section{CHAPTER I}

\section{INTRODUCTION}

\subsection{BACKGROUND AND REVIEW OF LITERATURE}

In the analysis and design of indeterminate structures, two different concepts are used. One is the elastic strength concept which leads to working stress design. In this concept yielding of a member is the failure criteria. A factor of safety is applied to the yield stress to obtain the allowable stress. Members of the structure are then sized to withstand the allowable stress. This gives rise to the allowable load of a member which is lower than the actual load the member can sustain. This results in a conservative structural configuration where few points of the structure are stressed to the allowable stress but the rest of the structure is understressed. The second approach is the Limit State Analysis. Conceptually this approach is similar to plastic analys is and design developed by Beedle (1). It calculates the collapse load of the structure and then applies a factor of safety to this value to calculate the allowable load. This approach allows the redistribution of moments as individual parts of the structure reach the ultimate moments or form plastic hinges. Failure will not occur until enough plastic hinges form to cause the collapse mechanism in the structural system.

Trusses are structures made up of members that sustain axial thrust but not bending. This axial thrust is either a compression or a tensile force depending on the configuration of the truss and loading conditions. Application of a Limit State Approach to indeterminate 
trusses allows the redistribution of loads to other members as individual members reach their ultimate load. Tensile members cause no concern in this type of analysis, since once they reach yield or the ultimate load they are able to sustain it through large deflections. Compression members on the other hand because of their susceptibility to buckling are a concern in this type of analysis. Once they reach failure or buckling can they sustain an internal force large enough to allow redistribution of load throughout the structure?

Transmission Towers are highly indeterminate structures and should therefore benefit from a Limit State Analysis. As members reach their ultimate loads and sustain them through larger deflections, the structure is able to redistribute it and resist higher structural loads. In developing a Limit State Analysis for indeterminate trusses like Transmission Towers a thorough knowledge of compression member performance is required. Only when this is accomplished can a Limit State Analys is technique be developed with confidence, utilizing the reserve strength of indeterminate trusses.

There are classical computer analys is techniques to determine internal forces of members in an indeterminate truss. The technique developed by Wang (2) is one of these. These internal forces are obtained by first calculating the joint displacements of the truss. One idealized approach to a Limit State Analys is is to assume a bilinear load-deflection curve for member performance. In this type of analys is it is assumed that when the member reaches its ultimate load capacity, it will provide a constant resisting force for increased member elongation (Fig. 1). Wang (2), Lee (3), Smith and Epstein (4) have assumed the above loaddeflection behavior in their analysis techniques. Compression tests 


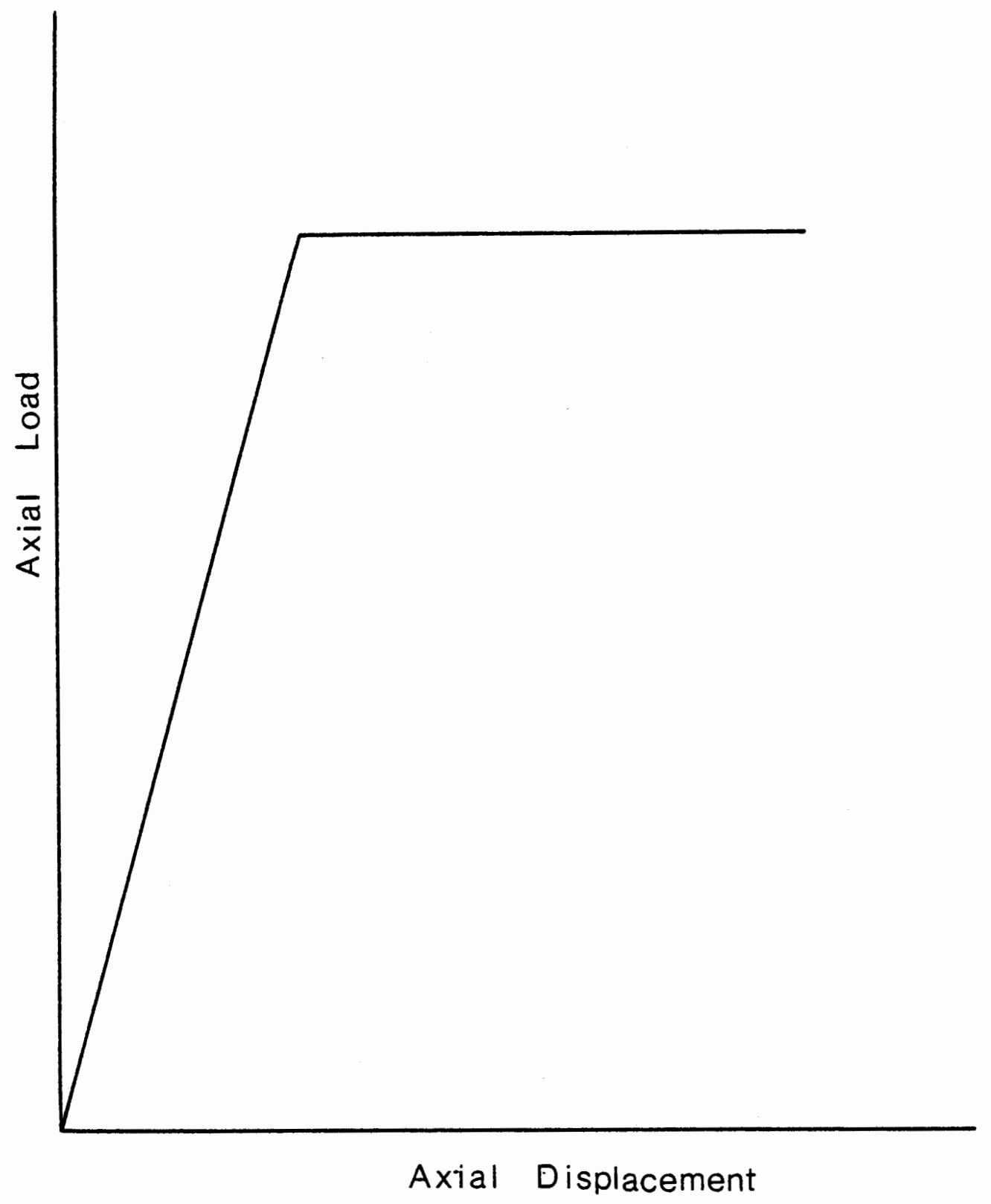

Figure 1 Bilinear load vs displacement curve 
reported in 'Force Limiting Devices in Space Trusses' by Schmidt and Hanaor (5) and 'Inelastic Cycles of Axially Loaded Steel Members' by Kahn and Hanson (6) document that this bilinear assumption may be unconservative. The load resistance that was shown in this type of member dropped off after the maximum load was reached. This unloading could affect the manner in which redistribution of load throughout the structure was accomplished if

a) the unloading was immediate after the ultimate load was reached

b) the elongation of the member was such as to put the member performance in the unloading phase.

The application of Limit State Analysis of trusses using the bilinear load-deflection curve is valid only if the actual load-deflection curve that depicts the member performance has a large enough plastic plateau to hold a constant force allowing the redistribution of load to other members. Otherwise a refinement to this constant force assumption is warranted. This refinement must account for any unloading which may exist after the plastic plateau is passed. Compression member performance can be categorized into three phases. They are
a) Elastic
b) Inelastic
c) Post buckling

Once the behavior of compression members in these phases are known a decision can be made as to whether a refinement is needed to the constant force approach of Limit State Analysis. If some members are unable to sustain a constant load over a large enough axial displacement then a refinement to the constant force approach will be necessary.

This refinement should allow the individual members to sustain 
lower loads than their ultimate load capacity when excessive elongations are attained.

\subsection{OBJECTIVE OF THIS INVESTIGATION}

As stated in Section 1.1 a thorough knowledge of compression member performance is needed before embarking on a Limit State Analys is of Indeterminate Trusses. This investigation is aimed at investigating compression member performance by conducting an experimental testing program and comparing it with the analytical computer program developed in Bonneville Power Administration contract 79-80BP24005 (7). A series of single member tests with varying lengths, eccentricities and yield strength were performed to investigate the overall member performance and to determine if the results were sensitive to particular parameters. Steel angles are the members used in construction of the majority of transmission towers. Hence a single angle steel member was chosen for this study. The size selected was $3 \times 3 \times \frac{1}{4}$ angle because the existing equipment was capable of loading this member to failure in various length configurations and support conditions that are of concern in this investigation.

The lengths selected were such that the length to radius of gyration $(L / r)$ ratio was as close as practical to 60,120 and 200 . The reason for this choice is that these are the $L / r$ ratios of members that are of interest in a Limit State Analysis of a Transmission Tower. Both Grade 50 and A-36 steel were used since these are the two common types of stee 1 used in construction.

The eccentricity of the load from the center of gravity of the test member is the third parameter chosen as relevant to effect 
member performance. Eccentricity about the weak axis $\left(e_{x}\right)$ with zero eccentricity about the strong axis and eccentricities about both axes ( $e_{x}$ and $e_{y}$ not equal to zero) were studied.

Different end connections were studied to obtain information on their effect on member performance. A Hinge-Hinge Connection which allows end rotation about only one axis, a Ball-Ball Connection which allows end rotation in all directions, a Bolted Connection to simulate a typical tower joint and a Fixed end connection,-fixed against joint rotations were used. Test members with Hinge or Ball Connections were welded to a plate and then directly connected to the Hinge or Ball as the case may be. Members with Bolted Connection were bolted to a stub angle extending from the ball joint allowing freedom to rotate in all directions.

The effect of local buckling in long member performance is of concern in this investigation. Local buckling causes a sudden decrease in the load resistance capacity of the member, thus if a local buckle formed in a long member which would be expected to have a large plastic plateau, might it not perform more like a short member with no plastic plateau? Hence two $5 \times 3 \times \frac{1}{4}$ non compact single angle steel members were tested using the ball-ball configuration. This angle member had a width-tothickness ratio of 20 which exceeds the limitation in AISC Manual of Stee 1 Construction (8) for compact members. This limit guards against local buckling.

A two dimensional indeterminate truss was selected to do a preliminary study of load transfer characteristics of diagonal bracing. The test setup was arranged such that the diagonal members control the 
limiting load of the structure. Figure 2 is a sketch of this truss. The objectives of these tests were accomplished by constructing the square test frame with large members relative to the diagonal bracing so that the test frame has little influence on the limiting load of the frame. Load is applied at a joint of the truss as shown in Fig. 2. The maximum experimental load capacity of the test frame was determined and compared with the theoretical maximum capacity as determined by statics which was calculated using a zero load in the compression member after failure and assuming yield force in the tension diagonal. This comparison makes it possible to obtain data as to how the buckled compression diagonal aids in the load carrying capacity of the frame by redistributing the loads to the tension member. 


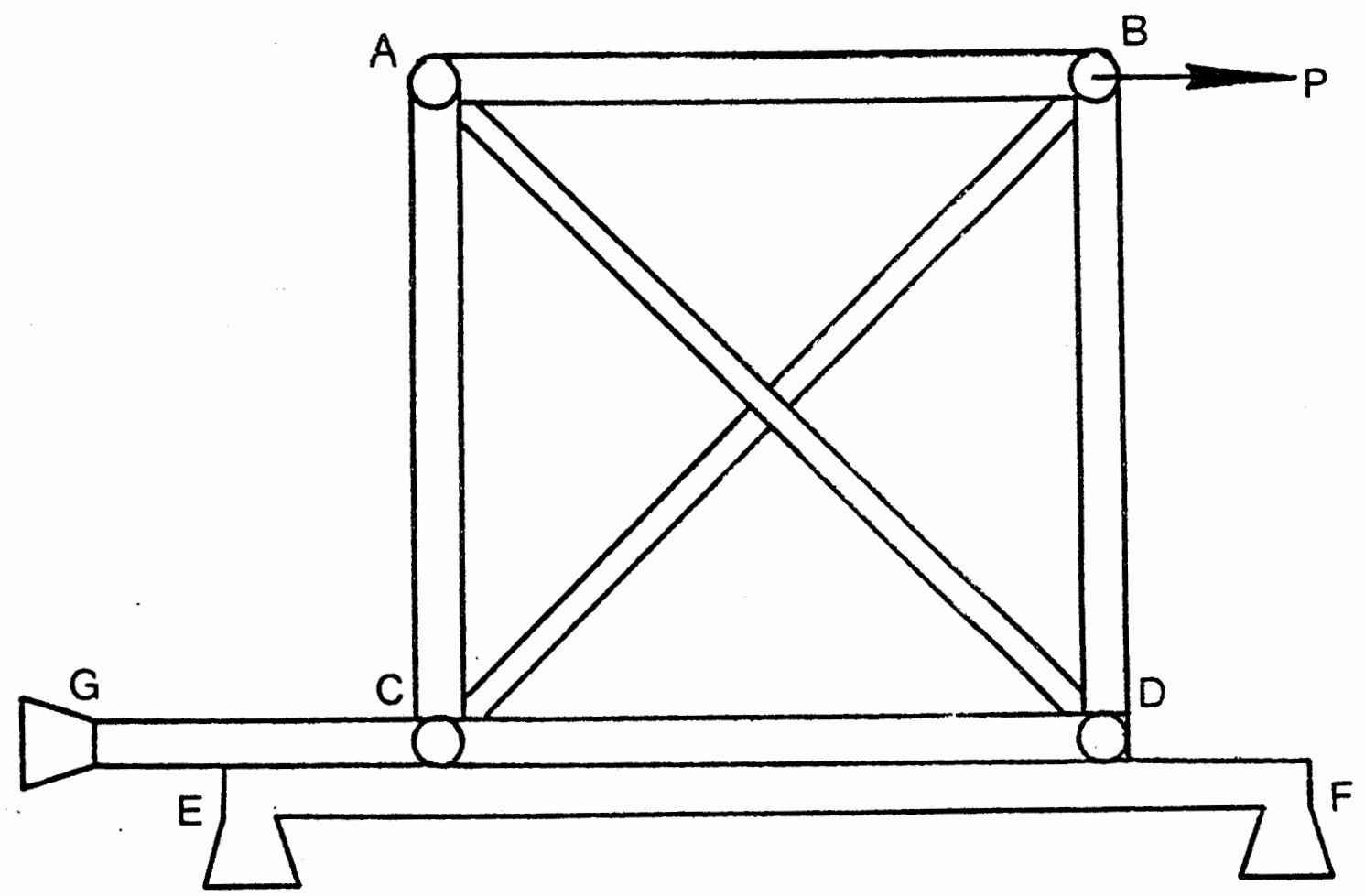

Figure 2 Indeterminate truss 


\section{EXPERIMENTAL PROGRAM FOR SINGLE ANGLE MEMBERS}

\subsection{OVERVIEW}

This chapter documents the testing program of single angle beamcolumns. Attention is given to the experimental setup, instrumentation and test procedure. Steel properties and coupon test results for these angles are included. Experimental results are compared with the loaddisplacement history predicted by the analytical computer model of Ref. 7 .

\subsection{EXPERIMENTAL SETUP FOR SINGLE ANGLE MEMBER TESTS}

An MTS series 810 Electro-hydraulic Material Testing System was used to test the members. The load was applied using a hydraulic actuator which has a maximum capacity of 110,000 pounds. The system is able to control stroke of the actuator, load and strain.

A horizontal load frame was designed and constructed as part of this research. The load frame consists of two 40 foot long $W 10 \times 21$ wide flanges spaced $47 \frac{1}{4}$ inches apart and supported $129 / 16$ inches from the floor. Lateral stability of this frame is provided by having $4 \times 4 \times \frac{1}{4}$ steel angles as cross members across the top flanges of the two $\mathrm{W} 10 \times 21$ 's. The hydraulic actuator is reacted by a W $21 \times 44$ attached to the inside of the W $10 \times 21$ 's. Horizontal stability at the front of the actuator is provided by physical connection to each of the $W 10 \times 21$ 's. To complete the framework at the other end, a W $21 \times 44$ reaction block is provided. The test member is then positioned between the front of the actuator and this reaction block. Figure 3 details this configuration. 


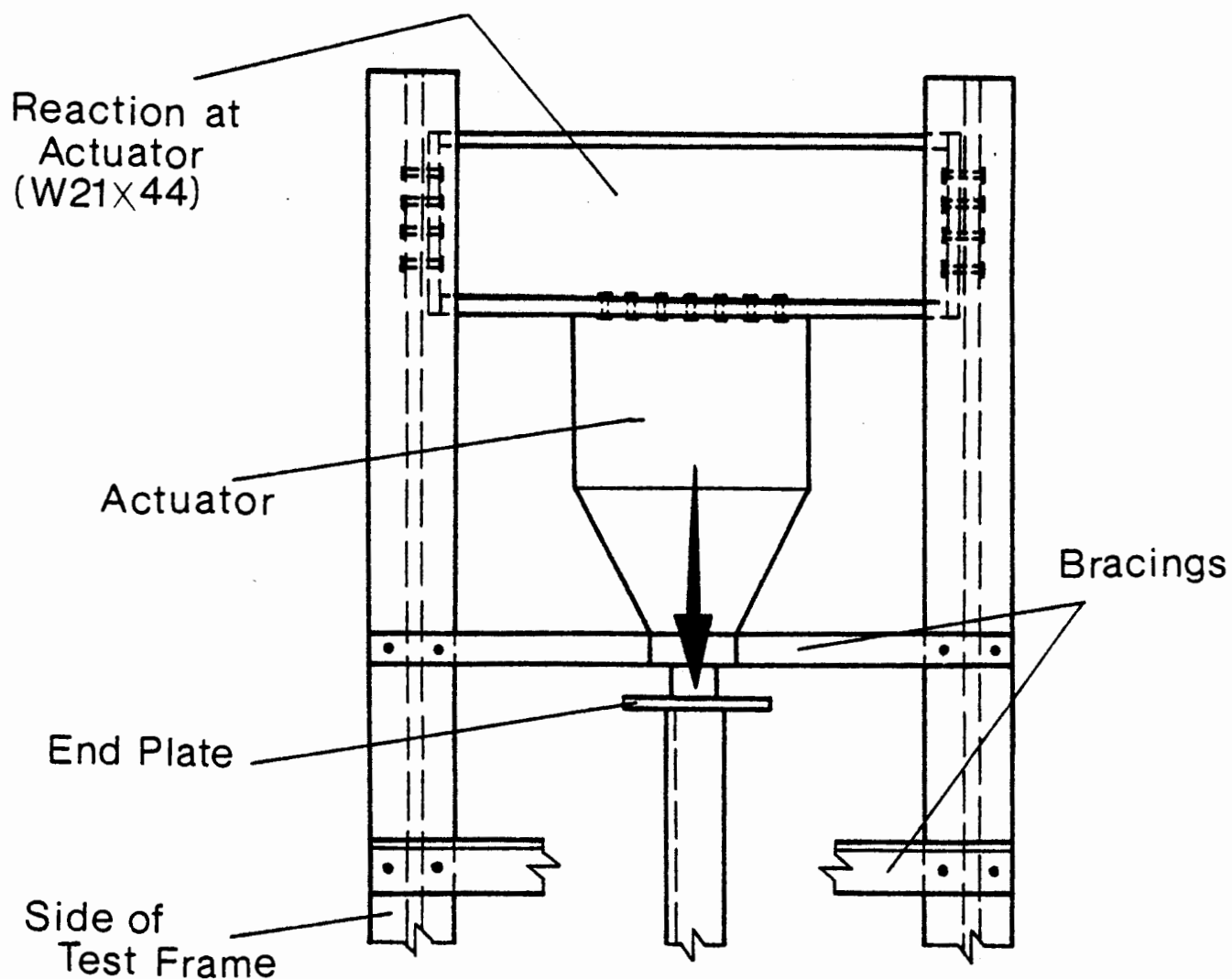

(W10 $\times 21)$

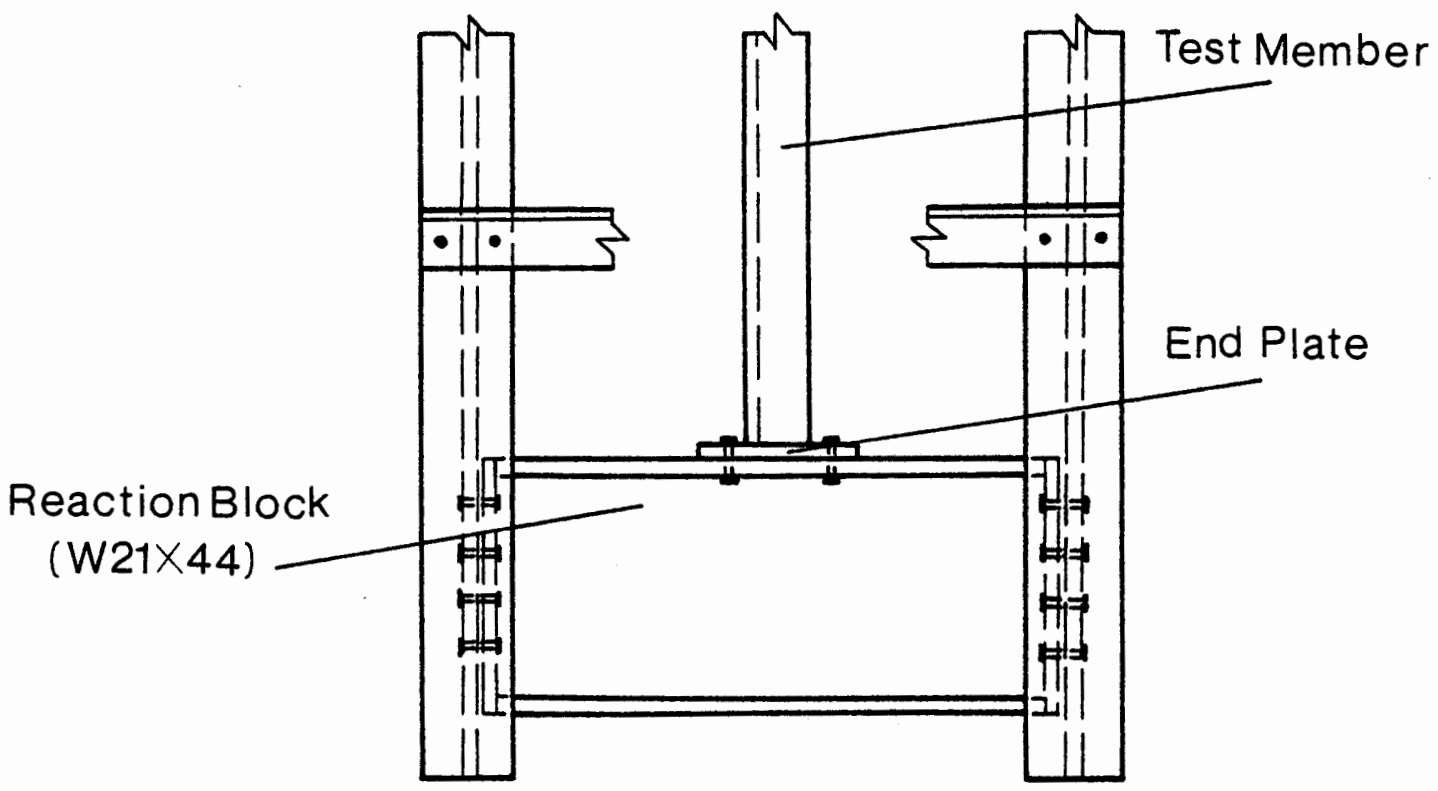

Figure 3 Experimental set up for single angle test member 
Two $12^{\prime \prime} \times 10^{\prime \prime} \times \frac{1}{2} "$ plates are used as end plates at each end of the test member to provide connection to the actuator and the reaction block. Details of connections of end plates are given in Fig. 4.

Figures 5 and 6 are two views of the experimental setup for single angle member tests. This configuration may be idealized as shown in Fig. 7 . Figures 8 and 9 are photographs of the hinge end and the ball joint respectively. The set up for Fig. 9 has a bolted member end connection attached to the ball joint. The eccentricity of the axial load was obtained by connecting the end plates to the test member with the desired offset. A list of the members tested is given in Table 1.

The end conditions consist of a hinge, a ball joint, a fixed end or a bolted connection. The hinged end condition was achieved by fabricating a rocker from a 1.25 inch diameter high strength rod which allowed rotation only about one axis. The ball joint end condition was a 4 inch diameter ball and socket machined to mate and lapped to obtain a contact fit. This ball joint was capable of rotating in all directions. High pressure grease was used to reduce friction in the ball joint. In a hinge or a ball joint the member was welded to the end plate and this plate was directly attached to the joint. A fixed end was achieved by welding the end of the test angle directly to a plate which was bolted to the reaction block of the test frame. Figure 4 details each of these attachments. A bolted joint consists of a bolt pattern as shown in Fig. 10 connecting the angle to be tested to a stub angle. This stub angle is then connected to a ball joint as its final attachment to the test frame. Bolts with $5 / 8$ inch diameter were used in this connection. The bolts were connected as tight as possible using a standard 15/16 inch combination wrench. This bolted configuration was chosen to provide 


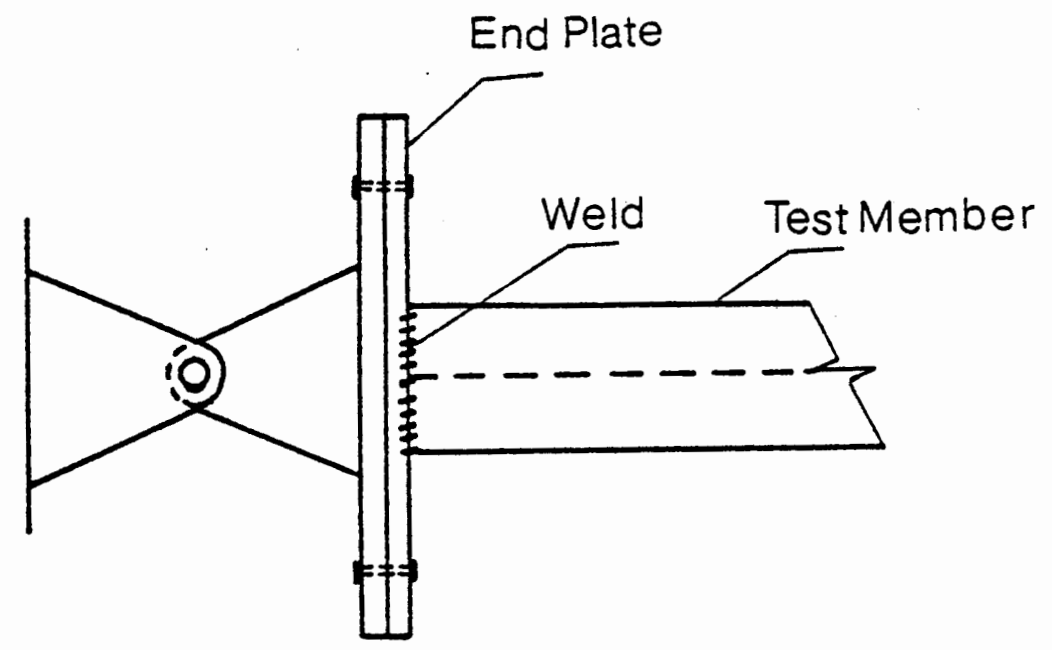

(a) PINNED JOINT

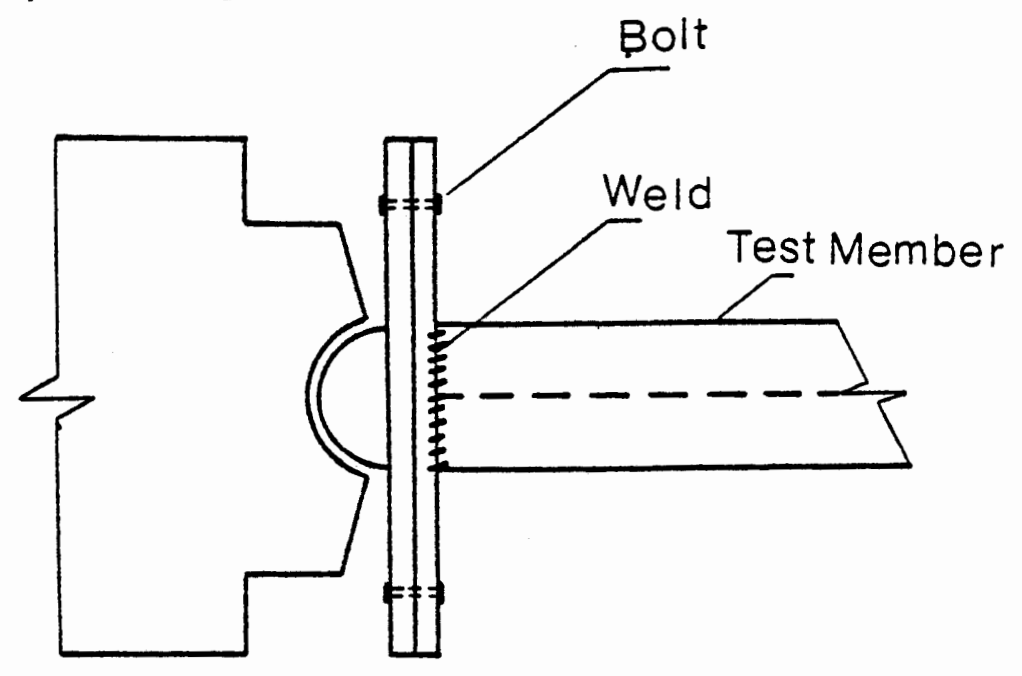

(b) BALL JOINT

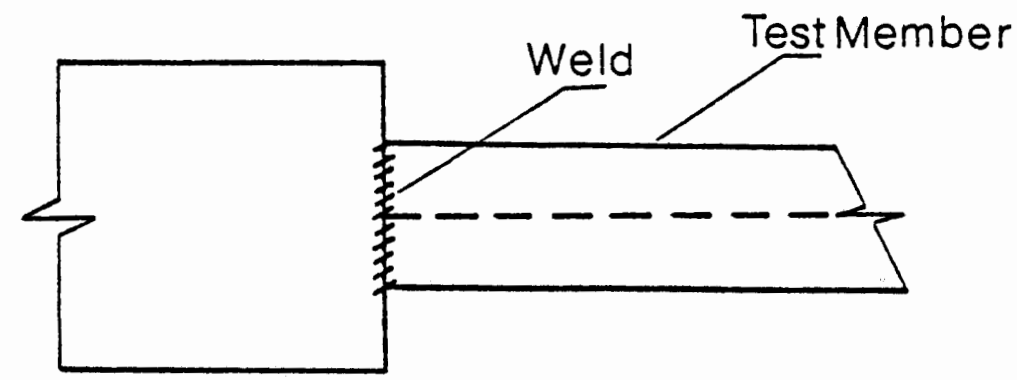

(c) FIXED JOINT

Figure 4 Details of end connections for single member tests 


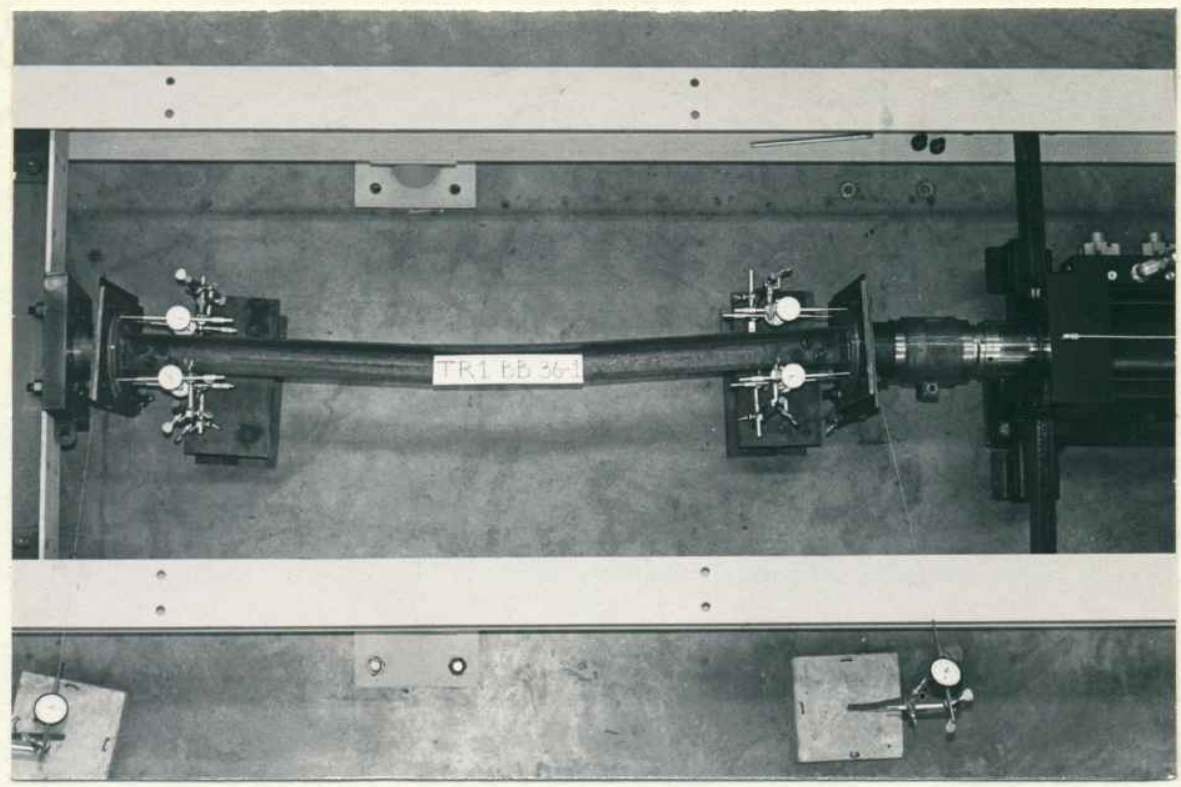

Figure 5. Experimental setup for single member tests

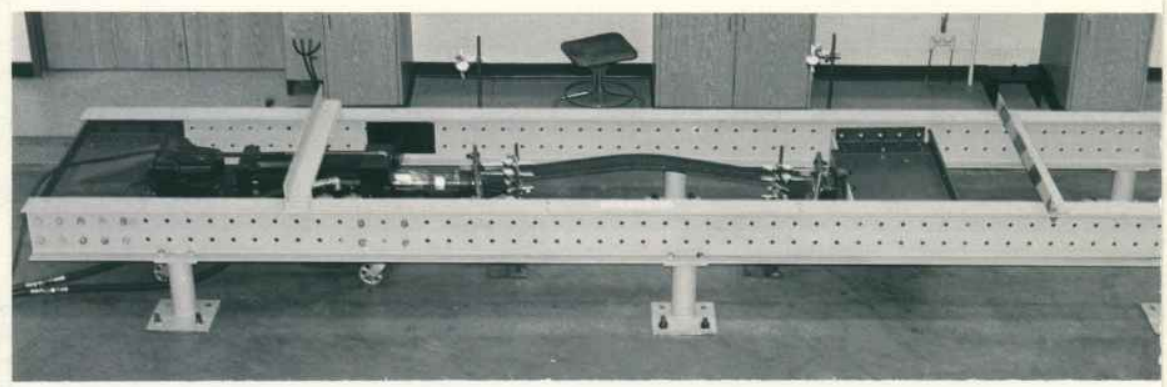

Figure 6. Experimental setup for single member tests 


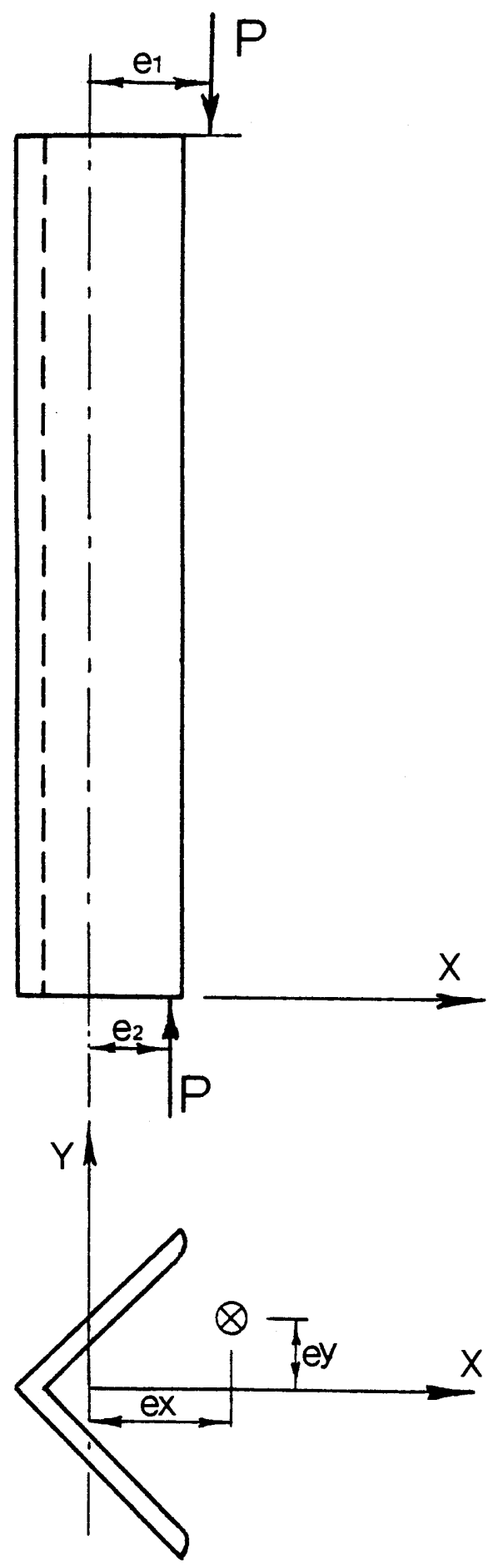

Figure 7 Loading configuration for single member tests 


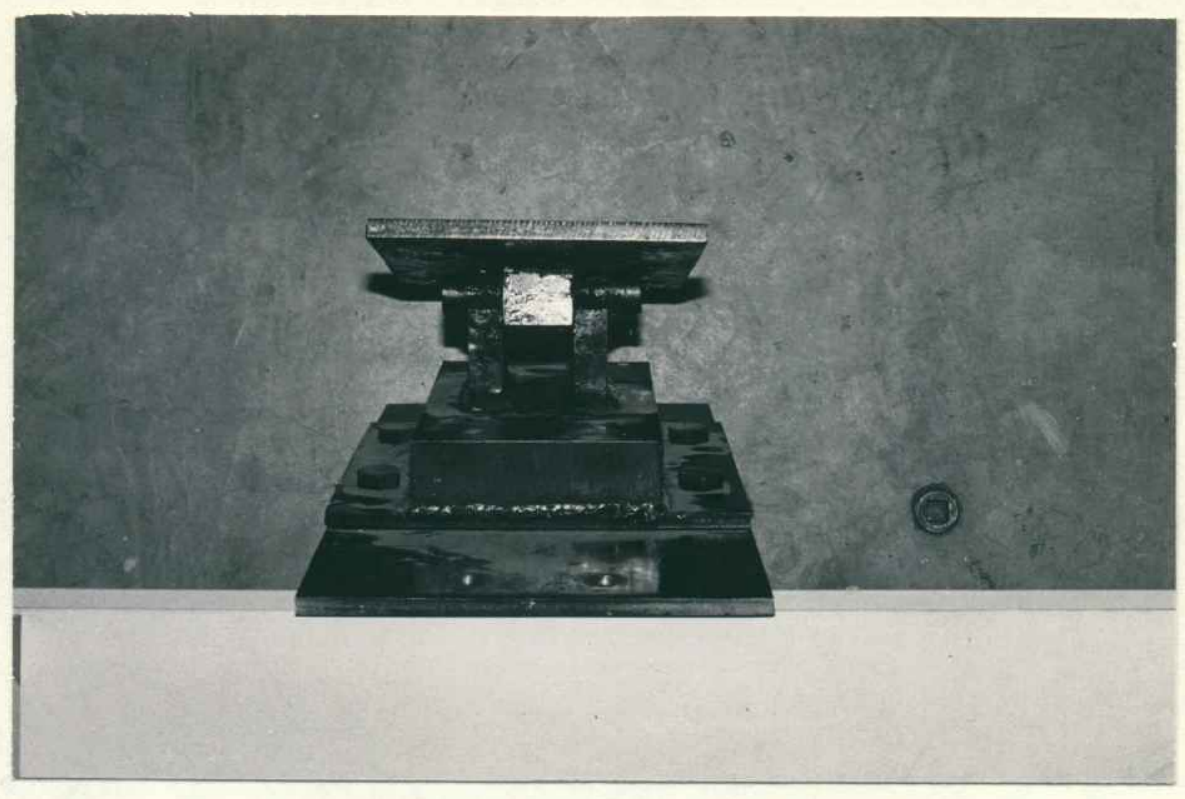

Figure 8. Hinged joint

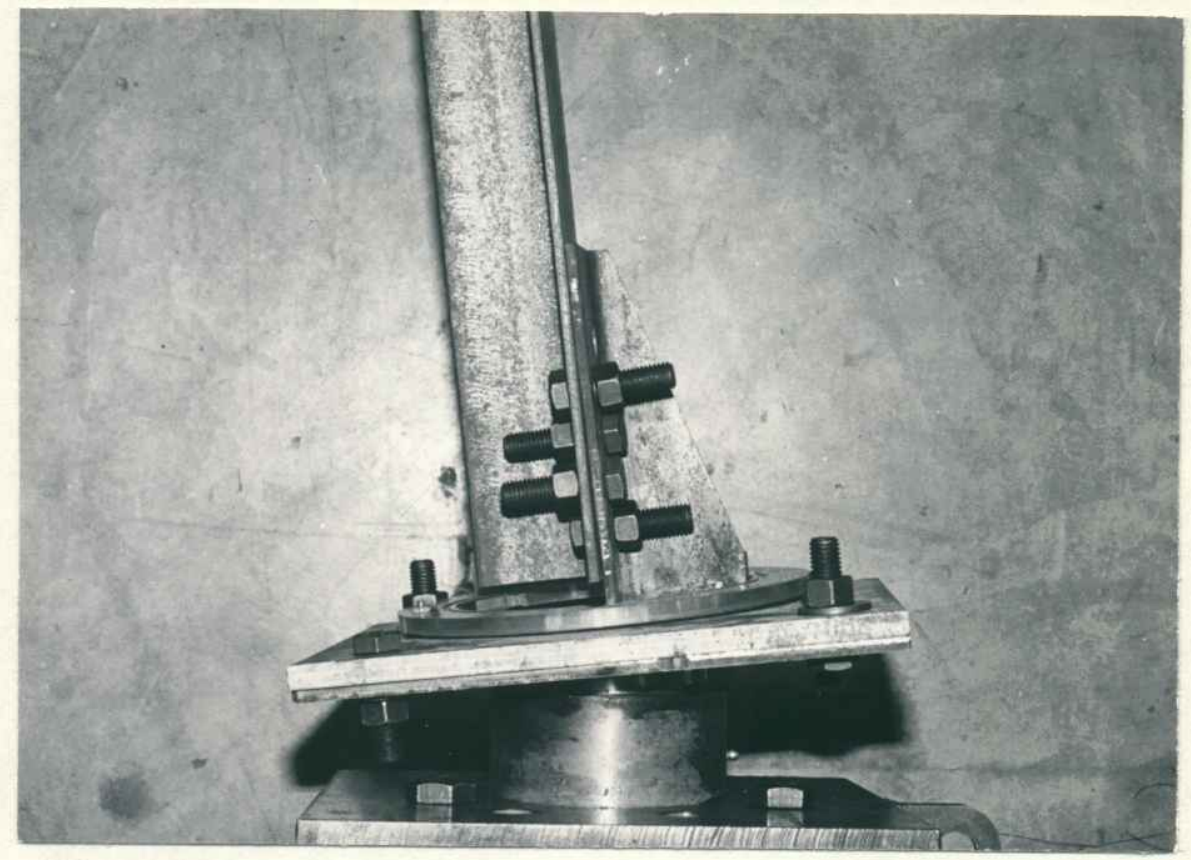

Figure 9. Bolted member end connection attached to the ball joint 


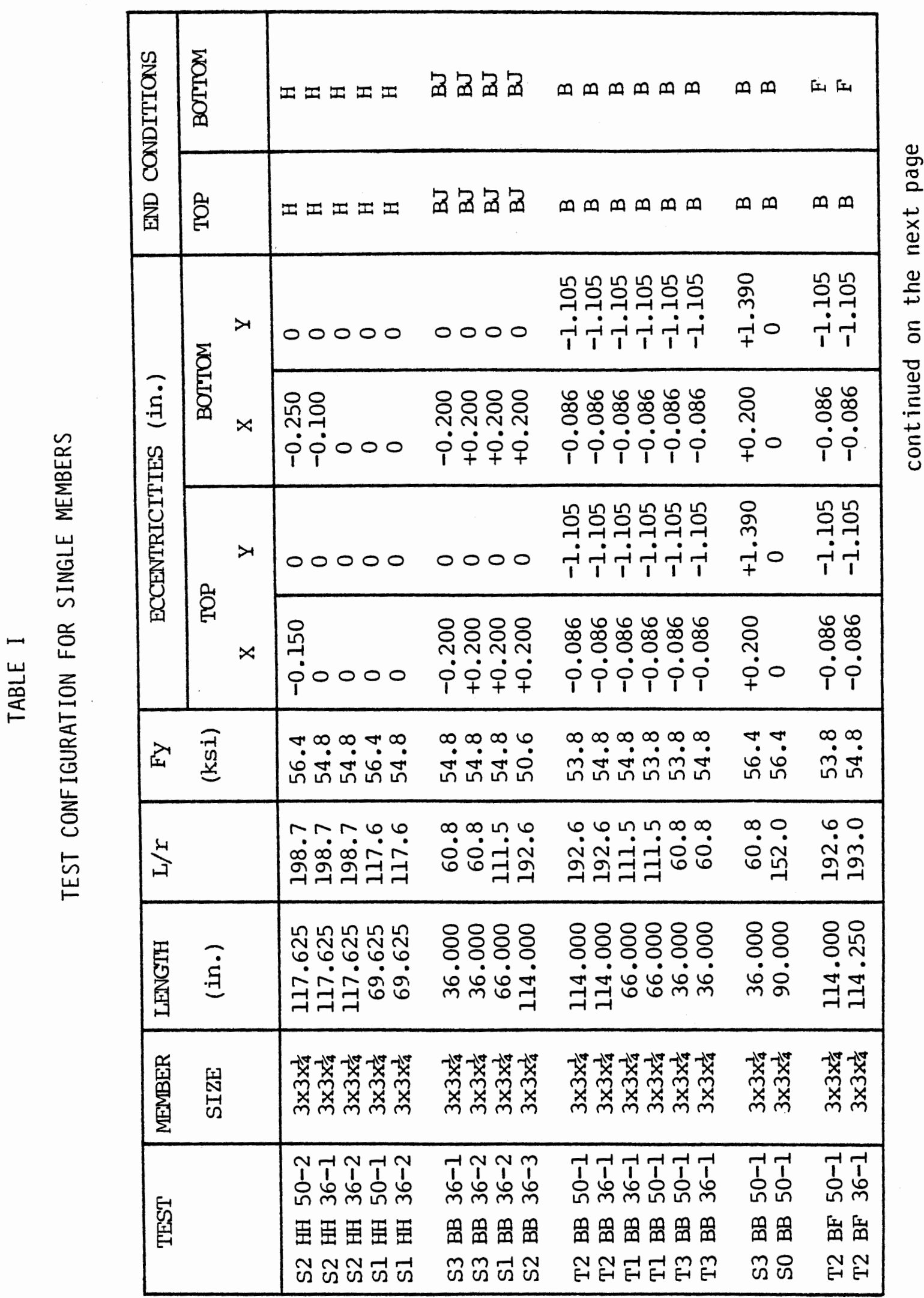




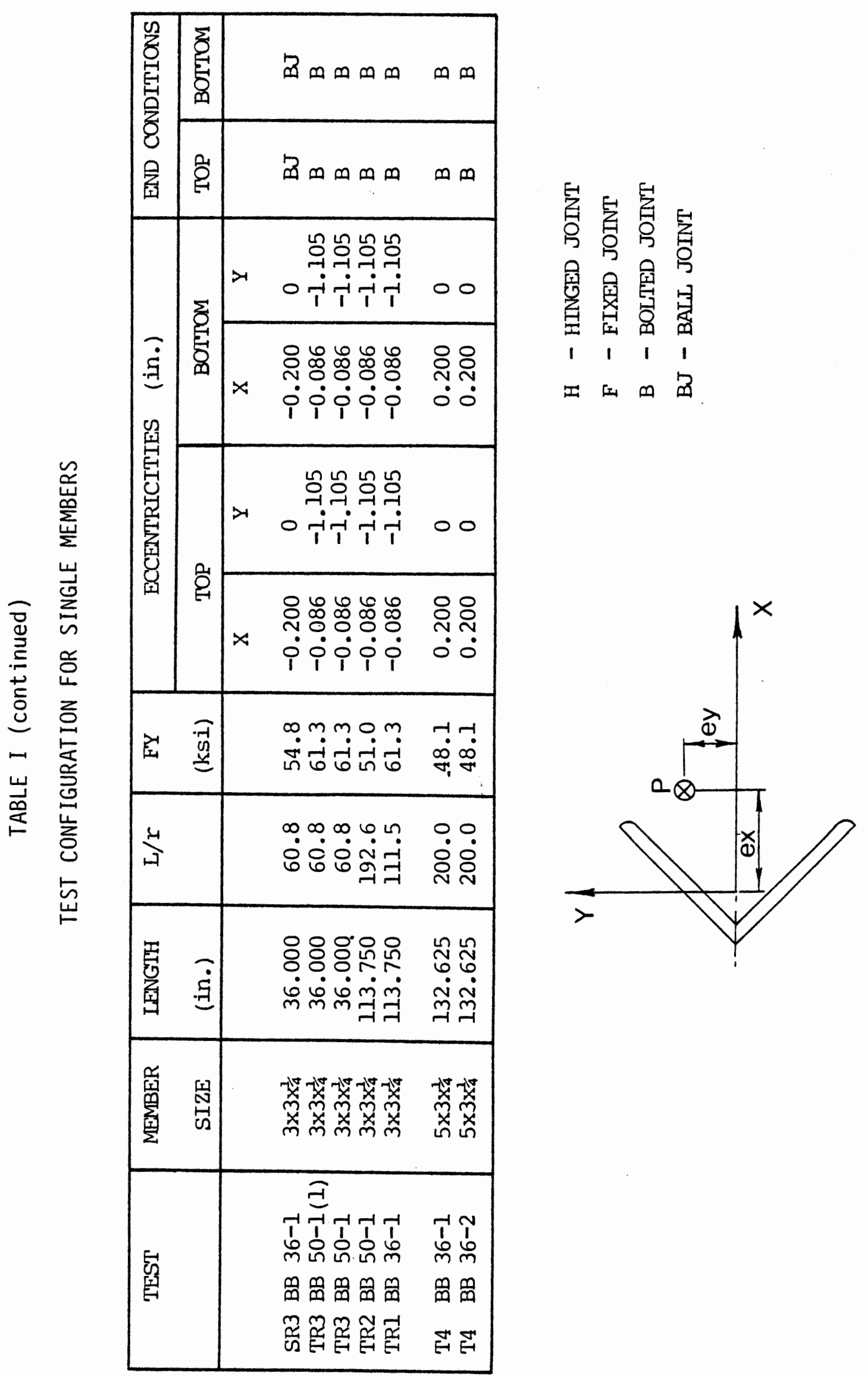




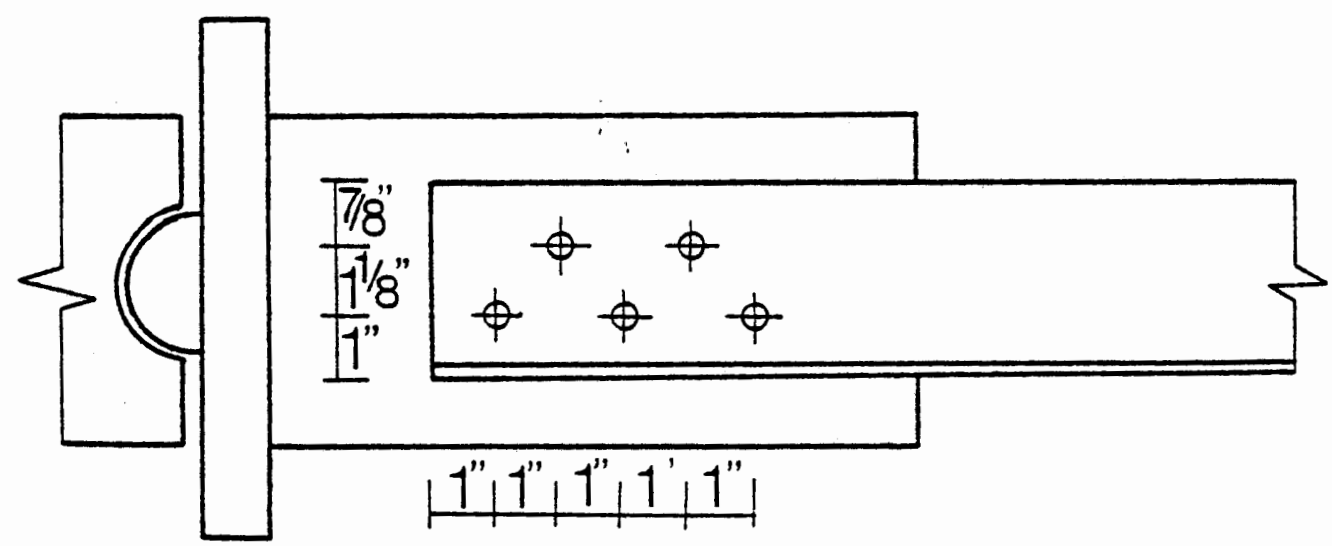

36 in. Members

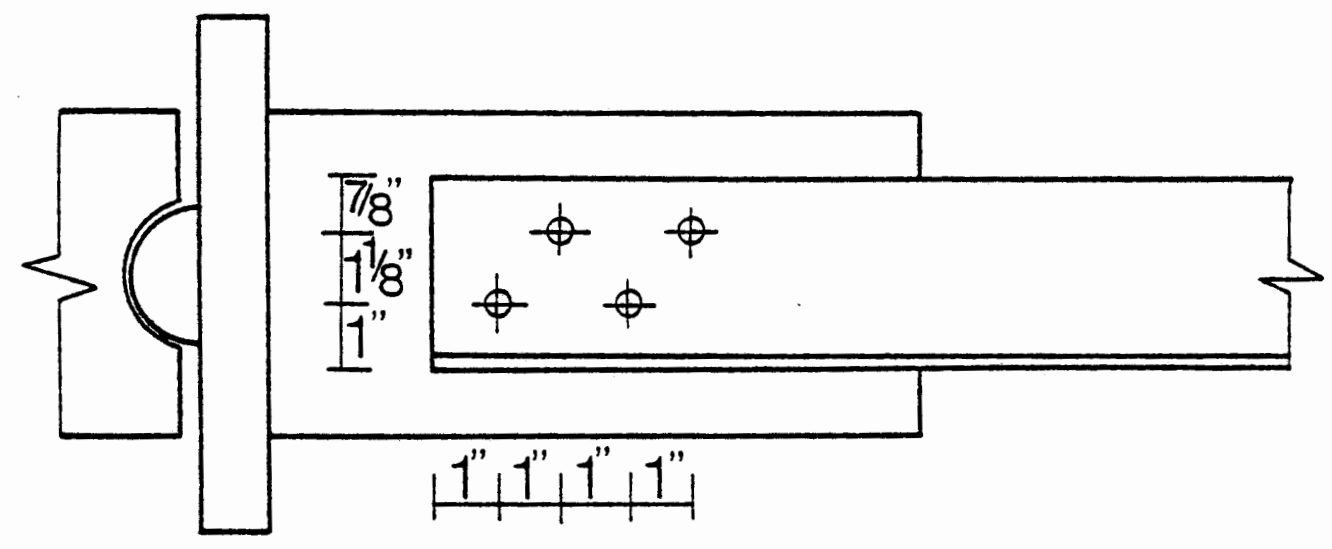

66 in. Members

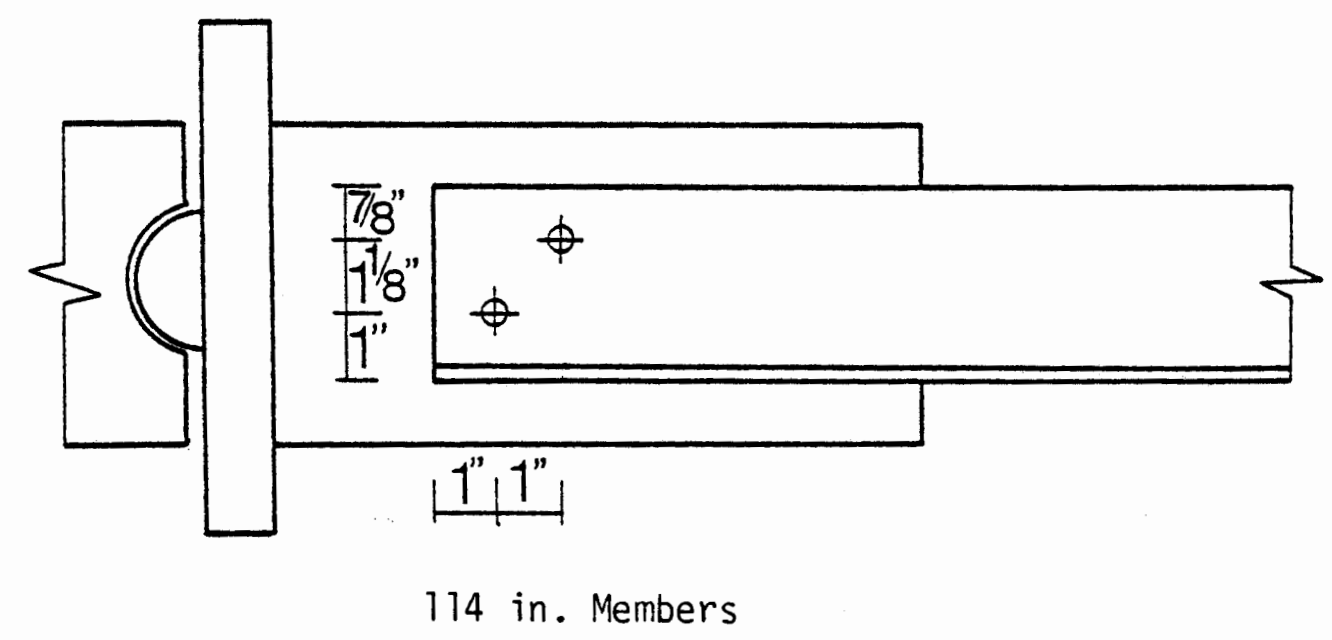

Figure 10 Bolted connections for single member tests 
eccentricities similar to those found in transmission towers.

\subsection{INSTRUMENTATION}

The instrumentation was similar for each of the angles tested. The MTS was used to load the specimen. As stated earlier in this chapter, this system has the capability to control actuator stroke. Since these tests were beyond the point of stability, safety dictated the use of stroke control. The stroke rate was set at $10^{-4}$ inch per second which resulted in a stress rate of $0.08 \mathrm{ksi}$ per second for the shortest member tests. ASTM (9) specification for static tests is a stress rate of less than $1.66 \mathrm{ksi}$ per second. The load value was read directiy from the MTS control panel.

Four dial gages at each end were used to measure the axial deflection and end rotation. They were placed an equal distance from the center of the endplate to form a square. Figure 11 is a photograph of this configuration. Taking measurements at each end allowed the elimination of the effect of test frame slippage on the displacement readings.

In the case of a Ball or a Bolted Joint where a Ball-Ball connection is used, the rotation of the joint about the axis of the test member is possible. This rotation at the ends of the test member was measured by a dial gage located perpendicular to the beam column at each end and connected by a circular offset to the center of gravity of the member. This circular offset allowed unwinding of the connecting cable and hence kept the offset constant. Figure 12 is a sketch of this setup. Rotation is given by the gage reading (linear displacement of the circumference of the circle) divided by the radius of the circle. Figure 13 is a sketch of gage layout for the test member including the gages used for 


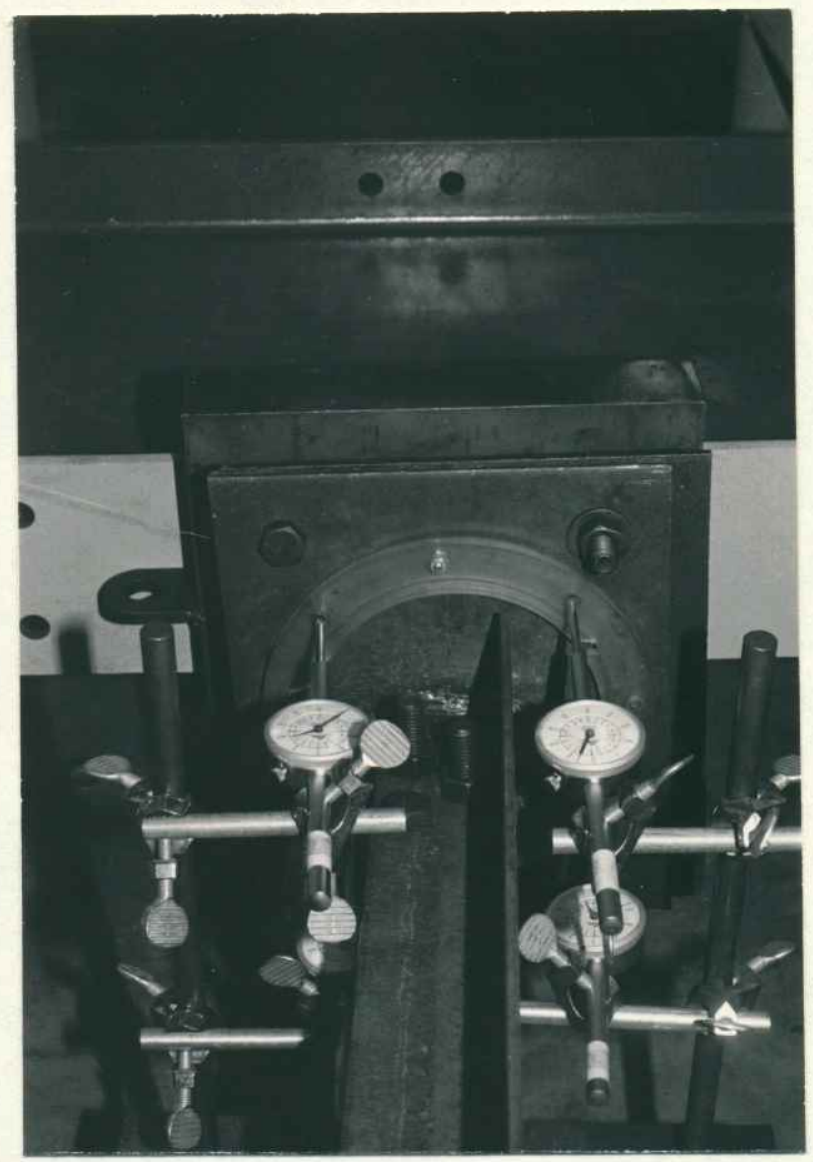

Figure 11. Dial gage setup for measuring displacements 


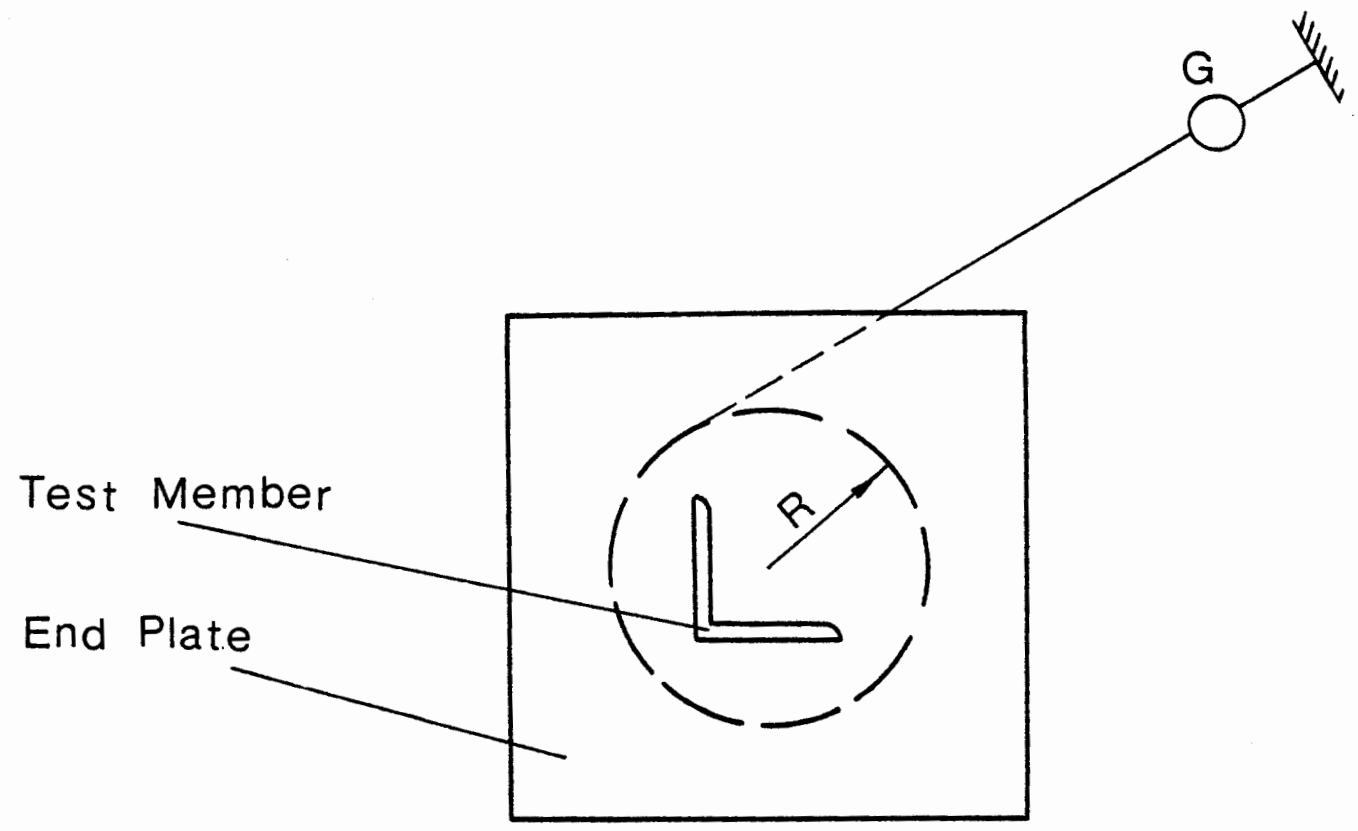

Figure 12 Gage layout to measure rotation about the axis of the member 

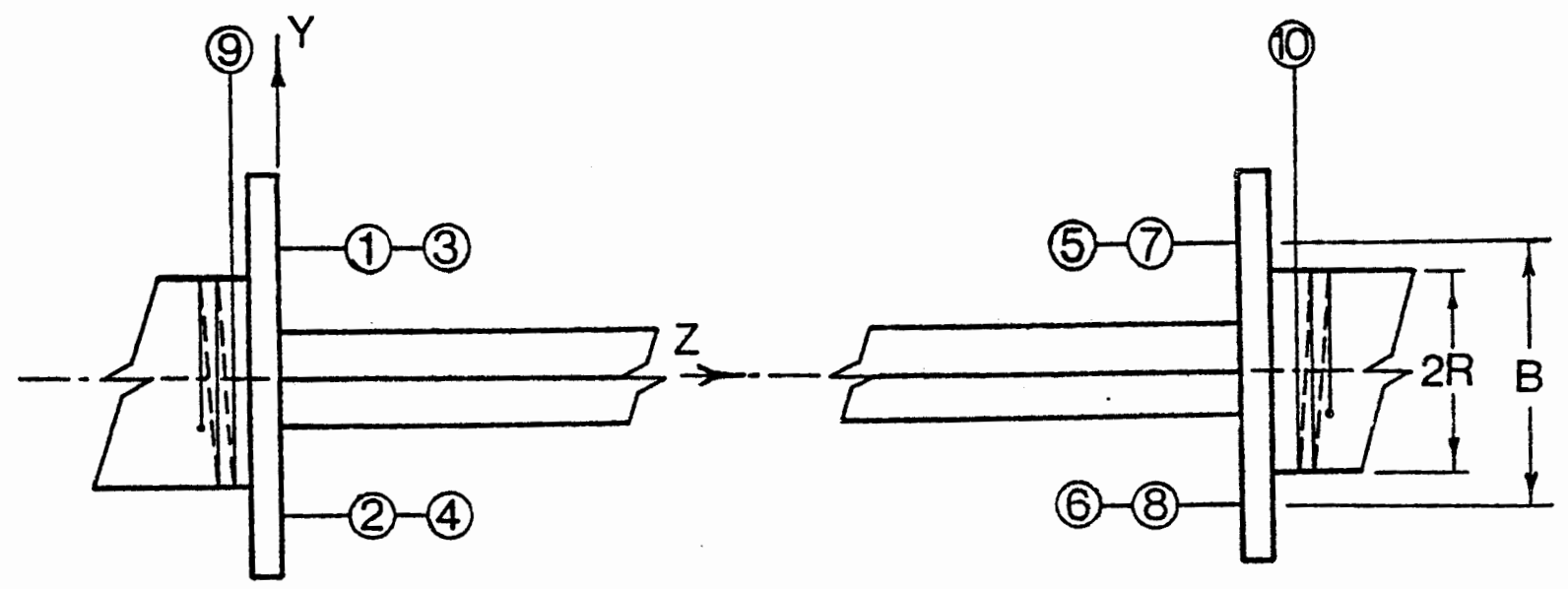

ELEVATION
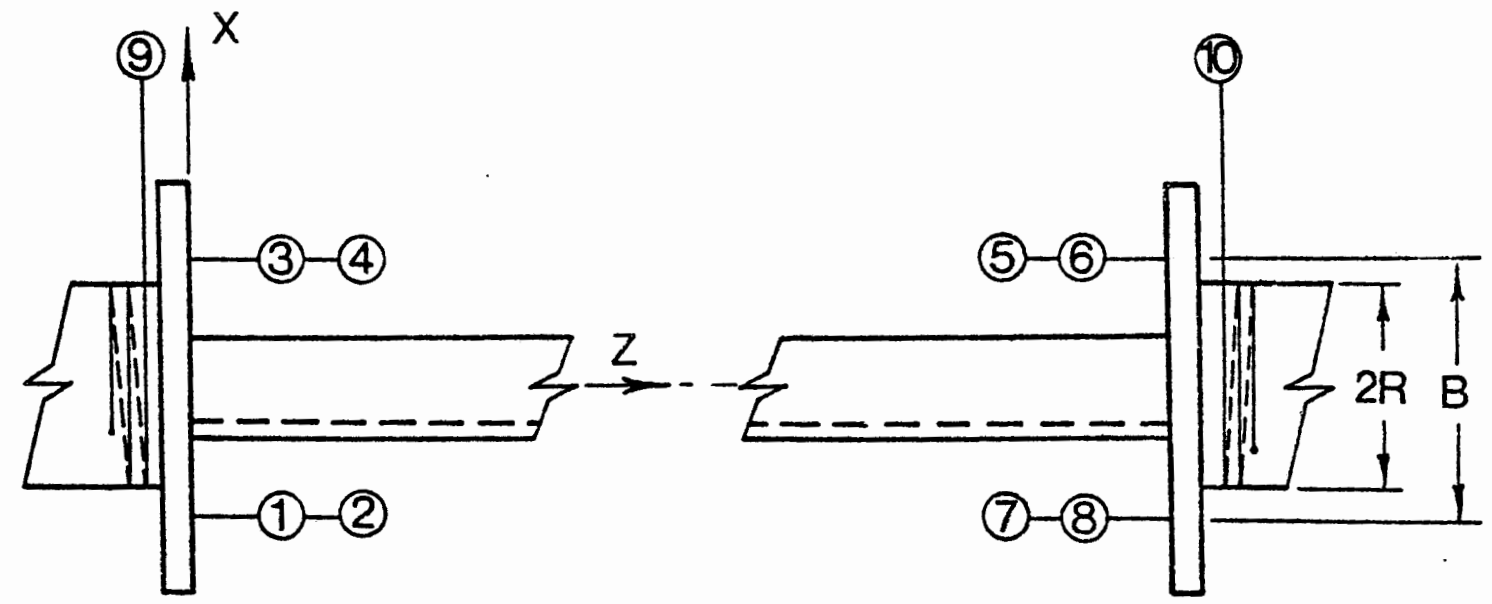

PLAN

End 1

End 2

Figure 13 Gage layout for single member tests including the rotational gages 
measuring rotations about the axis of the test member.

\subsection{TEST PROCEDURE}

The purpose of the chosen test procedure is to ensure that valid load vs. axial deflection data is obtained. To determine load resistance of the member, readings of load and axial deflection were taken at predetermined intervals chosen to be approximately $20 \%$ of the expected failure load. A loading rate was chosen to ensure that the static load resistance of the member could be determined.

The test procedure was as follows.

a) Load the member to $15 \%$ of the expected ultimate failure of the member, (this load was estimated using Euler buckling criteria) and take initial readings of the dial gages.

b) Readings of dial gages are taken for each load where the increment of 10 ad was $20 \%$ of the failure 10 ad.

c) Continue to deform the member beyond its ultimate load in decrements of $15 \%$ of the ultimate load. Readings of dial gages are taken at these intervals.

d) Resetting of gages was done just before any of the dial gages reached their maximum range. The reading of such a gage in its current position is noted and then moved to a new position either towards or away from the plate to facilitate further readings with the same set of gages. Reading at this new position is again noted, and the difference in reading due to resetting is accounted for when calculating the axial displacements.

e) Terminate the test when the load was reduced to $20 \%$ of the 
ultimate load.

\subsection{COMPUTATION OF AXIAL DISPLACEMENT}

The single angle member tests were configured using two types of end connections which connects the endplates to the actuator or the reaction block. They are the Hinged-Hinged and the Ball-Ball configurations. The Hinge in the Hinged-Hinged configuration was 1.75 inches from the end plate. The ball of the Ball-Ball configuration was fabricated such that the center of the ball coincides with the center of the end plate.

Derivation of axial displacement and the computer program to calculate this axial displacement for the Hinged-Hinged configuration is documented in Appendix $A$. Derivation of axial displacement and the computer program to calculate this axial displacement documented in Appendix $B$ is for the Ball-Ball configuration. Derivation for this configuration takes into account the eccentricity of the test member.

\subsection{STEEL PROPERTIES AND COUPON TESTS}

To obtain data on the material properties of the steel angles tested, coupon tests were performed using the MTS system. Tests were done for each batch of steel angles and for each grade of steel A-36 and Grade 50. Two coupons for the same material were cut in the longitudinal direction from a section of angle member. These were tested using load control with a load rate of $110 \mathrm{lb} / \mathrm{sec}$ which corresponds to a stress rate of $450 \mathrm{psi} / \mathrm{sec}$.

One of the test resuits obtained in the form of a stress-strain 
curve is illustrated in Fig. 14. All other coupon test curves followed the same shape as this curve, with a well defined yield point and large plastic deformation which are typical of mild steel meterials. Table II details the Yield stress, Ultimate stress, Modulus of Elasticity and Percent Elongation for each test. Percent elongation is a measure of ductility of the material.

\subsection{COMPARISON OF EXPERIMENTAL AND ANALYTICAL RESULTS FOR SINGLE ANGLE MEMBER TESTS}

The derivation of axial displacements using the data obtained in the single member tests, and the computer programs to perform these calculations are documented in Appendix $A$ and $B$. Appendix $A$ is for the members with the hinged end condition. Appendix $B$ documents these calculations for the members where the end plates are connected through a ball joint. Axial load vs. Axial displacement ( $P$ vs $\delta$ ) curves are plotted for each of these tests. Displacement at preload was taken as datum for measurements.

The $P$ vs $\delta$ curves plotted includes the experimental test curve as well as the prediction of the member behavior of the analytical computer program of Ref. 7. The analytical computer model of Ref. 7 is a nonlinear computer code which includes the analys is in the post-buckling region. The buckling modes considered includes flexural, torsional and combined flexural-torsional. The "secant stiffness" approach was selected in this to consider the yielding of cross sections both prior to the ultimate load and in the post-buckling range. In two dimension analys is the "secant stiffness" at a particular point in the moment-curvature diagram is the gradient of the line joining the origin and that particular point. 


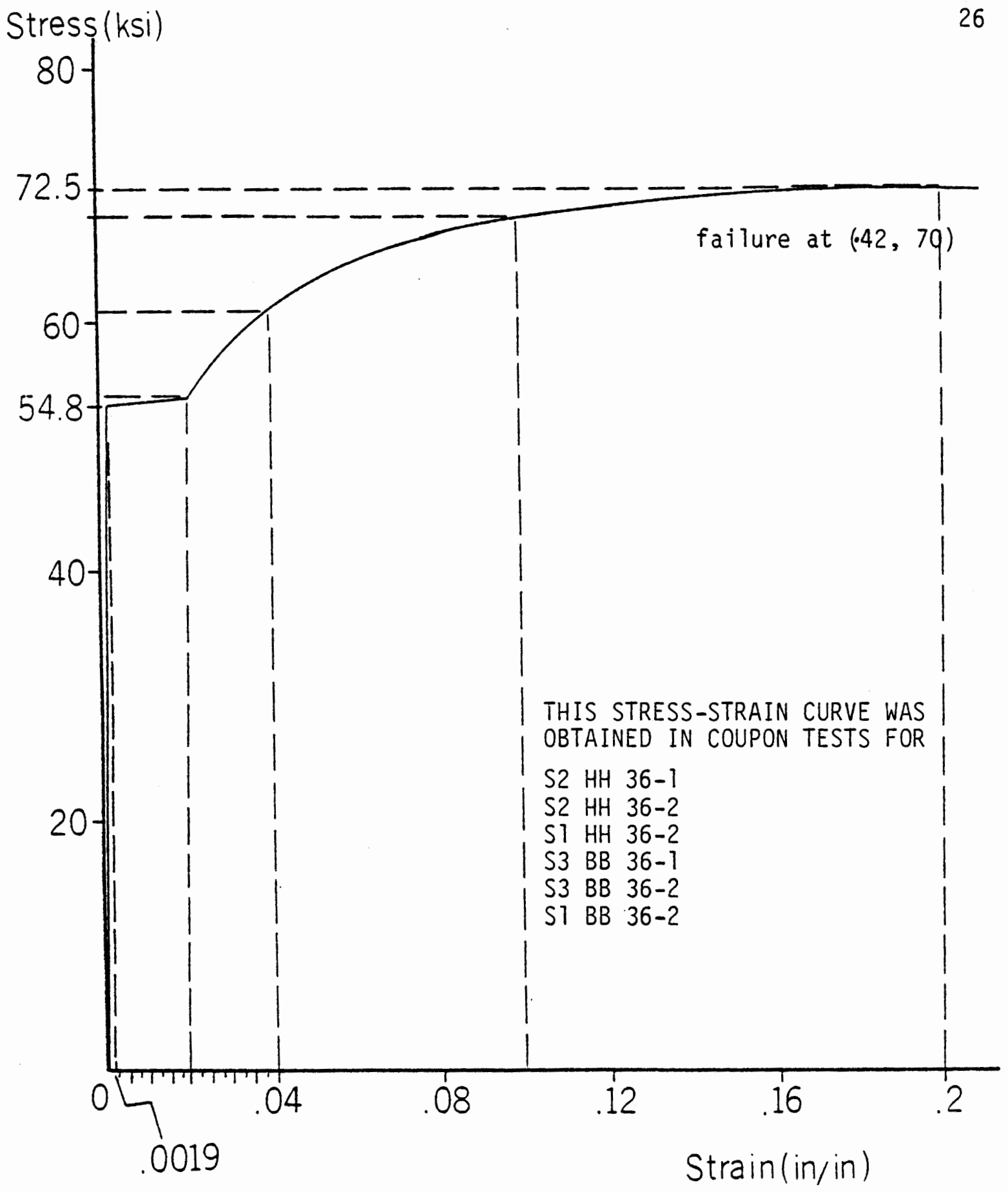

Figure 14 Typical stress strain curve 
TABLE II

RESULTS OF COUPON TESTS FOR SINGLE MEMBER TESTS

\begin{tabular}{|l|c|c|c|c|}
\hline TEST & $\begin{array}{c}\text { YIELD } \\
\text { STRESS } \\
\text { (KSI) }\end{array}$ & $\begin{array}{c}\text { ULTIMATE } \\
\text { STRESS } \\
\text { (KSI) }\end{array}$ & $\begin{array}{c}\text { MODULUS OF } \\
\text { EIASTICITY } \\
\text { (KSI) }\end{array}$ & $\begin{array}{c}\text { PERCENTAGE } \\
\text { EIONGATION } \\
(8)\end{array}$ \\
\hline & & & & \\
S2 HH 50-2 & 56.4 & 73.5 & 29100.0 & 42.0 \\
S2 HH 36-1 & 54.8 & 72.5 & 30700.0 & 41.5 \\
S2 HH 36-2 & 54.8 & 72.5 & 30700.0 & 41.5 \\
S1 HH 50-1 & 56.4 & 73.5 & 29100.0 & 42.0 \\
S1 HH 36-2 & 54.8 & 72.5 & 30700.0 & 41.5 \\
& & & & \\
S3 BB 36-1 & 54.8 & 72.5 & 30700.0 & 41.5 \\
S3 BB 36-2 & 54.8 & 72.5 & 30700.0 & 41.5 \\
S1 BB 36-2 & 54.8 & 72.5 & 30700.0 & 41.5 \\
S2 BB 36-3 & 50.6 & 68.4 & 30325.0 & 38.0 \\
T2 BB 50-1 & 53.8 & 76.3 & 29100.0 & 40.0 \\
T2 BB 36-1 & 54.8 & 71.2 & 29100.0 & 38.0 \\
T1 BB 36-1 & 54.8 & 71.2 & 29100.0 & 38.0 \\
T1 BB 50-1 & 53.8 & 76.3 & 29100.0 & 40.0 \\
T3 BB 50-1 & 53.8 & 76.3 & 29100.0 & 40.0 \\
T3 BB 36-1 & 54.8 & 71.2 & 29100.0 & 38.0 \\
S3 BB 50-1 & 56.4 & 73.5 & 29100.0 & 42.0 \\
S0 BB 50-1 & 56.4 & 73.5 & 29100.0 & 42.0 \\
T2 BF 50-1 & 53.8 & 76.3 & 29100.0 & 40.0 \\
T2 BE 36-1 & 54.8 & 71.2 & 29100.0 & 38.0 \\
SR3 BB 36-1 & 54.8 & 71.2 & 29100.0 & 38.0 \\
TR3 BB 50-1 (1) & 61.3 & 78.5 & 29400.0 & 32.0 \\
TR3 BB 50-1 & 61.3 & 78.5 & 29400.0 & 32.0 \\
TR2 BB 50-1 & 51.0 & 67.8 & 29200.0 & 34.0 \\
TR1 BB 36-1 & 61.3 & 79.0 & 29300.0 & 32.0 \\
T4 BB 36-1 & 48.1 & 63.0 & 29000.0 & 37.0 \\
T4 BB 36-2 & 48.1 & 63.0 & 29000.0 & 37.0 \\
& & & & \\
\hline
\end{tabular}


The stiffness of the member is adjusted using this method in the inelastic and post-buckling region to predict the load-deflection curve.

The $P$ vs $\delta$ curves given in Figs. 15 to 40 detail the comparison of experimental and analytical results for all the single member tests performed.

Tests performed can be placed in the following five categories:

(1) Equal angle test members with hinged-hinged end configuration

(2) Equal angle test members with ball-ball end configuration with 0.2 in. eccentricity in the $x$-direction only (Fig. 13)

(3) Equal angle test members with bolted connection having eccentricity in the $X$ and $Y$ directions (Fig. 13)

(4) Equal angle test members with bolted configuration at one end and fixed at the other end.

(5) Unequal angle test members with ball-ball configurations.

These five categories were sufficient to study the effect of various parameters that are of concern in member performance of single angle members. In the first category basically the effect of length to radius of gyration $(L / r)$ ratio and the yield stress were the parameters used. In the second category the effect of $L / r$ ratio, yield stress and the eccentricity of loading on the stronger axis were used to study the effect of these on the member behavior. The eccentricity of loading on the weaker axis and the effect of bolted connection were the new parameters used in the third category. As the effect of local buckling in member behavior of non compact long members are of concern, the last category includes these members.

Table III compares the experimental and analytical values of ultimate 
TEST S2 HH ED-2 $L / r=198.7$

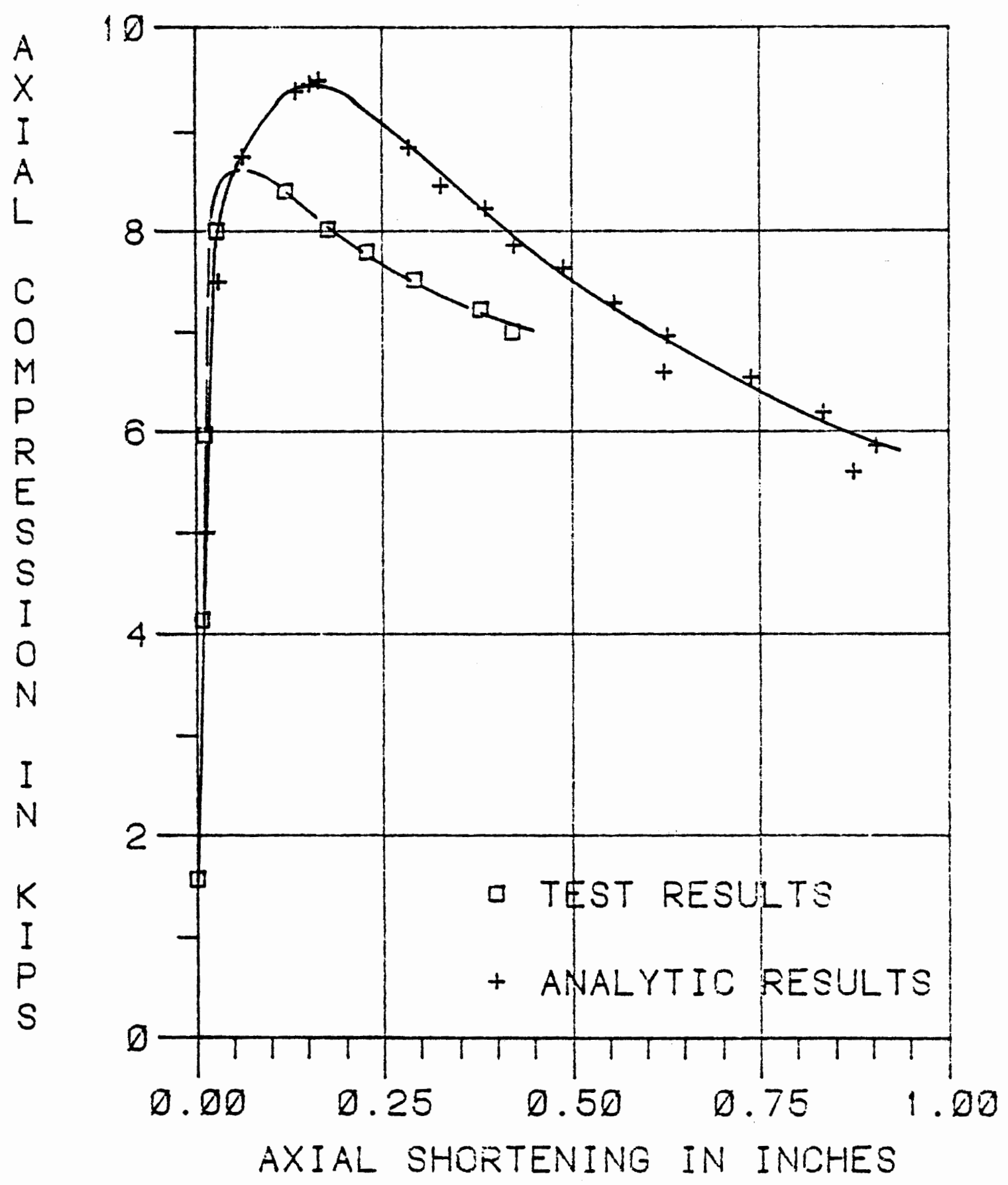

Figure 15. Test S2 HH 50-2 
TEST S2 HH 36-1 $L / r=198.7$

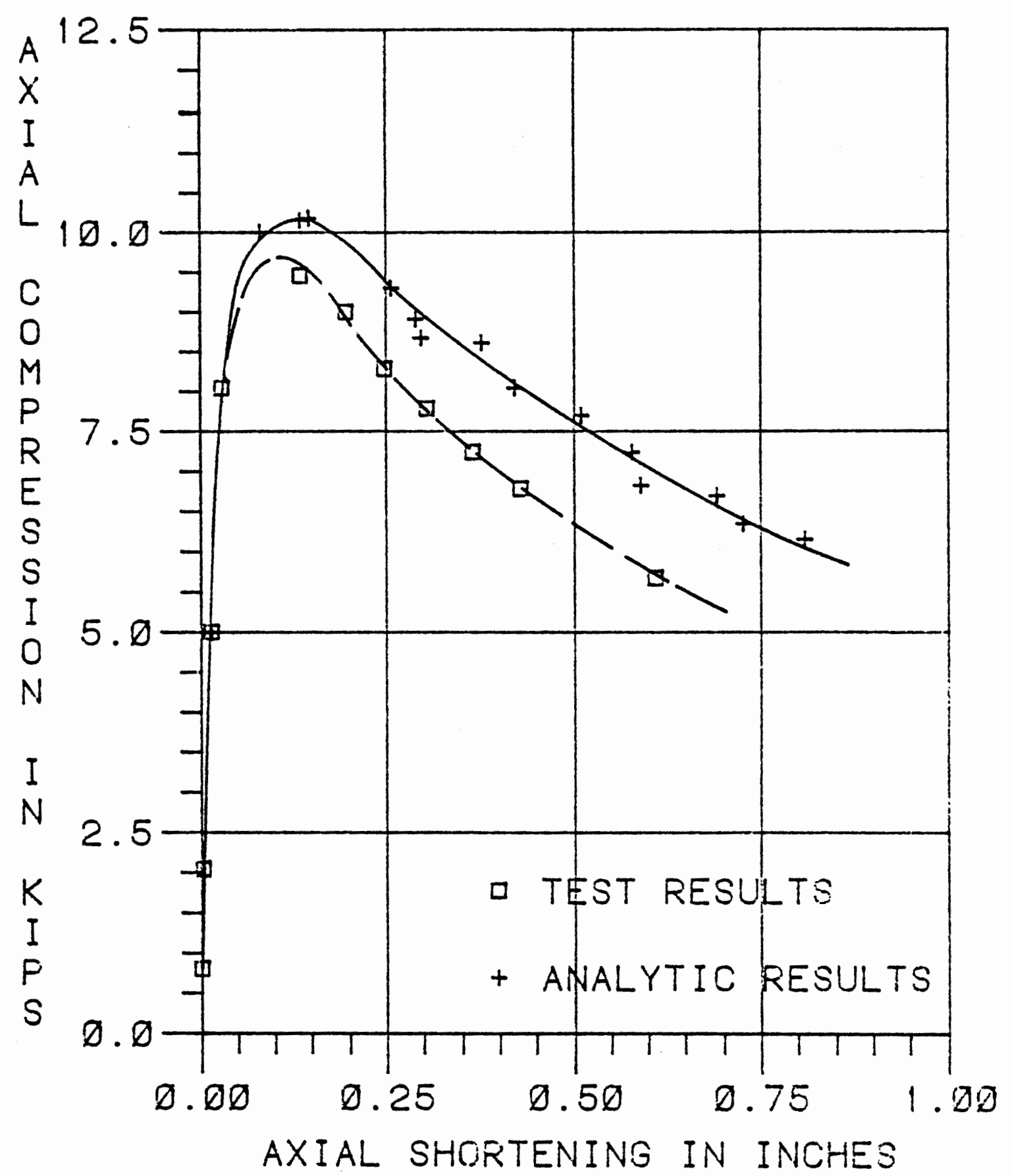

Figure 16. Test S2 HH 36-1 
TEST S2 HH 36-2 $L / r=198.7$

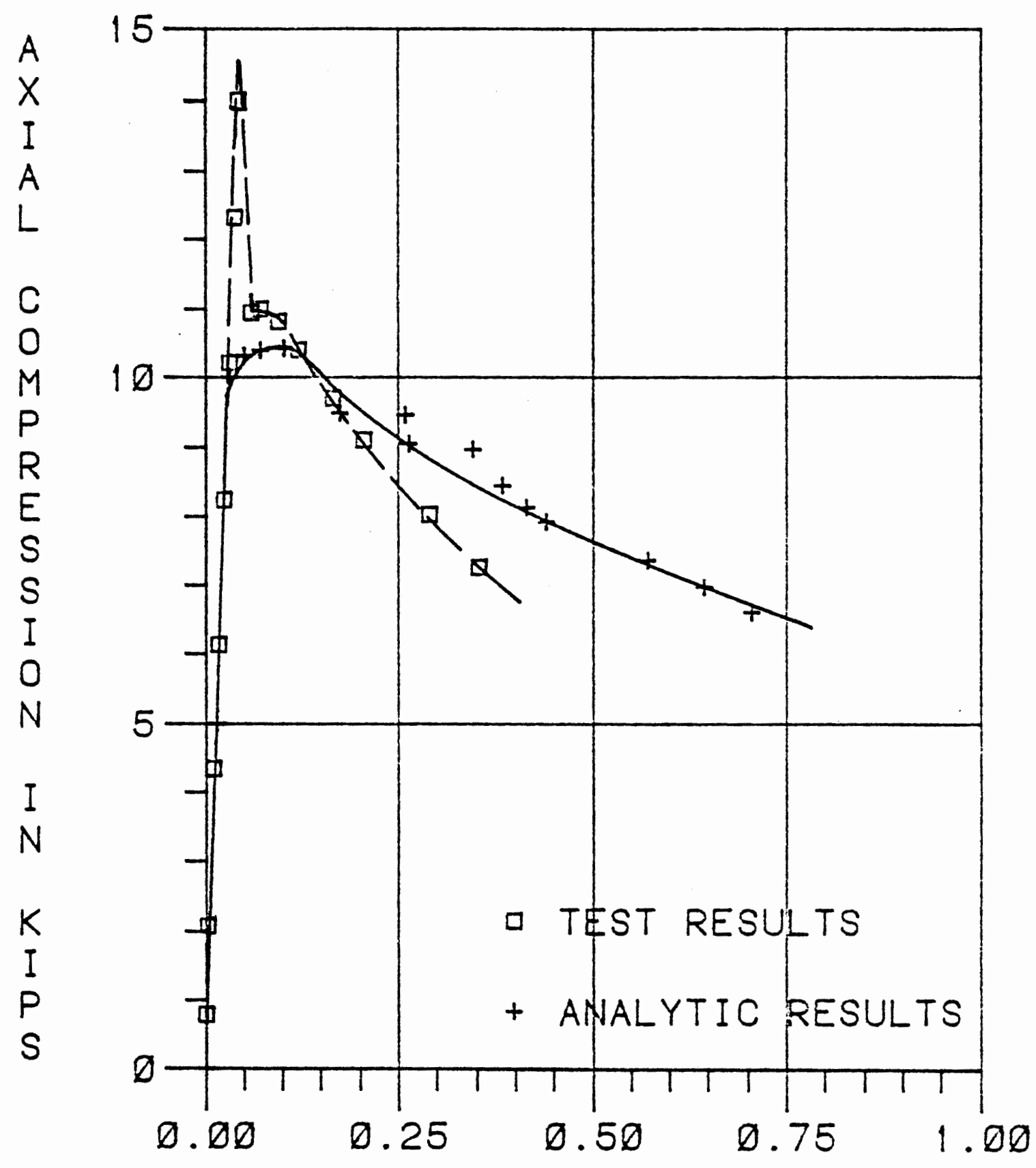

AXIAL SHORTENING IN INCHES

Figure 17. Test S2 HH 36-2 
TEST SI HH 50-1 L/r=117.6

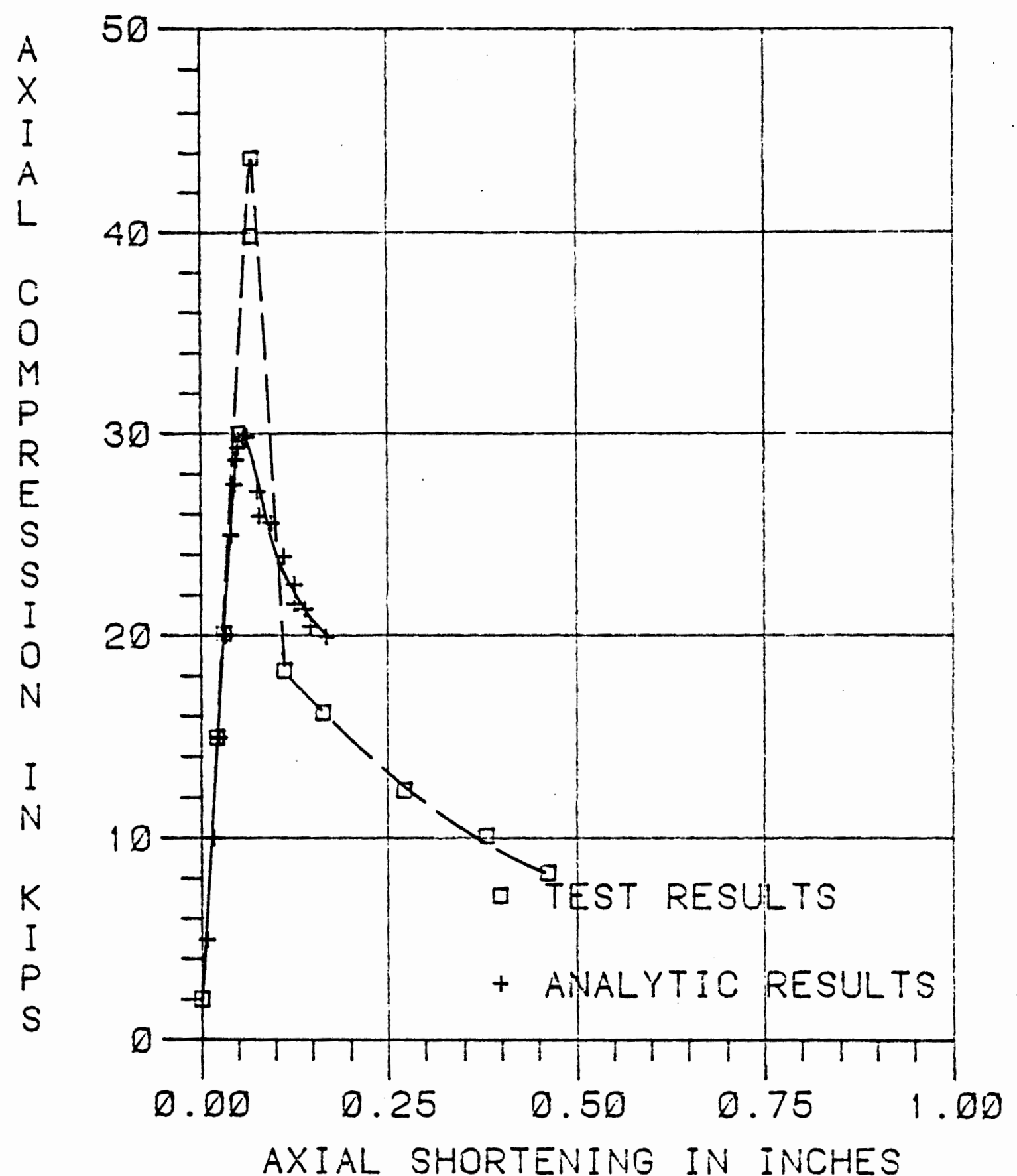

Figure 18. Test SI HH 50-1 
TEST S1 HH 30-2 $L / r=117.8$

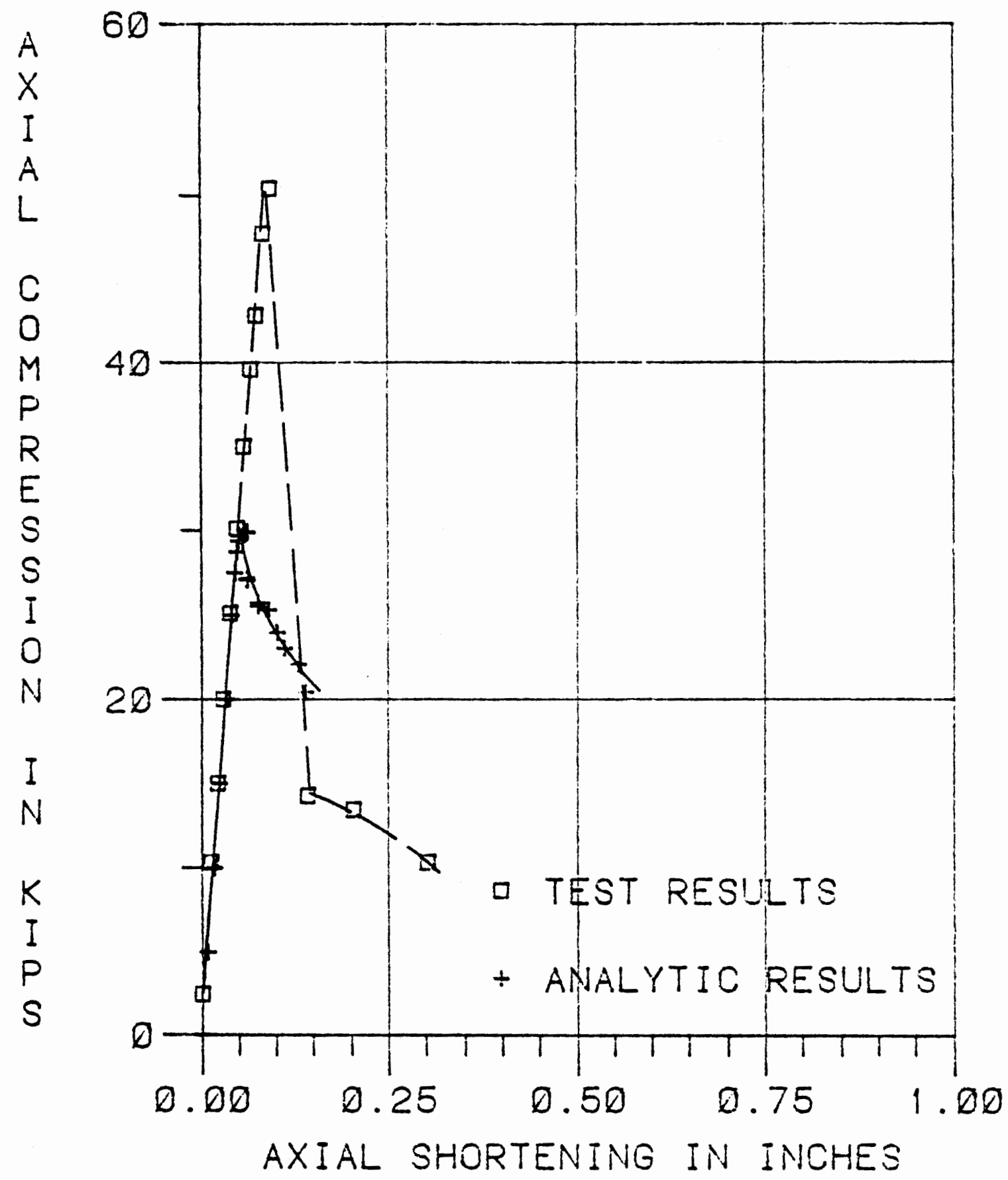

Figure 19. Test SI HH 36-2 
TEST S3 BB 36-1 $L / r=60.8$

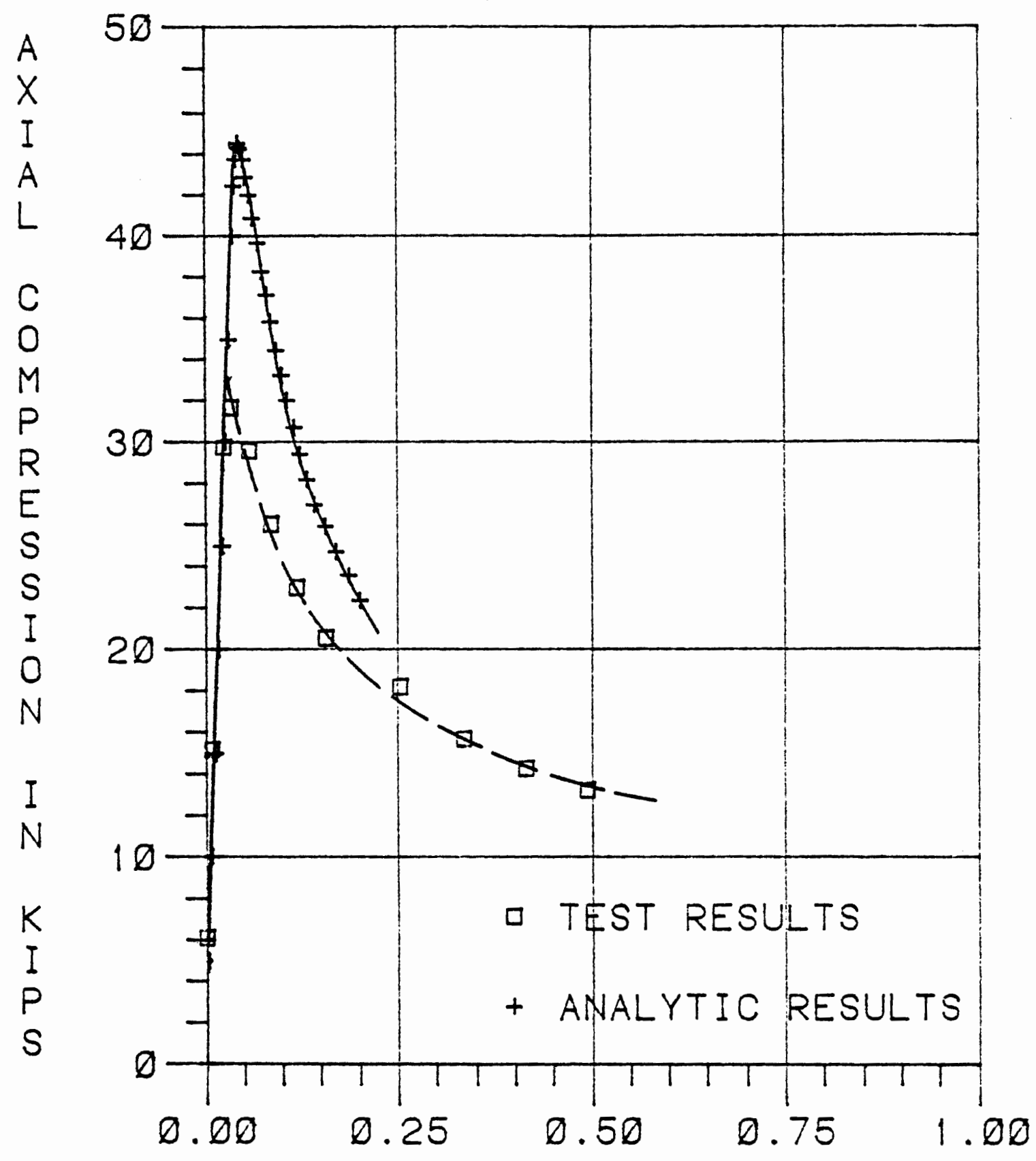

AXIAL SHORTENING IN INCHES

Figure 20. Test S3 BB 36-1 
TEST S3 BB 36-2 $L / r=60.8$

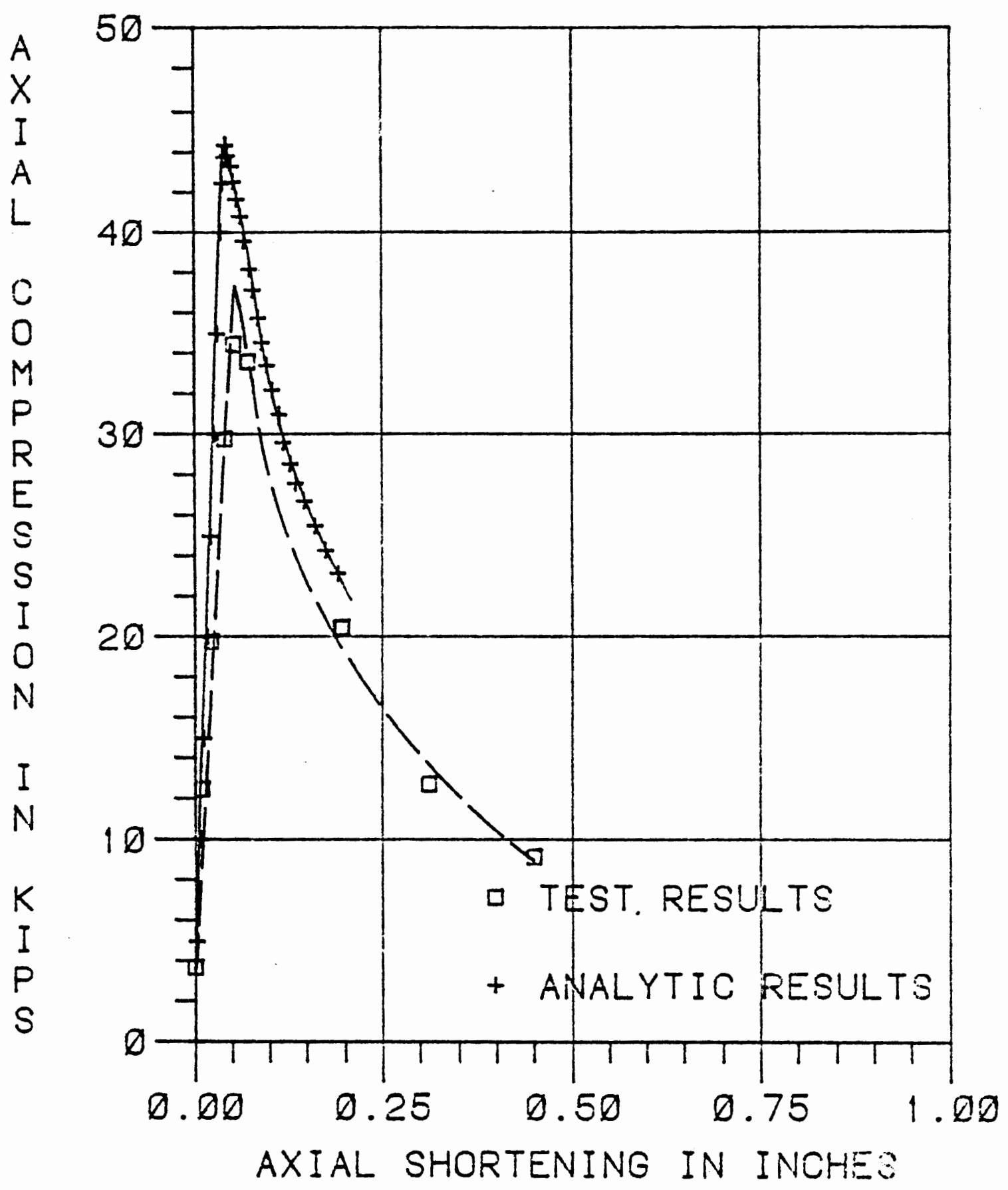

Figure 21. Test S3 BB 36-2 
TEST SI $B B \quad 36-2 \quad L / r=111.5$

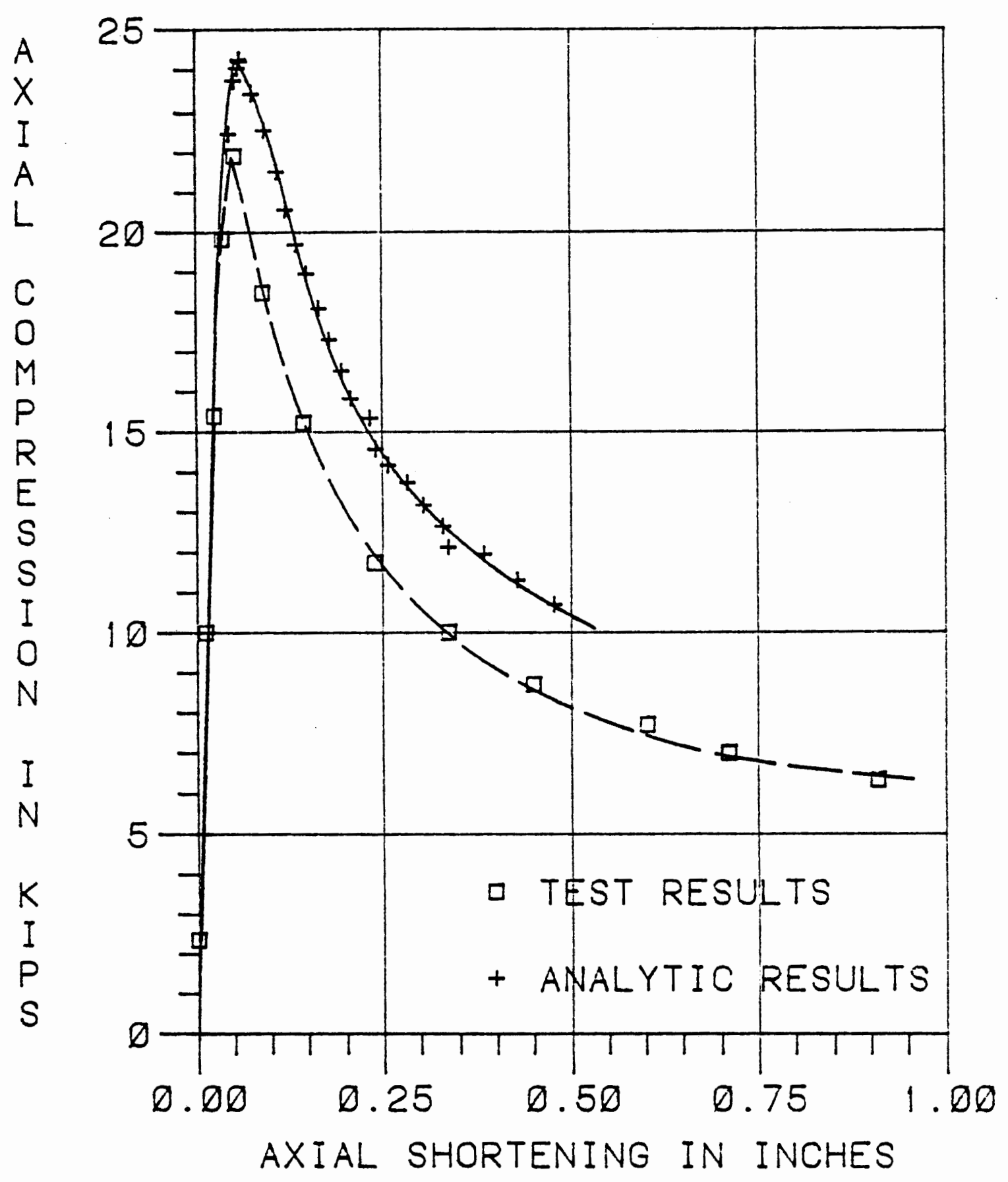

Figure 22. Test S1 BB 36-2 
TEST S2 BB 36-3 L/r $=192.6$

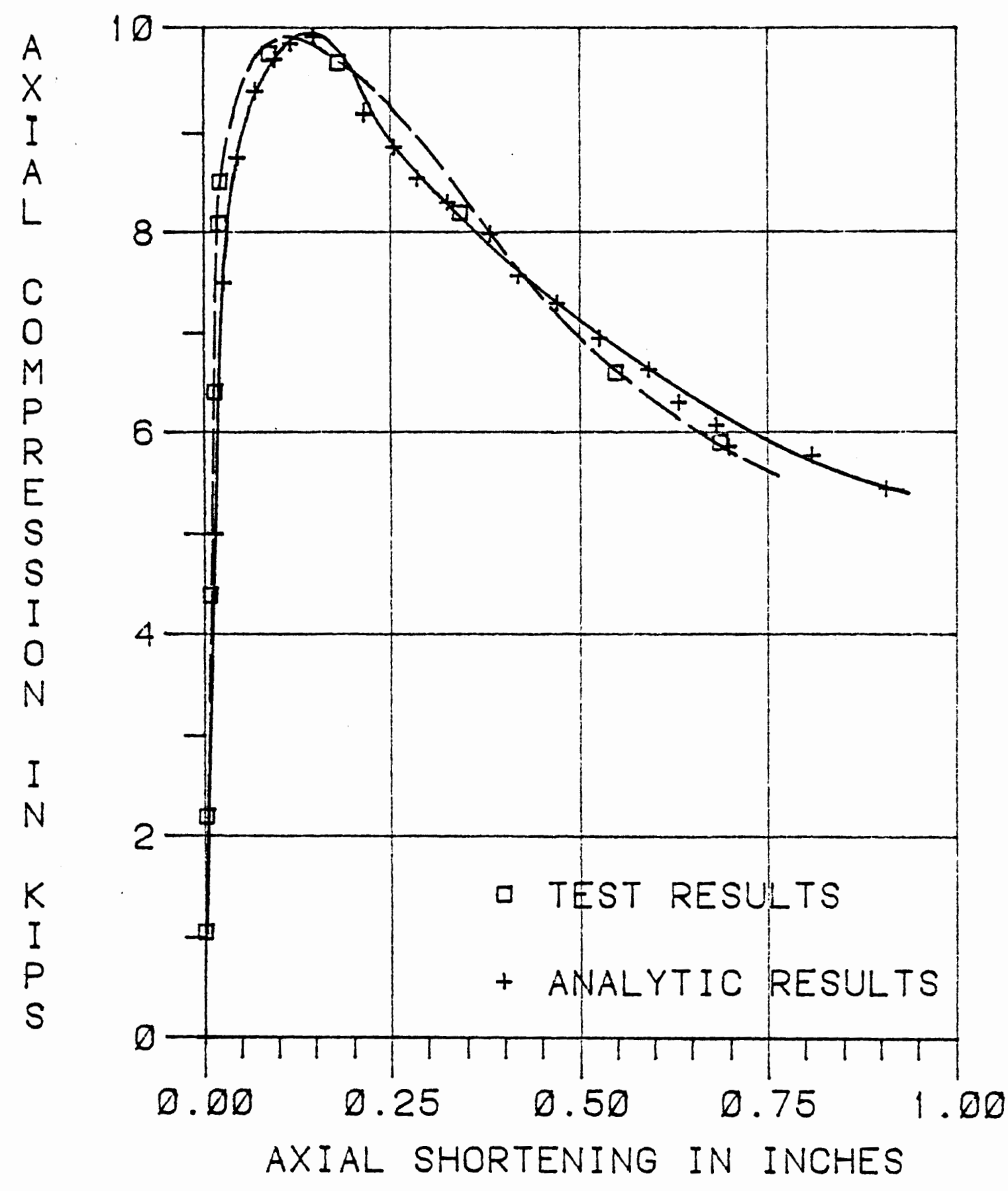

Figure 23. Test S2 BB 36-3 
TEST T2 BB 50-1 $L / r=192.6$

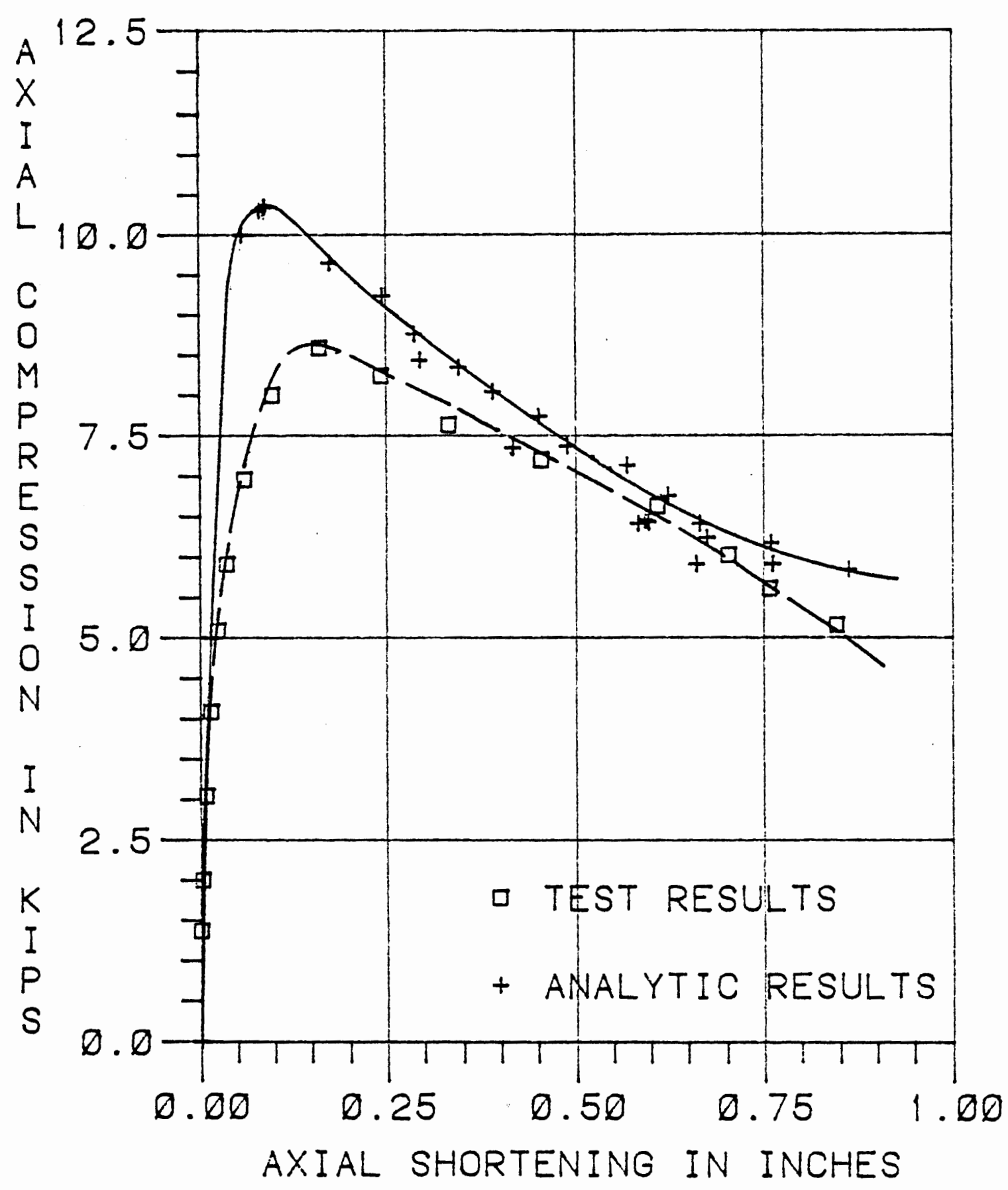

Figure 24. Test T2 BB 50-1 
TEST T2 BB 36-1 $L / r=192.6$

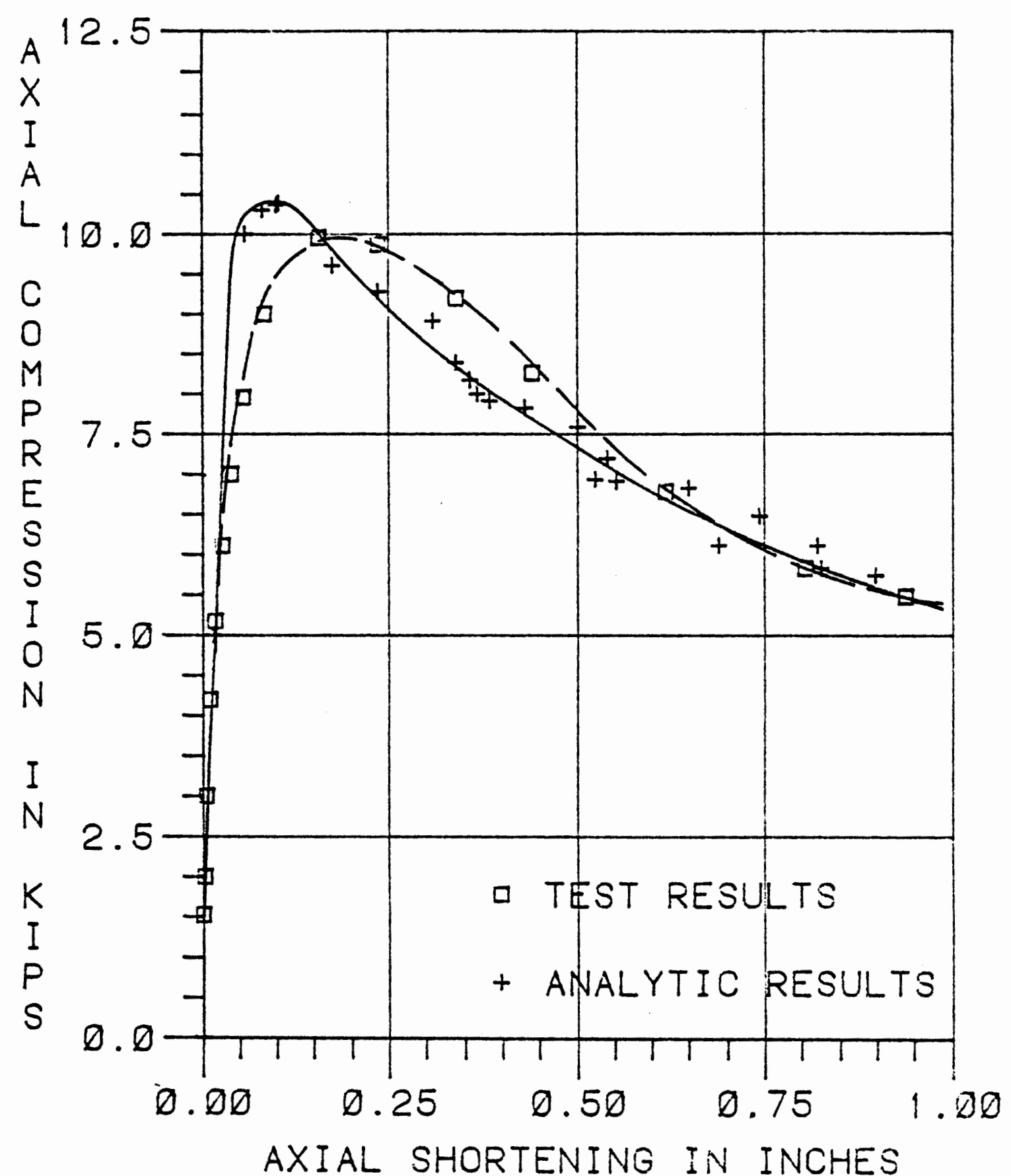

Figure 25. Test T2 BB 36-1 
TEST TI BB 36-1 $L / r=111.5$

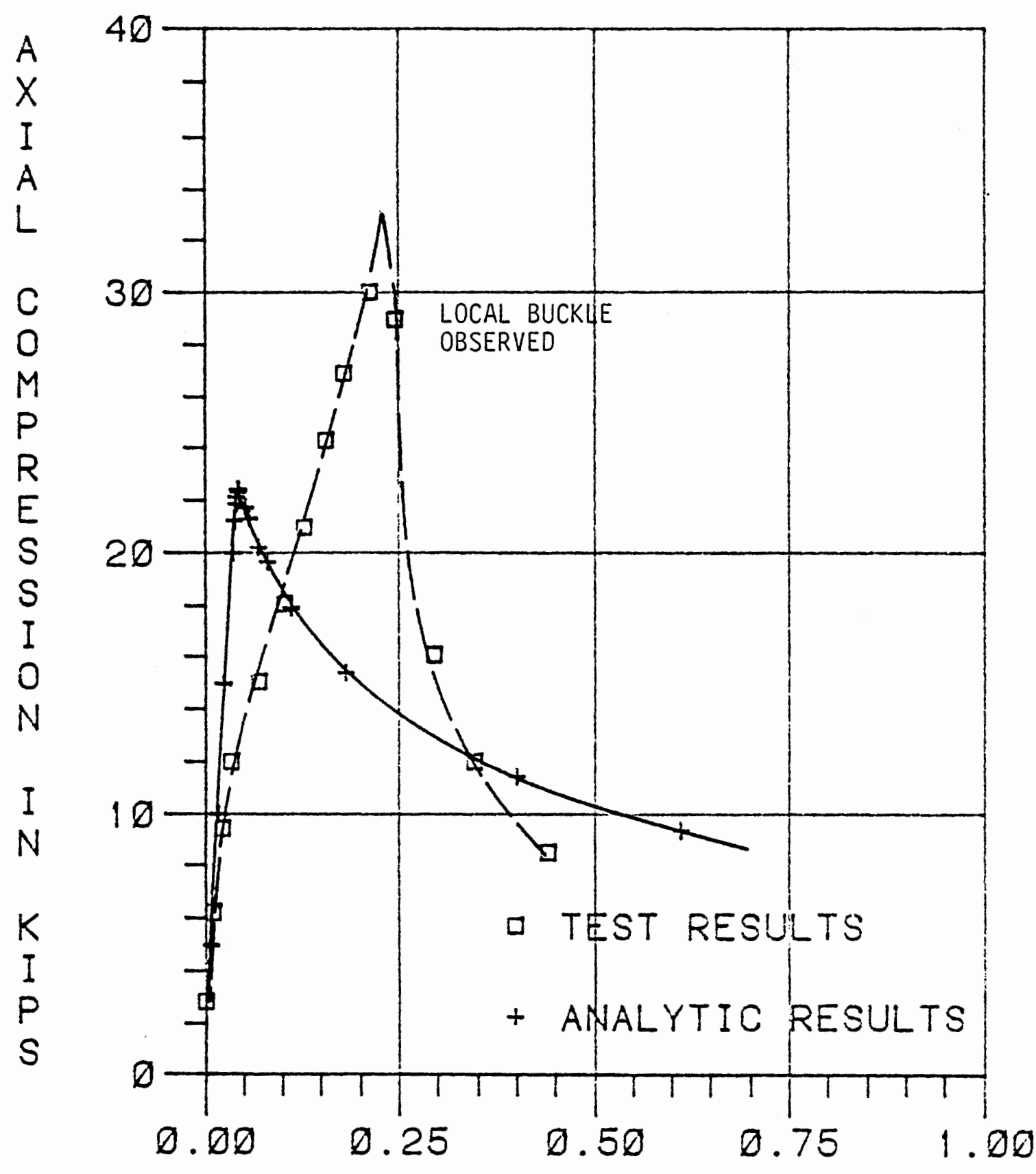

AXIAL SHORTENING IN INCHES

Figure 26 Test T1 BB 36-1 
TEST TI BB 5D-1 L/r $=111.5$

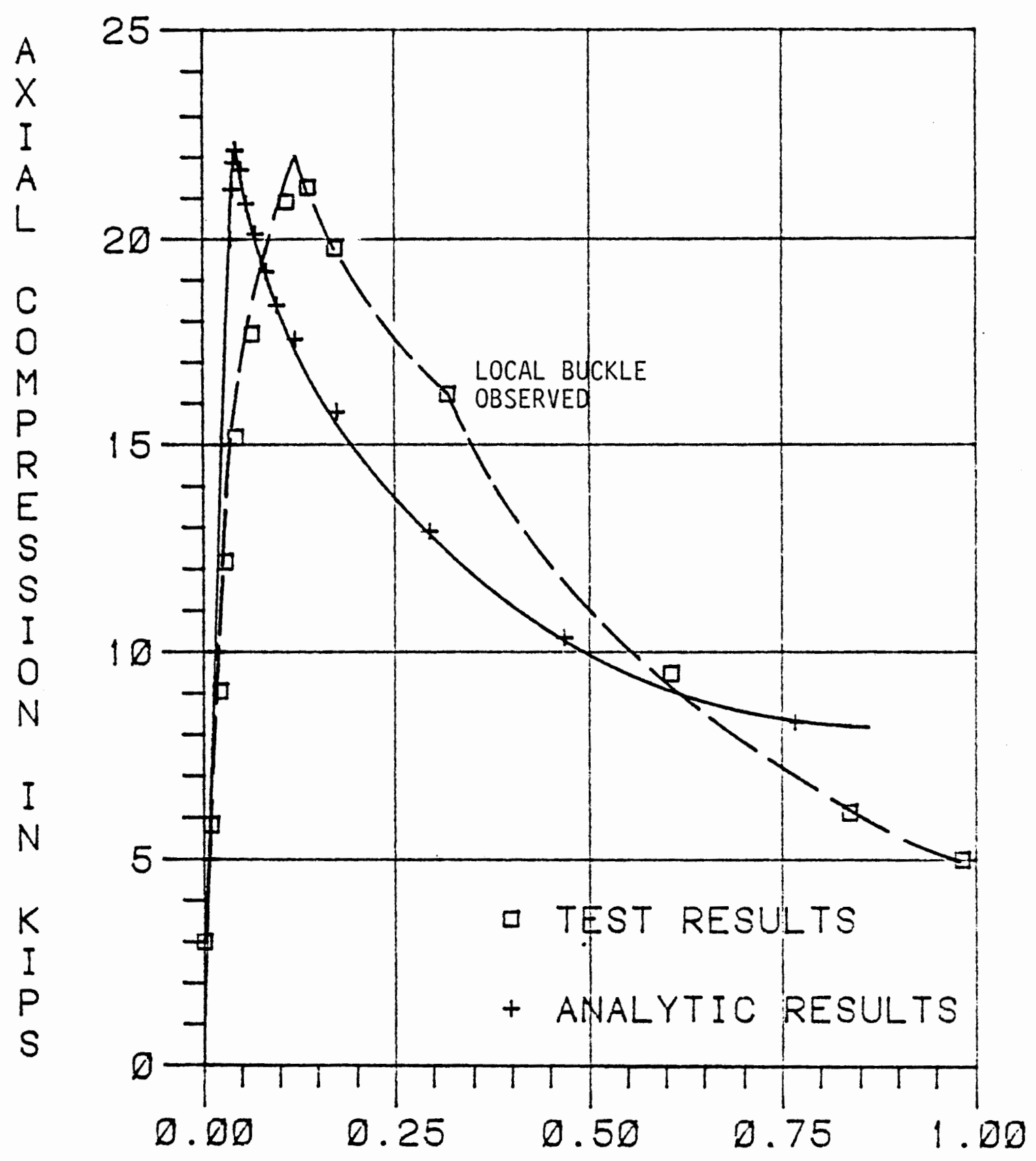

AXIAL SHORTENING IN INCHES

Figure 27 Test $T 1$ BB 50-1 
TEST T3 BB $5 D-1 \quad L / r=6 D .8$

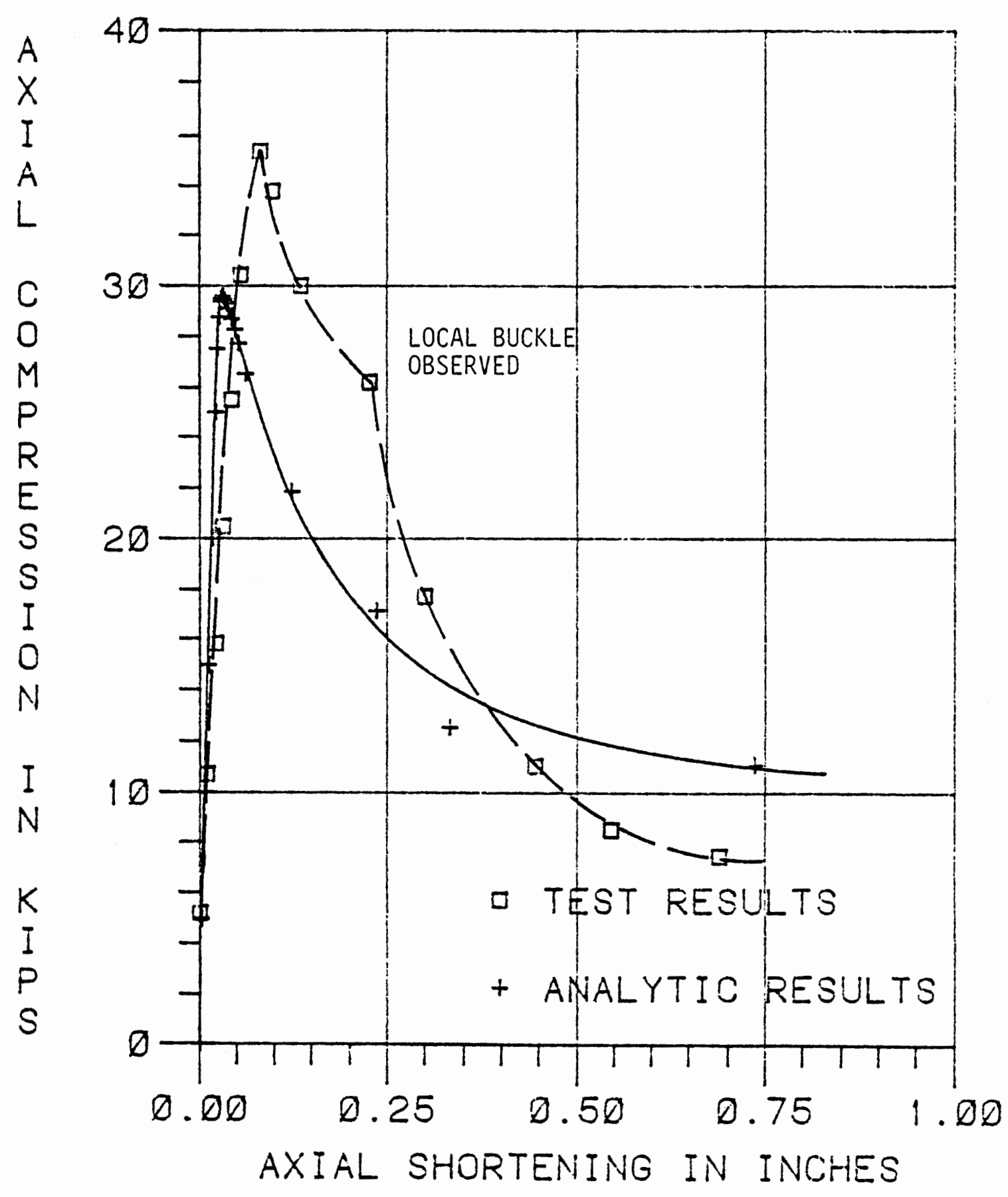

Figure 28 Test T3 BB 50-1 
TEST T3 BE $36-1 \quad L / r=60.8$

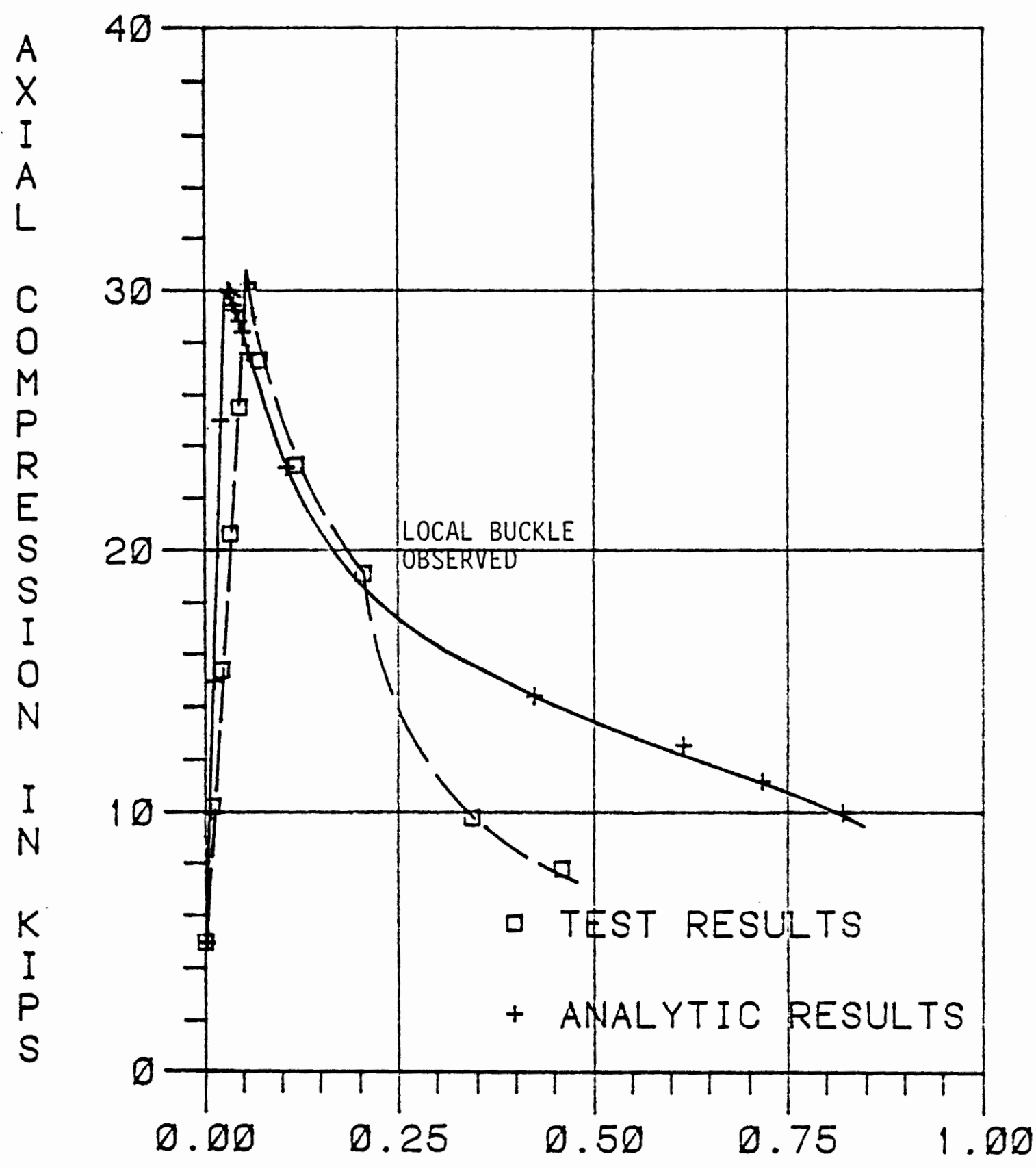

AXIAL SHORTENINE IN INCHES

Figure 29 Test T3 BB 36-1 
TEST S3 BB 50-1 $L / r=60.8$

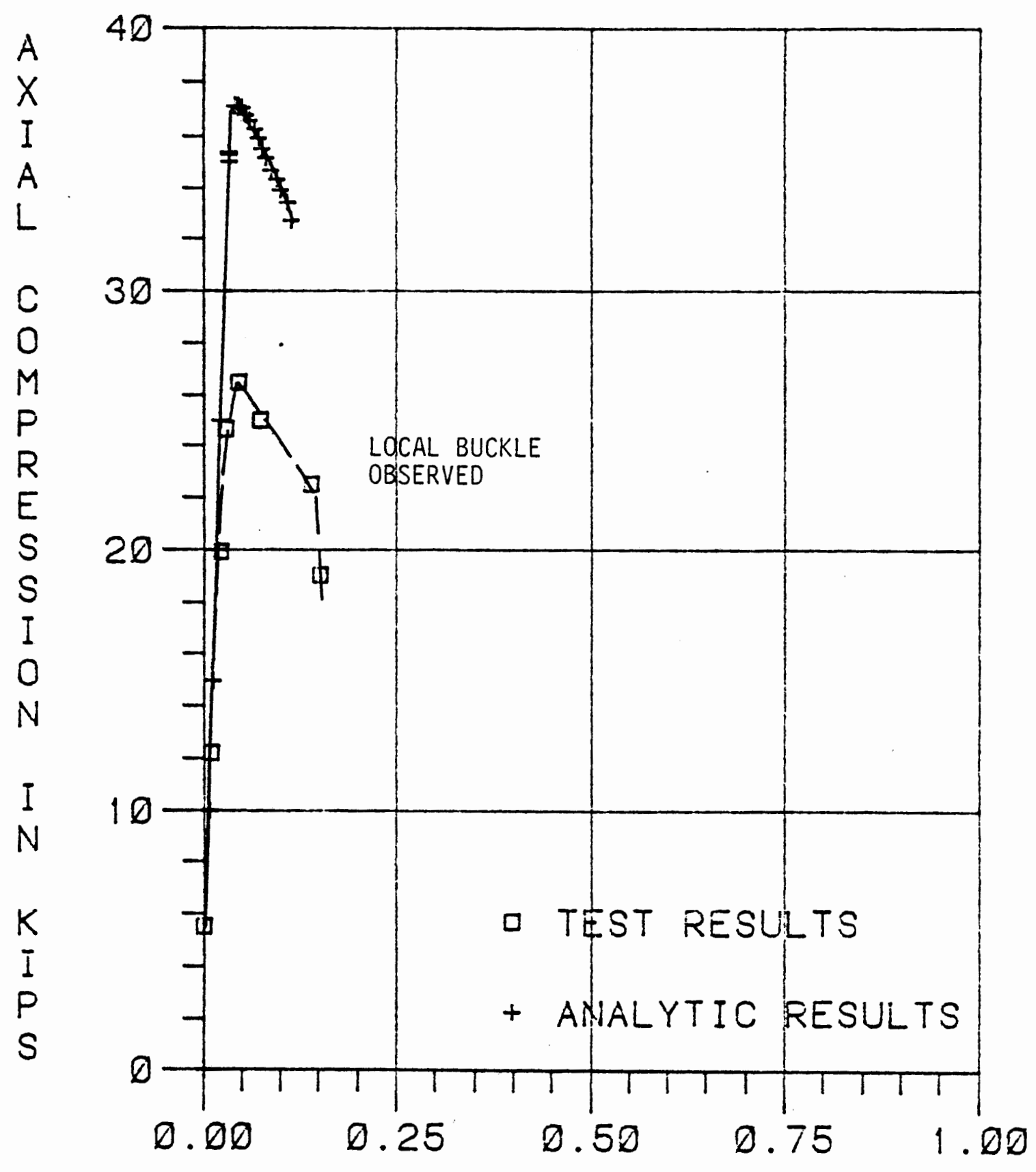

AXIAL SHORTENING IN INCHES

Figure 30 Test S3 BB 50-1 
TEST SD BB 50-1 L/r $=152.0$

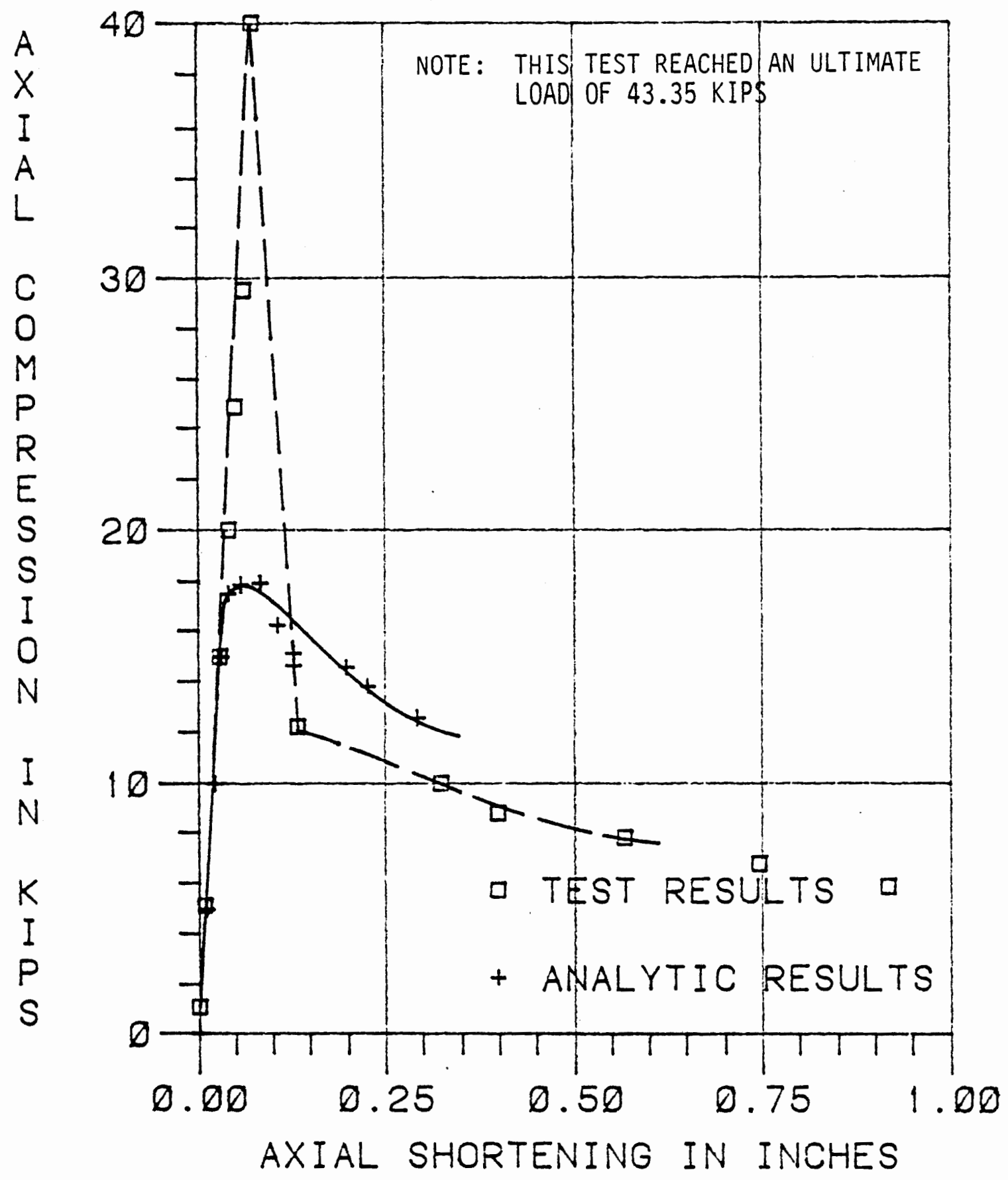

Figure 31 Test $S \emptyset$ BB $50-1$ 
TEST T2 BF 5D-1 L/r $=192.6$

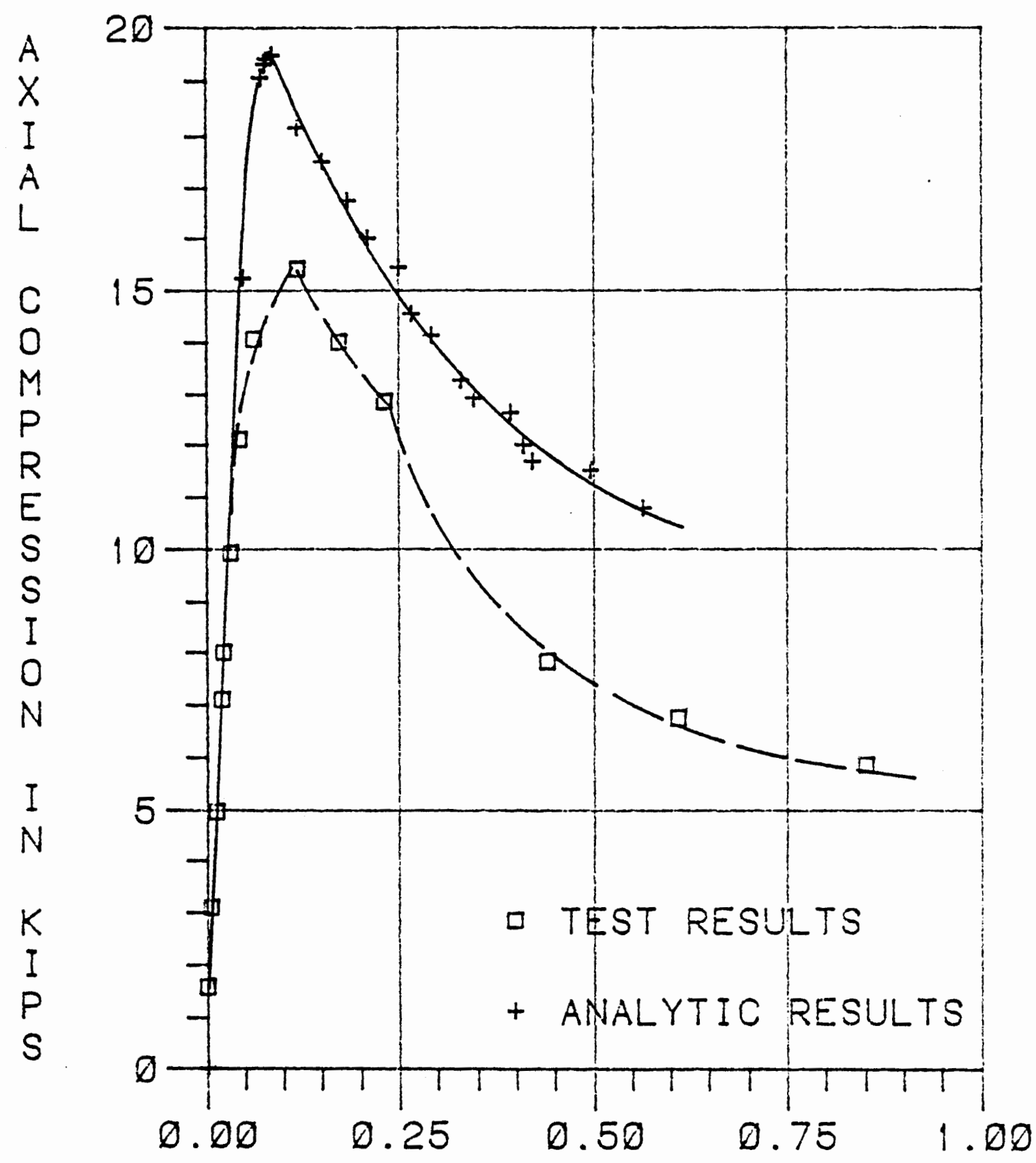

AXIAL SHORTENING IN INCHES

Figure 32 Test $T 2$ BF $50-1$ 
TEST T2 BF 36-1 L/r=193.D

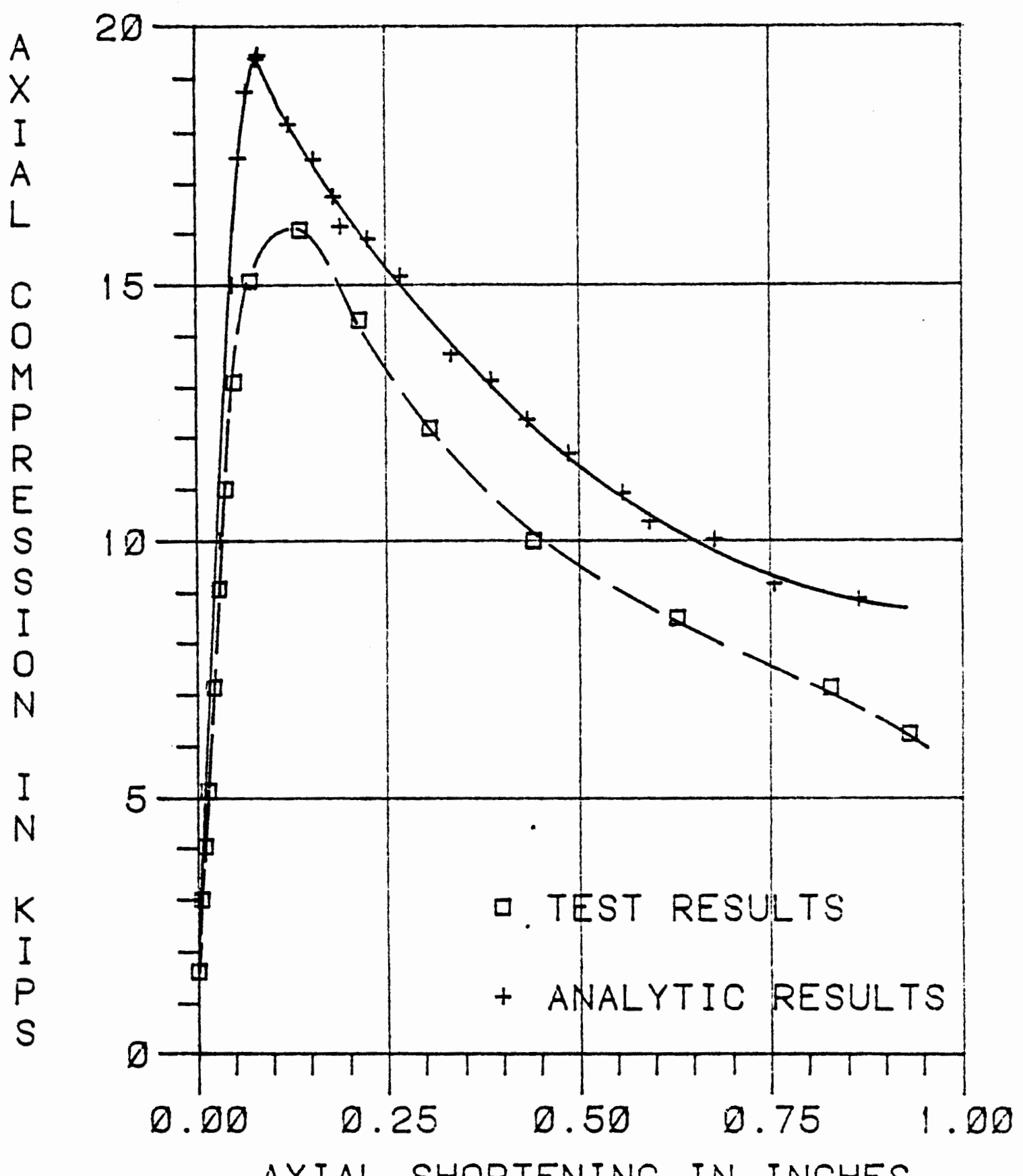

AXIAL SHORTENING IN INCHES

Figure 33. Test T2 BF 36-1 
TEST SR3 BB 36-1 L/r $=60.8$

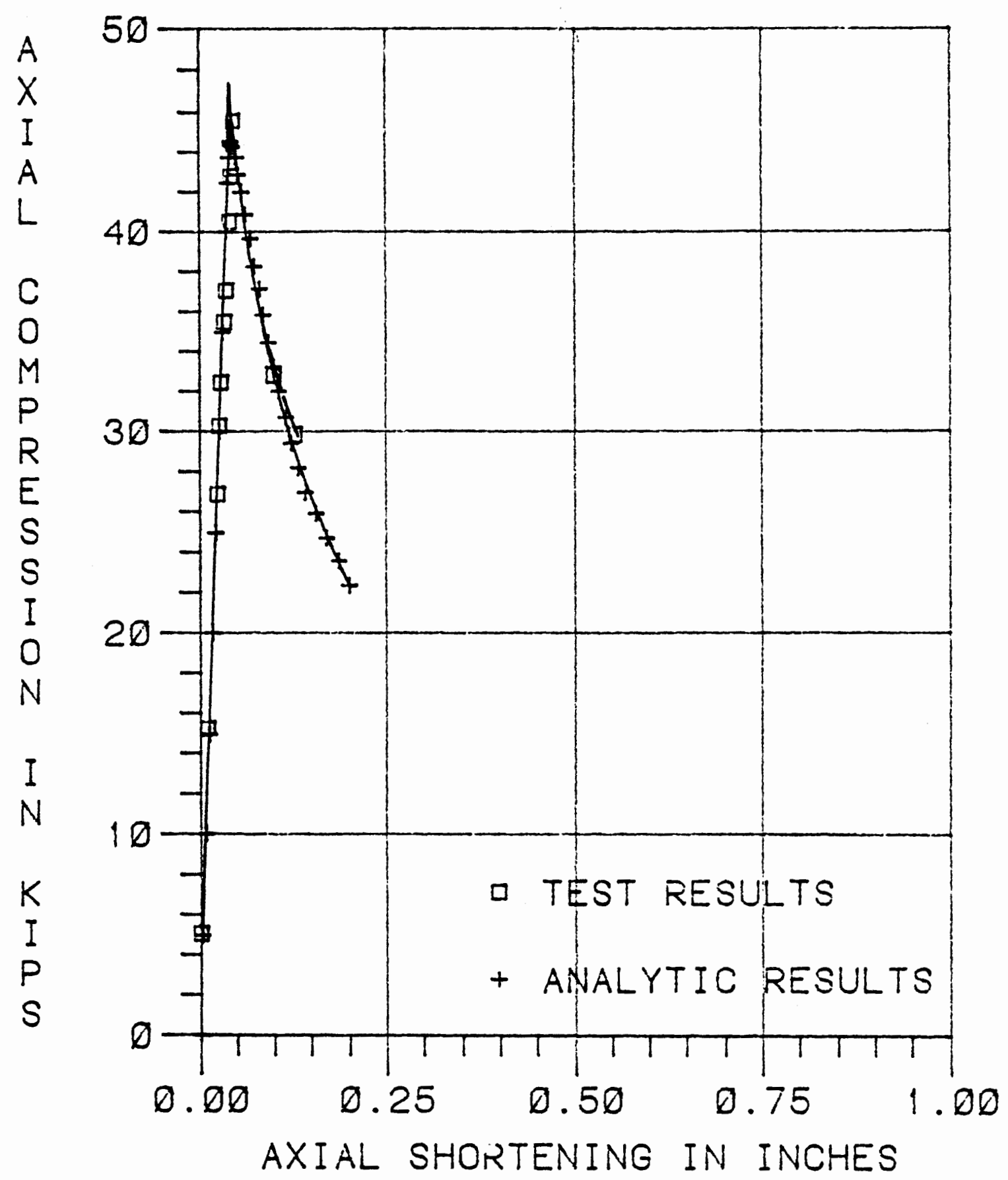

Figure 34 Test SR3 BB 36-1 
TEST TR3 BB $50-1(1) \quad L / r=60.8$

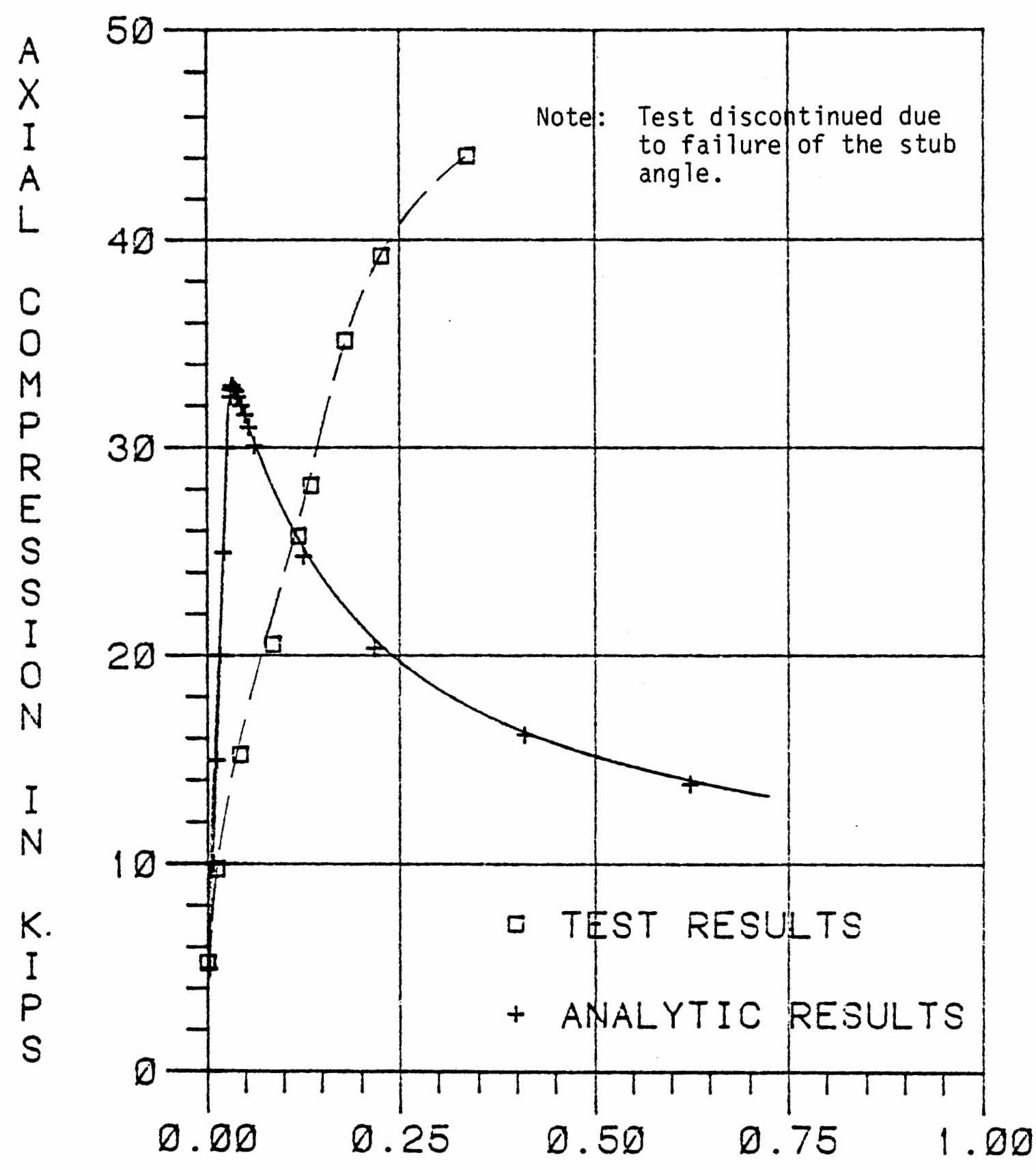

AXIAL SHORTENING IN INCHES.

Figure 35 Test TR3 BB 50-1 (1) 
TEST TR3 BB 5D-1 L/r $=60.8$

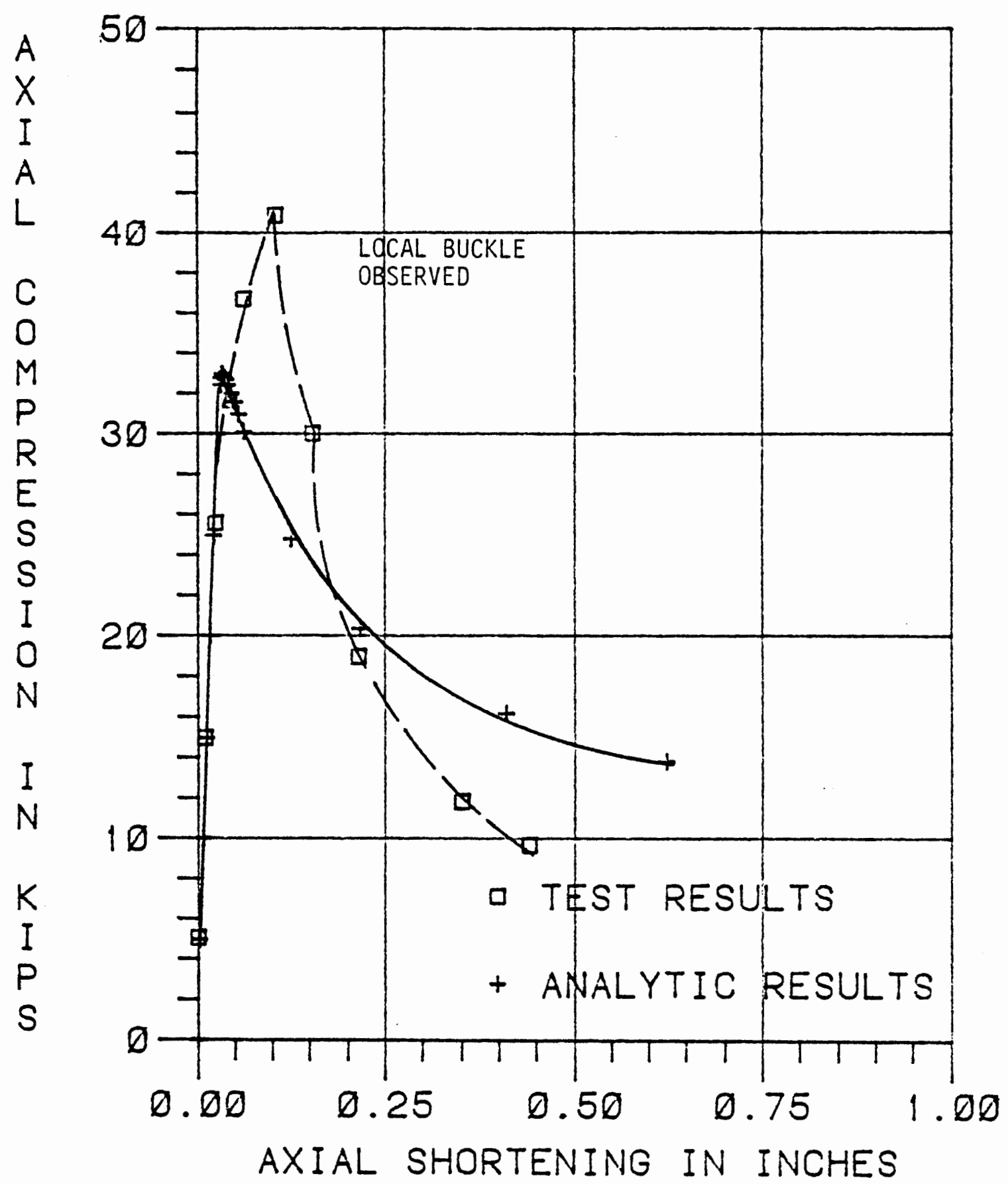

Figure 36 Test TR3 BB 50-1 
TEST TR2 BB $50-1 \quad L / r=192.6$

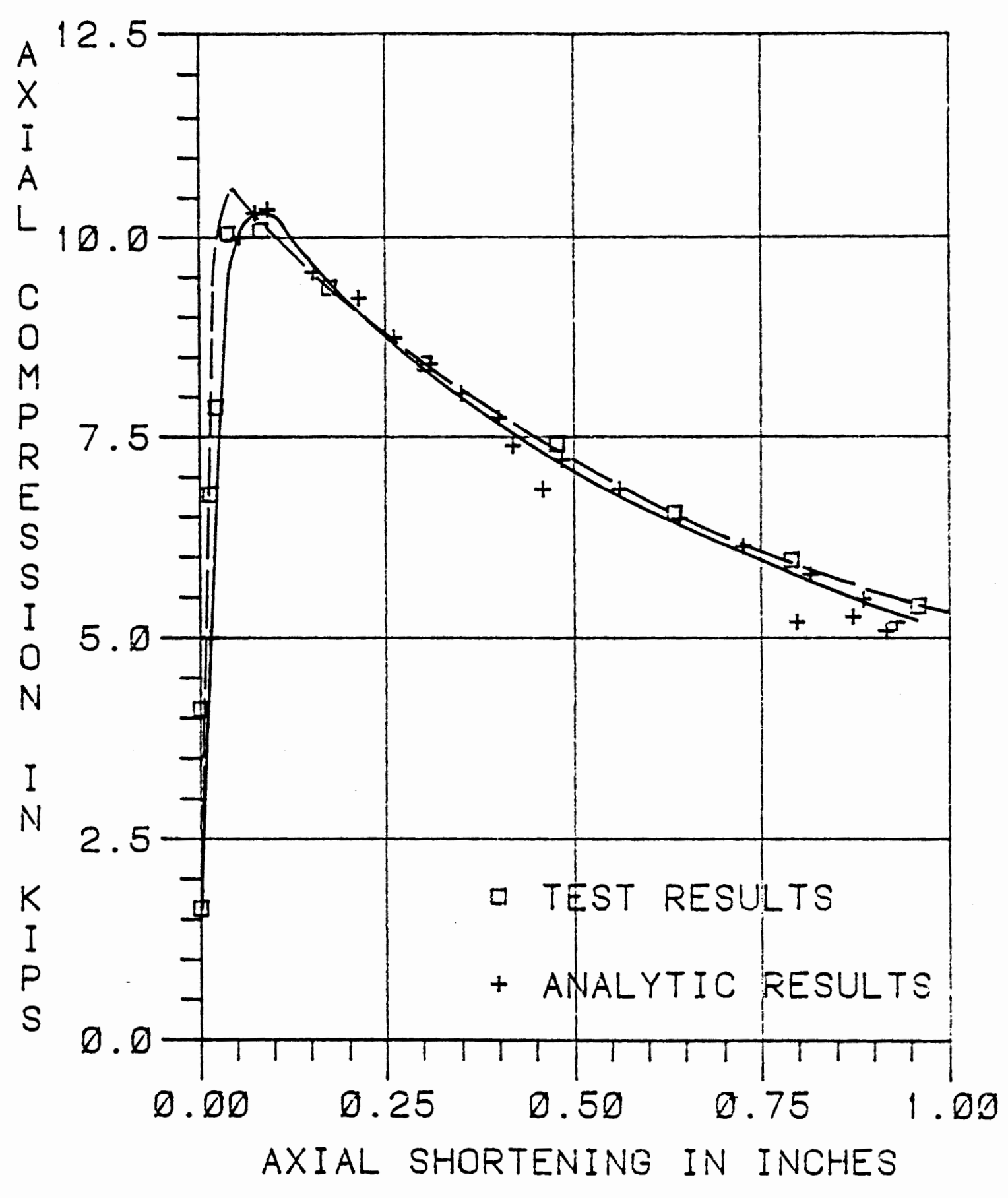

Figure 37 Test TR2 BB 50-1 
TEST TR $1 \quad B B \quad 36-1 \quad L / R=111.5$

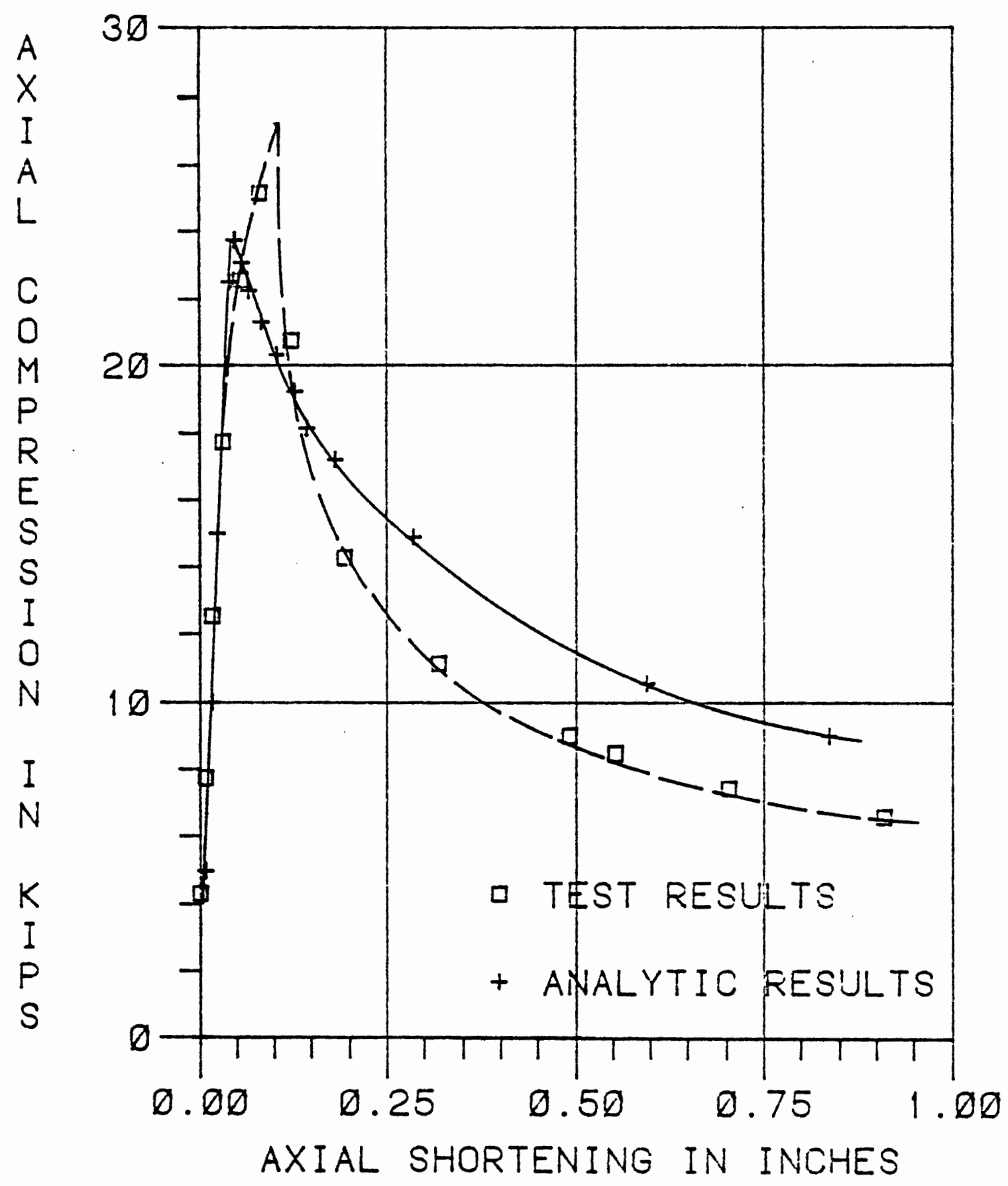

Figure 38 Test TRI BB 36-1 
TEST T4 BB 36-1 L/r $=200.0$

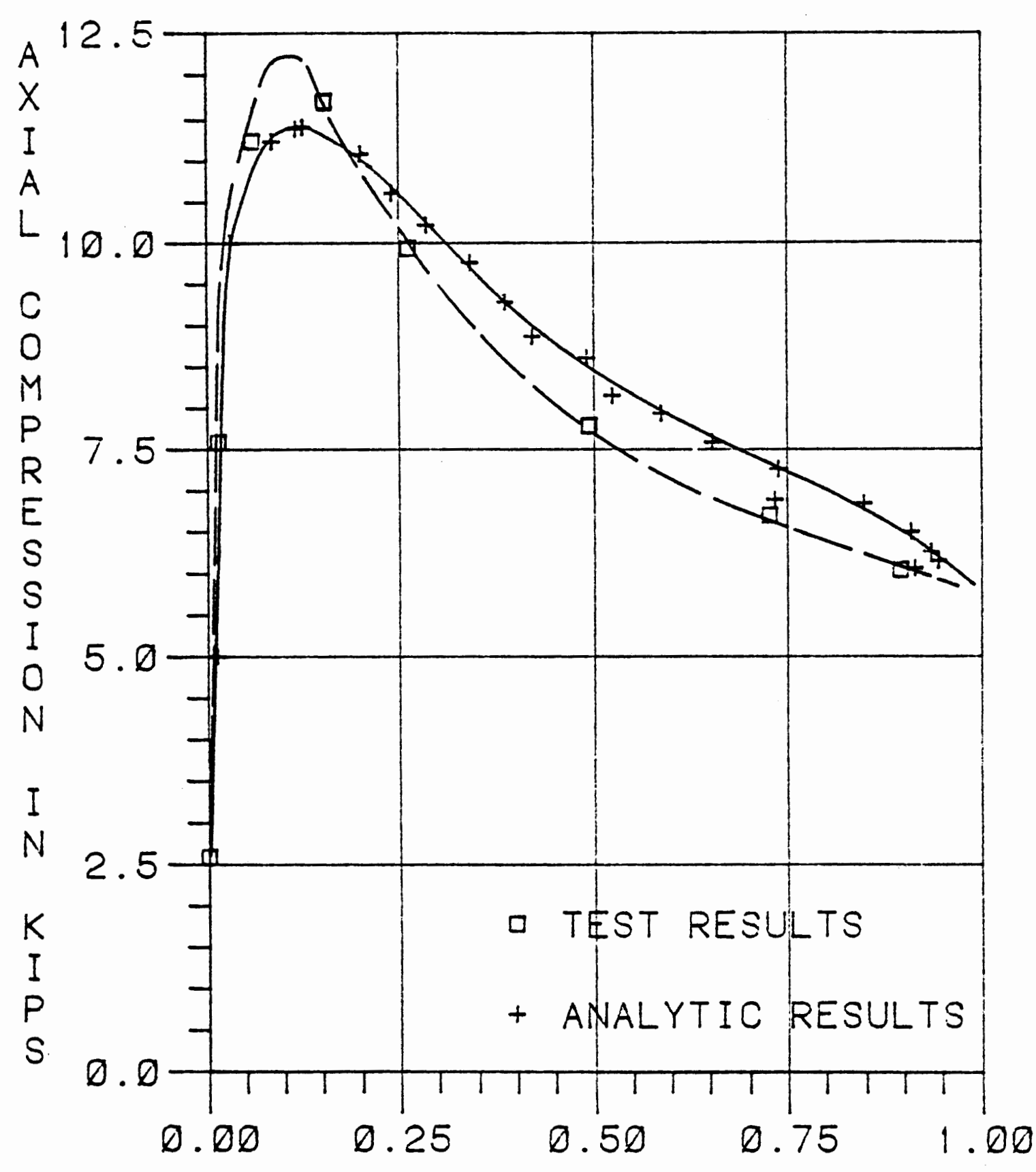

AXIAL SHORTENING IN INCHES

Figure 39 Test T4 BB 36-1 
TEST T4 BB 36-2 L/r=20D.

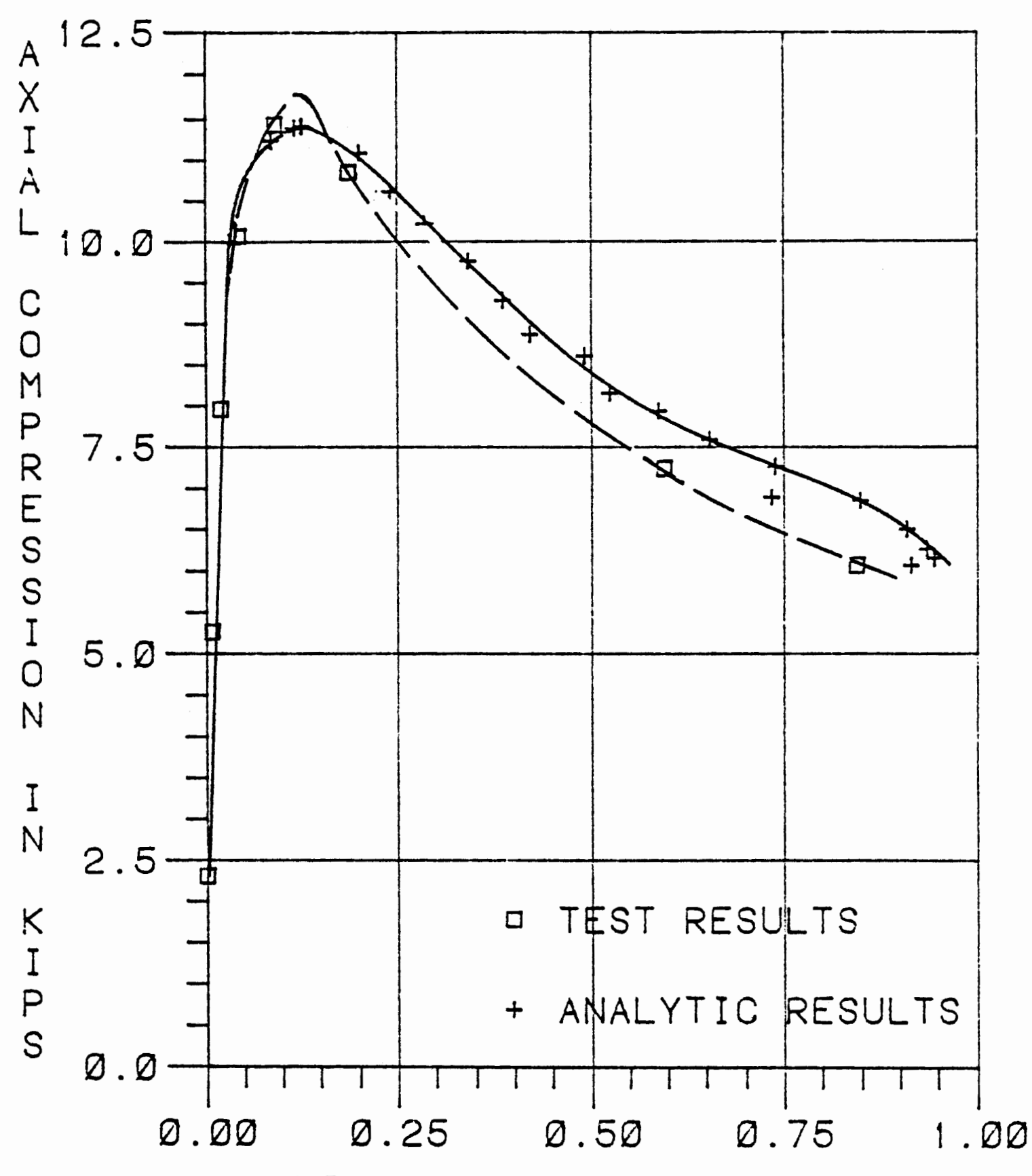

AXIAL SHORTENING IN INCHES

Figure 40 Test T4 BB 36-2 
TABLE II I

FAILURE LOAD COMPARISON FOR SINGLE MEMBER TESTS

\begin{tabular}{|c|c|c|c|}
\hline \multirow[t]{2}{*}{ TEST } & \multicolumn{3}{|c|}{ ULTIMATE IOAD (KIPS) } \\
\hline & CALCULATED & EXPERIMENTAL & 음 DIFF. \\
\hline $\begin{array}{lll}\text { S2 } & \text { HH } & 50-2 \\
\text { S2 } & \text { HH } & 36-1 \\
\text { S2 } & H H & 36-2 \\
\text { S1 } & H H & 50-1 \\
\text { S1 } & \text { HH } & 36-2\end{array}$ & $\begin{array}{r}9.5 \\
10.2 \\
10.4 \\
29.9 \\
29.9\end{array}$ & $\begin{array}{r}8.7 \\
9.7 \\
14.7 \\
43.8 \\
50.4\end{array}$ & $\begin{array}{c}8.4 \\
4.9 \\
41.3^{*} \\
46.5^{*} \\
68.6^{\star}\end{array}$ \\
\hline $\begin{array}{lll}\text { S3 } & \text { BB } & 36-1 \\
\text { S3 } & \text { BB } & 36-2 \\
\text { S1 } & \text { BB } & 36-2 \\
\text { S2 } & \text { BB } & 36-3\end{array}$ & $\begin{array}{r}44.5 \\
44.4 \\
24.3 \\
9.9\end{array}$ & $\begin{array}{r}33.0 \\
37.4 \\
21.9 \\
9.8\end{array}$ & $\begin{array}{r}25.8 \\
15.9 \\
9.9 \\
1.0\end{array}$ \\
\hline $\begin{array}{lll}\text { T2 } & \text { BB } & 50-1 \\
\text { T2 } & \text { BB } & 36-1 \\
\text { T1 } & \text { BB } & 36-1 \\
\text { T1 } & \text { BB } & 50-1 \\
\text { T3 } & \text { BB } & 50-1 \\
\text { T3 } & \text { BB } & 35-1\end{array}$ & $\begin{array}{l}10.4 \\
10.4 \\
22.4 \\
22.2 \\
29.6 \\
30.0\end{array}$ & $\begin{array}{r}8.7 \\
10.0 \\
31.3 \\
21.9 \\
35.9 \\
30.4\end{array}$ & $\begin{array}{r}16.3 \\
3.8 \\
39.7 \\
1.4 \\
21.3 \\
1.3\end{array}$ \\
\hline $\begin{array}{lll}\text { S3 } & \text { BB } & 50-1 \\
\text { S0 } & \text { BB } & 50-1\end{array}$ & $\begin{array}{l}37.2 \\
17.9\end{array}$ & $\begin{array}{l}26.5 \\
43.4\end{array}$ & $\begin{array}{c}28.8 \\
142.4^{*}\end{array}$ \\
\hline $\begin{array}{lll}\text { T2 } & \text { BF } & 50-1 \\
\text { T2 } & \text { BF } & 36-1\end{array}$ & $\begin{array}{l}19.5 \\
19.5\end{array}$ & $\begin{array}{l}15.4 \\
16.2\end{array}$ & $\begin{array}{l}21.0 \\
16.9\end{array}$ \\
\hline $\begin{array}{llll}\text { SR3 } & \text { BB } & 36-1 & \\
\text { TR3 BB } & 50-1 & \text { (1) } \\
\text { TR3 B } & 50-1 & \\
\text { TR2 BB } & 50-1 & \\
\text { TR1 } & \text { BB } & 36-1\end{array}$ & $\begin{array}{l}44.5 \\
33.0 \\
33.0 \\
10.4 \\
23.8\end{array}$ & $\begin{array}{l}47.8 \\
44.0 \\
41.2 \\
10.7 \\
27.2\end{array}$ & $\begin{array}{r}7.4 \\
33.3 \\
24.8 \\
2.9 \\
14.3\end{array}$ \\
\hline $\begin{array}{lll}\text { T4 } & \text { BB } & 36-1 \\
\text { T4 } & \text { BB } & 36-2\end{array}$ & $\begin{array}{l}11.4 \\
11.4\end{array}$ & $\begin{array}{l}12.2 \\
11.8\end{array}$ & $\begin{array}{l}9.9 \\
3.5\end{array}$ \\
\hline
\end{tabular}

$\%$ DIFF. $=\frac{\text { CALC.-EXP. }}{\text { CALC. }} \times 100$

*ECCENTRICITY $=0$ (BOTH ENDS) 
loads. Computer results are somewhat higher than the test values. This may be due to the fact that the computer model assumes a perfect column which is not possible to achieve in tests.

In the tests where the axial load was applied at the center of gravity of the member, large differences in peak load values did occur. In tests S2 HH 36-2 (Fig. 17), S1 HH 50-1 (Fig. 18), S1 HH 36-2 (Fig. 19) and $S \emptyset B B$ 50-1 (Fig. 31) where the eccentricities of the applied load was zero, the load reached a considerably higher value than that predicted by the computer program (Ref. 7) and dropped suddnely. This rise and abrupt drop of load is known as the 'spike.' It is believed to be caused by the internal friction of the end joints. The holding force in the end joints causes the member to function as a fixed ended column rather than the assumed case of a pin-ended column, thus explaining the higher ultimate loads observed in these tests. When other imperfections overcome this holding force the load drops rapidly because the member changes instantly to a pinned-pinned case from a fixed-fixed case. The comparison of test $\mathrm{S} 2 \mathrm{HH} \mathrm{36-1} \mathrm{(Fig.} \mathrm{16)} \mathrm{and} \mathrm{S2} \mathrm{HH} \mathrm{36-2} \mathrm{(Fig.} \mathrm{17)} \mathrm{gives} \mathrm{supporting} \mathrm{evidence}$ to this phenomena. It should be noted that all parameters were the same for these two tests except for the small eccentricity at one end of the test S2 HH 36-1. This small eccentricity was instrumental in displacing the member without causing a temporary fixed-fixed condition.

Tests S2 HH 50-2 and S2 HH 36-1 are those with hinged-hinged connections which had loading eccentricities. They followed a gradual curve in the inelastic and post buckling region without a spike. The post buckling strength of the tests were about $10-15 \%$ less than that predicted by the analytical model. This may be due to the fact that the analytical model assumes a perfect column which is not possible to achieve in tests. 
Tests S3 BB $36-1$, S3 BB $36-2$, S1 BB $36-2$ and $S 2$ BB $36-3$ used the ball-ball configuration with eccentricity on the $x$-axis only. Favorable comparison of these tests with the computer model of Ref. 7 were obtained (Fig. 20 to Fig. 23), except for tests $S 3 B B 36-1$ and $S 3 B B 36-2$. In these two tests the ultimate load values were lower than that predicted by the computer program of Ref. 7 by $25.8 \%$ and $15.9 \%$ respectively. These two tests are the same except that the value of eccentricities are in opposite directions from the center of gravity of the angle. Test S3 BB 36-1 was repeated as given in SR 3 BB 36-1 (Fig. 34) and a good correlation was obtained with the computer model of Ref. 7 .

The next six tests are those with bolted joints with eccentricities about both axes which simulate a typical tower joint. In this series, tests $T 3 B B 50-1, T 2 B B 50-1$ and $T 1 B B$ 36-1 were repeated in an attempt to obtain better data. They are documented in TR 3 BB 50-1 (1), TR 3 BB 50-1, TR 2 BB 50-1 and TR 1 BB 36-1 (Fig. 35 to Fig. 38). Test TR 3 BB 50-1 (1) was discontinued after the failure of the stub angle. All tests in this series exhibit a "softer" load vs axial displacement ( $P$ vs $\delta$ ) curve in the elastic range. This can be attributed to the slippage of the bolted joints when the load is being applied. Another factor causing this wider $P$ vs $\delta$ curve is the eccentricity of the load from the center of gravity of the member. The fact that the bolt slippage is the predominant factor contributing to this softer load vs axial displacement ( $P$ vs $\delta$ ) curve is supported by comparing test results for S3 BB 50-1 (Fig. 30) and T3 BB 50-1 (Fig. 28). Both of these tests are loaded with eccentricity of load in both directions from the center of gravity. Inspite of the fact that test $S 3 B B$ 50-1 had higher eccentricity than test $T 3 B B$ 50-1, the test $T 3 B B$ 50-1 exhibited a softer curve in the 
elastic range.

The tests T2 BF 50-1 (Fig. 32) and T2 BF 36-1 (Fig. 33) are the tests with one end fixed and the other with a ball joint. The computer model of Ref. 7 is not capable fo handling fixed joints. Hence a fixed joint was simulated by two hinged joints at close proximity at one end. The difference in experimental and theoretical curves may be due to this assumption or to the difficulty in fabricating a truly fixed end in the experimental set up.

Tests $T 4$ BB $36-1$ and $T 4$ BB $36-2$ were performed to ascertain the effect of local buckling in long compression members. These angle members had a width-to-thickness ratio $(\mathrm{w} / \mathrm{t})$ of 20 which exceeds the limitation in the AISC Manual of Steel Construction (8) for compact members. These tests did not show the formation of a local buckle before the yielding of the member as they failed in an elastic buckling mode and thus the stress level remained low.

The formation of a local buckle if any, is indicated on the curves presented in Figs. 15 to 40 . It is noted that all the local buckling observed has occurred after attaining the full ultimate strength of the member. The formation of a local buckle was predominantly seen in shorter members, because members with smaller $\mathrm{L} / \mathrm{r}$ ratios sustained high stresses.

In general the test results show that a long member has greater ability to sustain load after the critical buckling load than the shorter members. However, in all cases some resistance to axial load was evident in the post buckling region. Hence members with larger $L / r$ ratios exhibit larger load plateaus before a gradual drop-off of load occurs. This is because the members with larger $L / r$ ratios require large axial displacements to cause yielding due to the bowing of the member. On the other- 
hand members with smaller $L / r$ ratios displayed a brittle type failure with steep drop-off of load capacity after reaching the ultimate strength.

By comparing the $P$ vs $\delta$ curves for various tests it is evident that the effect of the eccentricity of applied load from the center of gravity of the member is to make the $P$ vs $\delta$ curve softer. A typical example is the comparison of tests S2 HH 50-2 and S2 HH 36-2. The test S2 HH 50-2 (Fig. 15) being loaded eccentrically from the center of gravity of the angle has a softer curve than the curve for the test S2 HH 36-2. Eccentrically loaded members have a more ductile type of failure with a wider plateau but attain a lower ultimate load.

It is evident that the effect of a fixed end condition is to attain higher ultimate strength of the member than in ball or hinge connections. This is expected as fixed ends give greater resistance to applied loads. However tests with bolted connections demonstrated their suseptibility to bolt slippage, which resulted in wider $P$ vs $\delta$ curves.

The study of the effect of the yield strength on the member performance was handicapped to a certain extent by the non-availability of the steel stock with wide range of yield strengths. It is shown in Table I that the yield strengths of members tested do not exhibit a considerable difference in value between A-36 steel and Grade 50 steel. However it is observed that members with higher yield strength with other parameters being constant give rise to higher ultimate strengths as expected.

It should be emphasized that the above observations pertaining to the effect of various parameters in the member performance are done in general terms. The limited number of tests performed and the test data 
scatter was a problem when extrapolating the results. However, it is evident that the tests performed were sufficient to verify the analytical computer program of Ref. 7 . 


\section{PRELIMINARY EXPERIMENTAL PROGRAM FOR} INDETERMINATE TRUSS TESTS

\subsection{OVERVIEW}

This chapter documents the Preliminary Experimental Program carried out to investigate the load transfer characteristics of diagonal bracing in an indeterminate truss. Attention is given to the Experimental set up, Instrumentation and the Test Procedure. The Steel Properties and Coupon test results are included. The experimental load capacity of the test frame for various diagonal members tested were compared with the theoretical capacity determined by statics.

\subsection{EXPERIMENTAL SET UP}

Experimental set up for the indeterminate truss is shown in Figures 41 and 42 . Figure 41 is a picture of the indeterminate truss without diagonal bracing. Diagonal bracing is shown in Fig. 42. The idealized configuration is shown in Fig. 43. A 48 inch square frame was constructed using $8 \times 8 \times 7 / 8$ double angles as a model to do preliminary study of load transfer characteristics in an indeterminate truss. The double angles between $C D$ (Fig. 43) are welded to a $W 24 \times 68$ which is restrained at $E$ and $F$. From the geometry the reactions at $E$ and $F$ are equal and opposite and the magnitude is less than the pulling force in the actuator. The reaction at $G$ is equal to the pulling force in the actuator (assuming supports $E$ and $F$ do not contribute reactions in the $C D$ direction). Supports were provided at $E, F$ and $G$ to resist the above reactions 


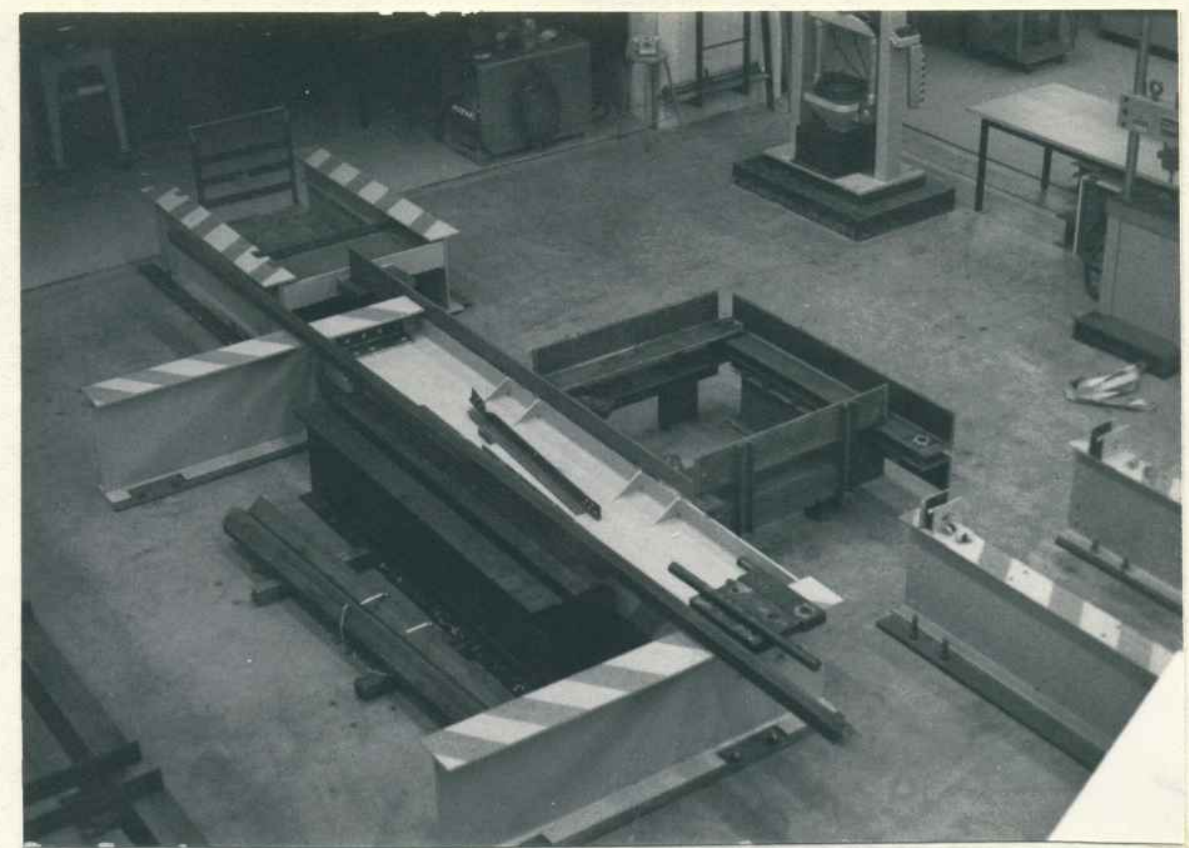

Figure 41. Setup of truss without diagonal bracing

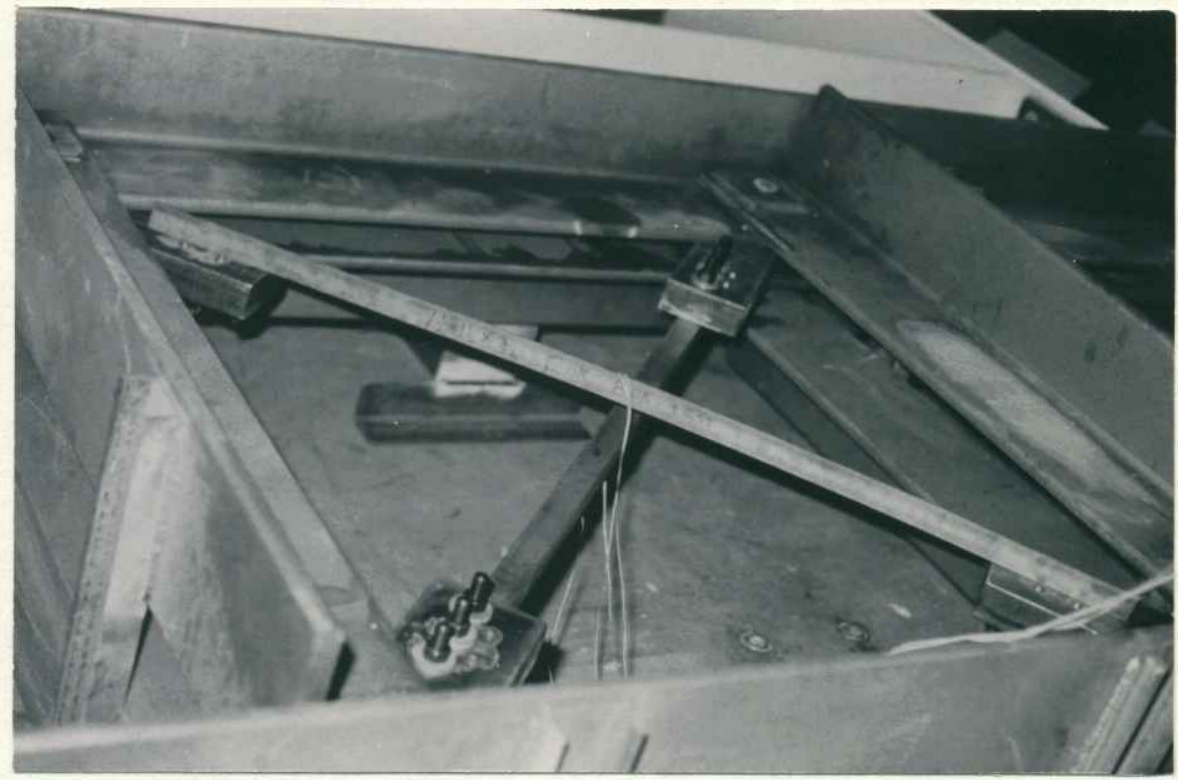

Figure 42. Indeterminate truss with diagonal bracing 


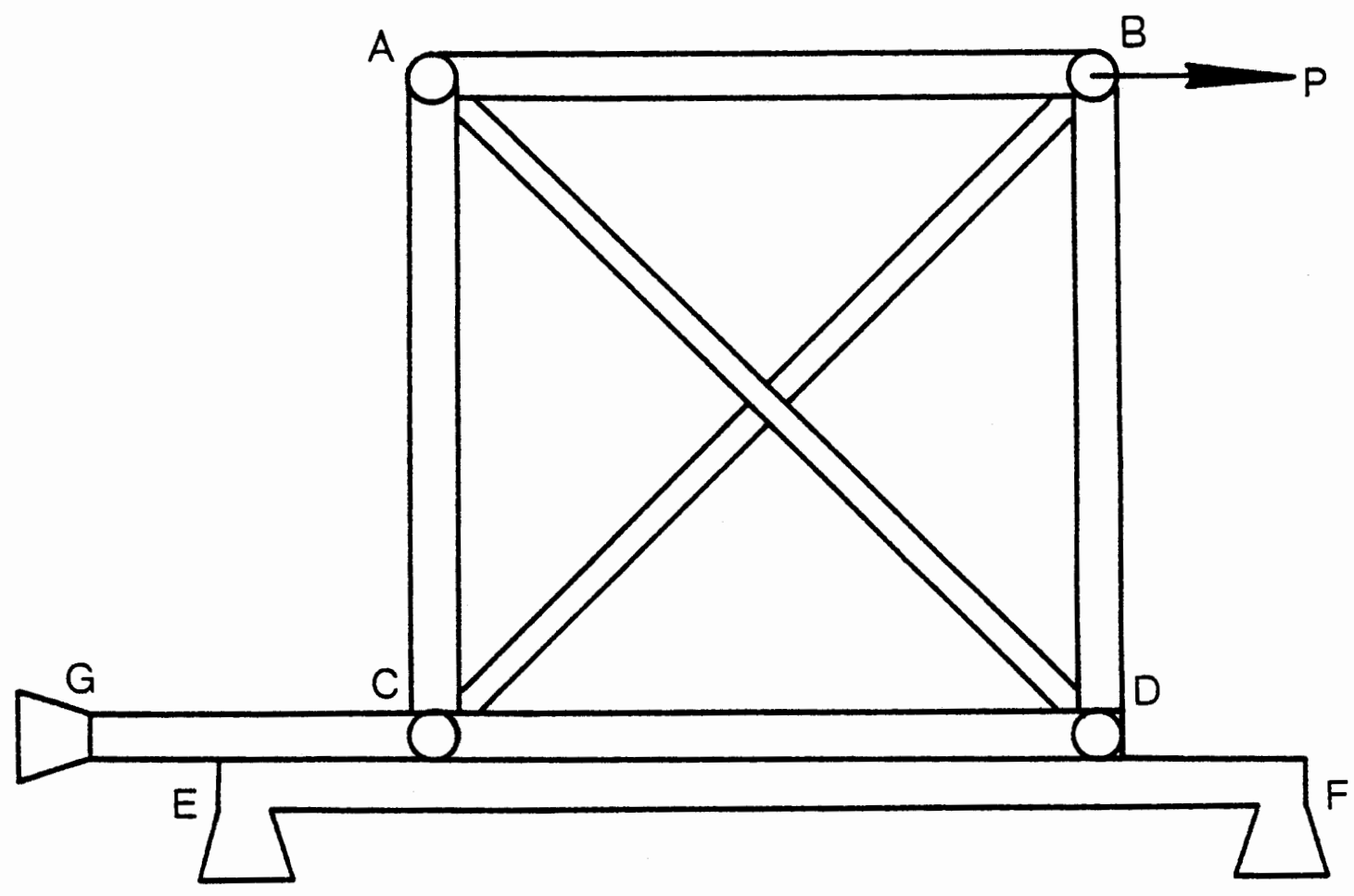

Figure 43 Indeterminate truss 
(Fig. 43). The $8 \times 8 \times 7 / 8$ angles were separated by 2 inches to facilitate connection of the diagonal test member to the frame. The diagonal test angles are bolted to a $13^{\prime \prime} \times 5^{\prime \prime} \times 2^{\prime \prime}$ connecting plate with $5 / 8$ inch bolts at each end. These plates are then pin connected to the frame to simulate a frame as shown in Fig. 43. Members of the test frame were selected large to give the frame a capability of testing larger members and to minimize their size effect on the test results.

\subsection{INSTRUMENTATION}

The MTS system was used with stroke control to apply the load. The load value was read directly from the MTS control panel. The deflection of the sidesway of the portal was measured using a Linear Variable Differential Transducer (LVDT) with read out directed to the MTS control panel.

\subsection{TEST PROCEDURE}

The chosen test procedure was selected to ensure that the compression diagonal was well seated and compressed before the tension diagonal sustained any load. This was an attempt to minimize the bolt shippage in the compression test member connection.

The test procedure was as follows

1) mount the compression diagonal in the test frame

2) Apply a load at the joint B (Fig. 43) using the actuator of the MTS system until the compression member is well seated. Five hundred pounds is the normal load value used.

3) mount the tension diagonal 
4) load until failure of the tension diagonal.

The members tested and final results are given in Table IV. The theoretical load capacity of the truss was determined by statics assuming zero load resistance in the compression diagonal and a yield force in the tension diagonal. A plot of the load deflection curves obtained from these truss tests are presented in Figures 44 to 52 . The load is the load applied by the actuator and the deflection is the sidesway of the portal.

\subsection{STEEL PROPERTIES AND COUPON TESTS}

To obtain data on the material properties of the steel angles tested, coupon tests were performed using the MTS Testing Machine. Details of these tests are documented in Chapter II, section 2.6. A typical stress-strain curve is illustrated in Fig. 14. Table V summarizes the steel properties of steel members used in the indeterminate truss tests.

\subsection{DISCUSSION OF RESULTS}

Table IVA summarizes the properties and configuration of diagonal members used in preliminary truss tests. The areas listed for tension members are for net sections calculated in accordance with the provisions of section 1.14 .2 of Ref. 8. The tension member used in test $F \times 3$ was a C $5 \times 9$ and was coped at its ends to facilitate mounting. Comparison of experimental and analytical results of the preliminary truss tests are given in Table IVB. The theroretical frame load capacity of the frame is that load sustained by the frame when the tension diagonal is 


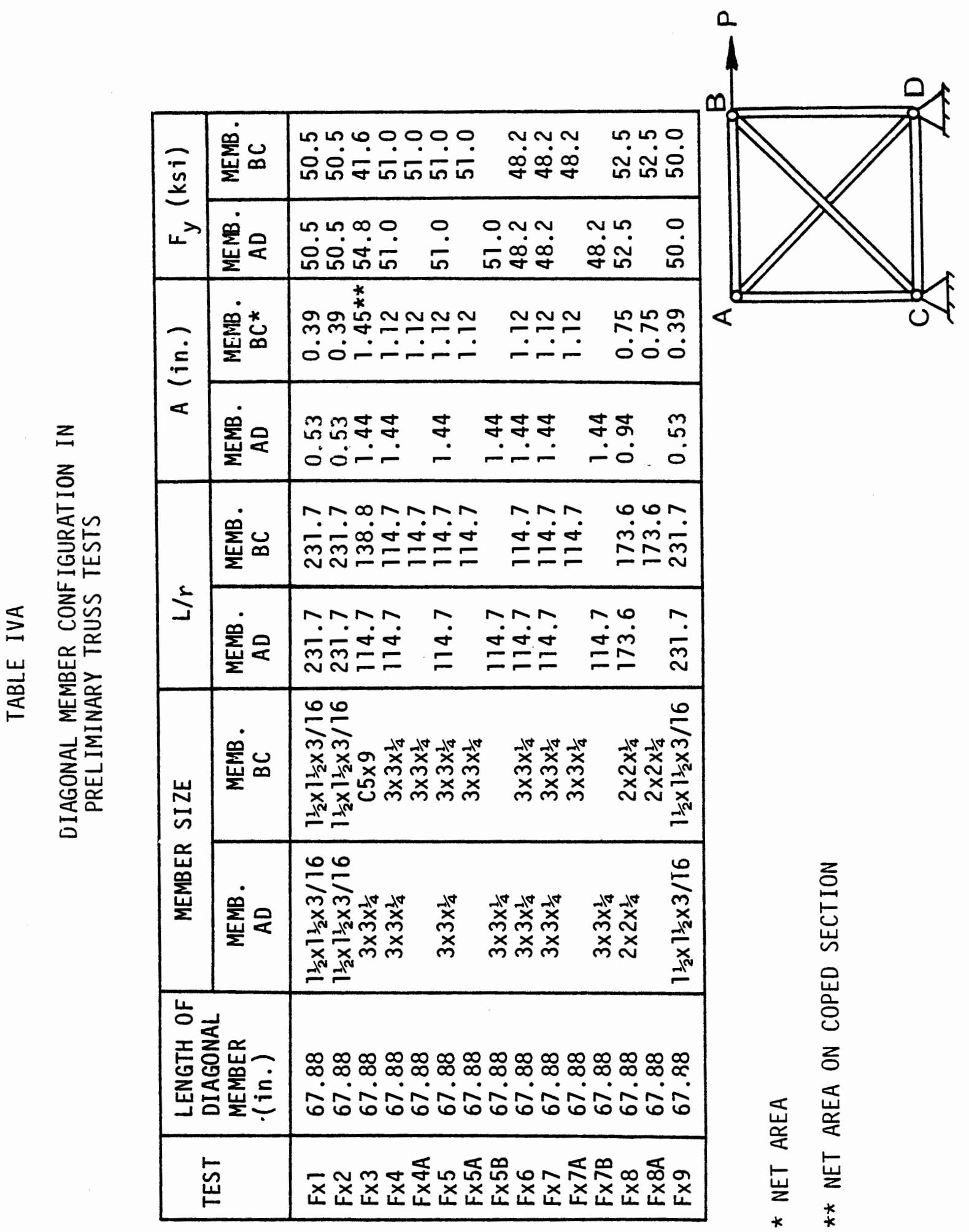




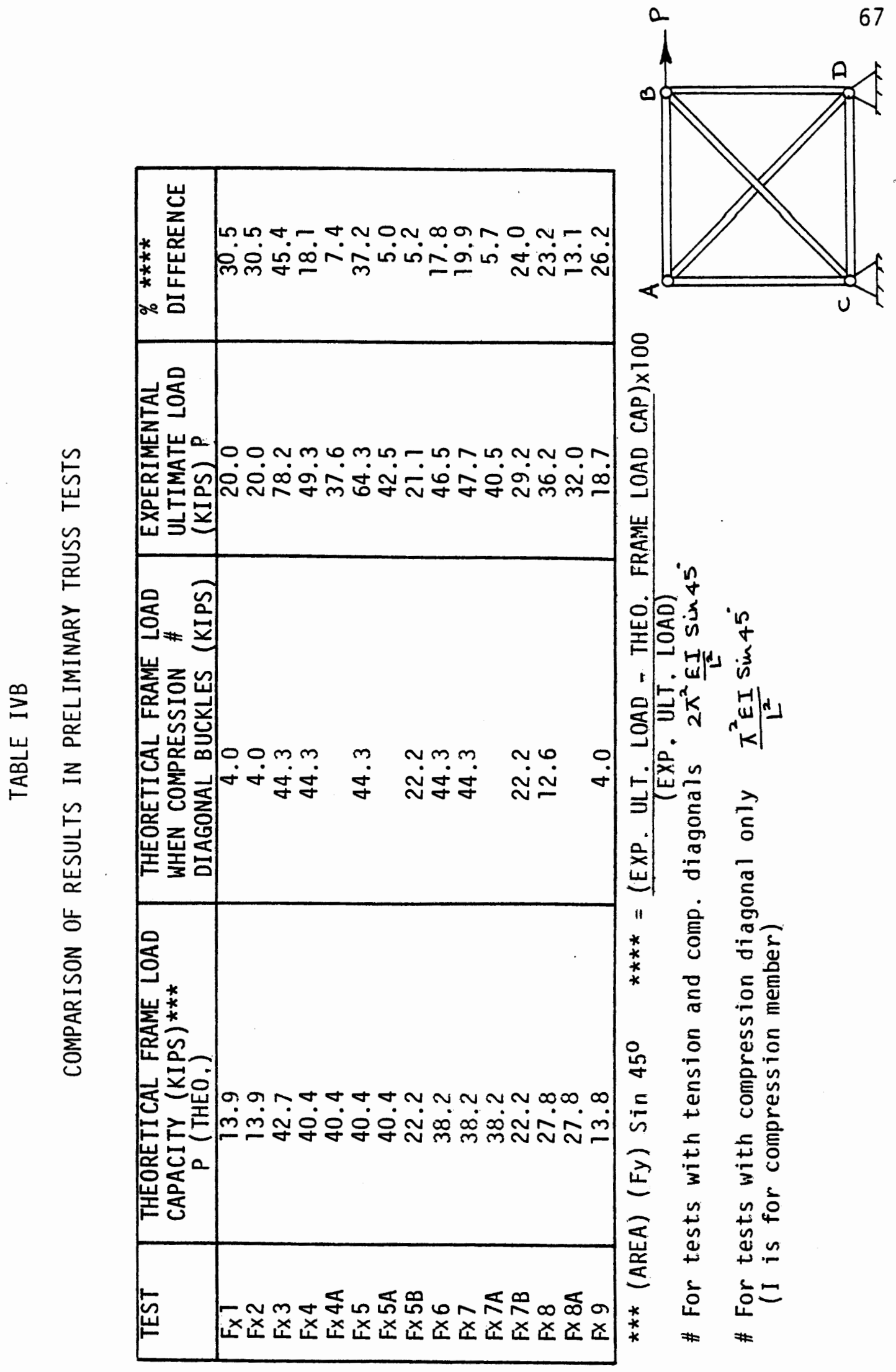


TABLE V

STEEL PROPERTIES OF INDETERMINATE TRUSS TESTS

\begin{tabular}{|c|c|c|c|c|}
\hline TEST & $\begin{array}{c}\text { YIELD } \\
\text { STRESS } \\
\text { (KSI) }\end{array}$ & $\begin{array}{c}\text { ULTIMATE } \\
\text { STRESS } \\
\text { (KSI) }\end{array}$ & $\begin{array}{c}\text { MODULUS } \\
\text { OF } \\
\text { ELASTICITY }\end{array}$ & $\begin{array}{c}\text { PERCENTAGE } \\
\text { EIONGATION } \\
(\%)\end{array}$ \\
\hline ExI & 50.5 & 72.3 & 29100 & 31.0 \\
\hline Fx2 & 50.5 & 72.3 & 29100 & 31.0 \\
\hline $\mathrm{F} \times 3(\mathrm{TM}) *$ & 41.6 & 59.0 & 29700 & 38.0 \\
\hline $\mathrm{F} \times 3(\mathrm{CM}) * *$ & 54.8 & 71.2 & 29100 & 38.0 \\
\hline $\mathrm{F} \times 4$ & 51.0 & 67.8 & 29200 & 34.0 \\
\hline Fx5 & 51.0 & 67.8 & 29200 & 34.0 \\
\hline Fx6 & 48.2 & 65.6 & 29100 & 35.0 \\
\hline Fx7 & 48.2 & 65.6 & 29100 & 35.0 \\
\hline Fx8 & 52.5 & 72.7 & 29100 & 34.0 \\
\hline $\mathrm{F} \times 9$ & 50.0 & 67.5 & 29300 & 39.0 \\
\hline
\end{tabular}

* TM = TENSION MEMBER IN TEST F $\times 3$

$\star * C M=$ COMPRESSION MEMBER IN TEST F $\times 3$ 


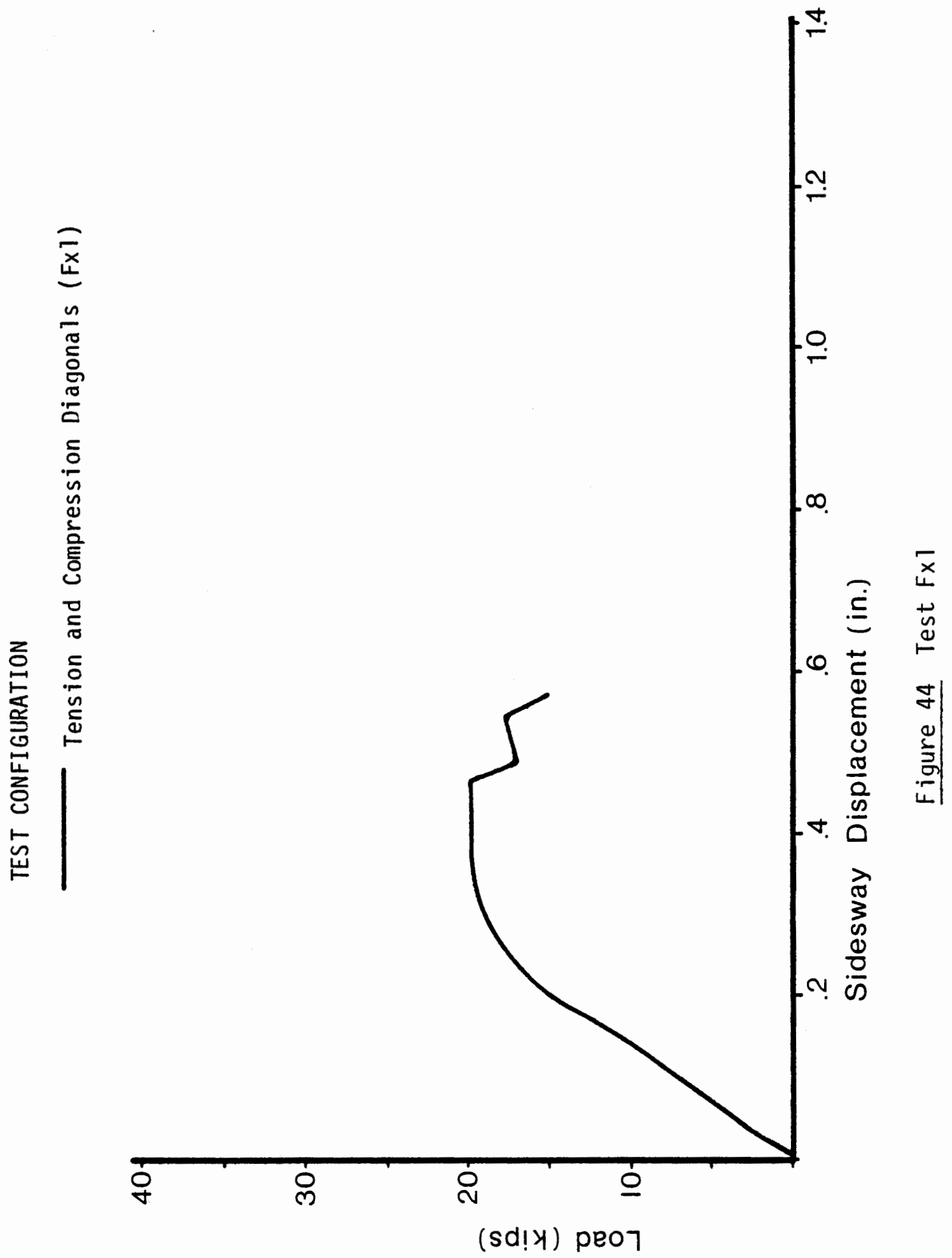




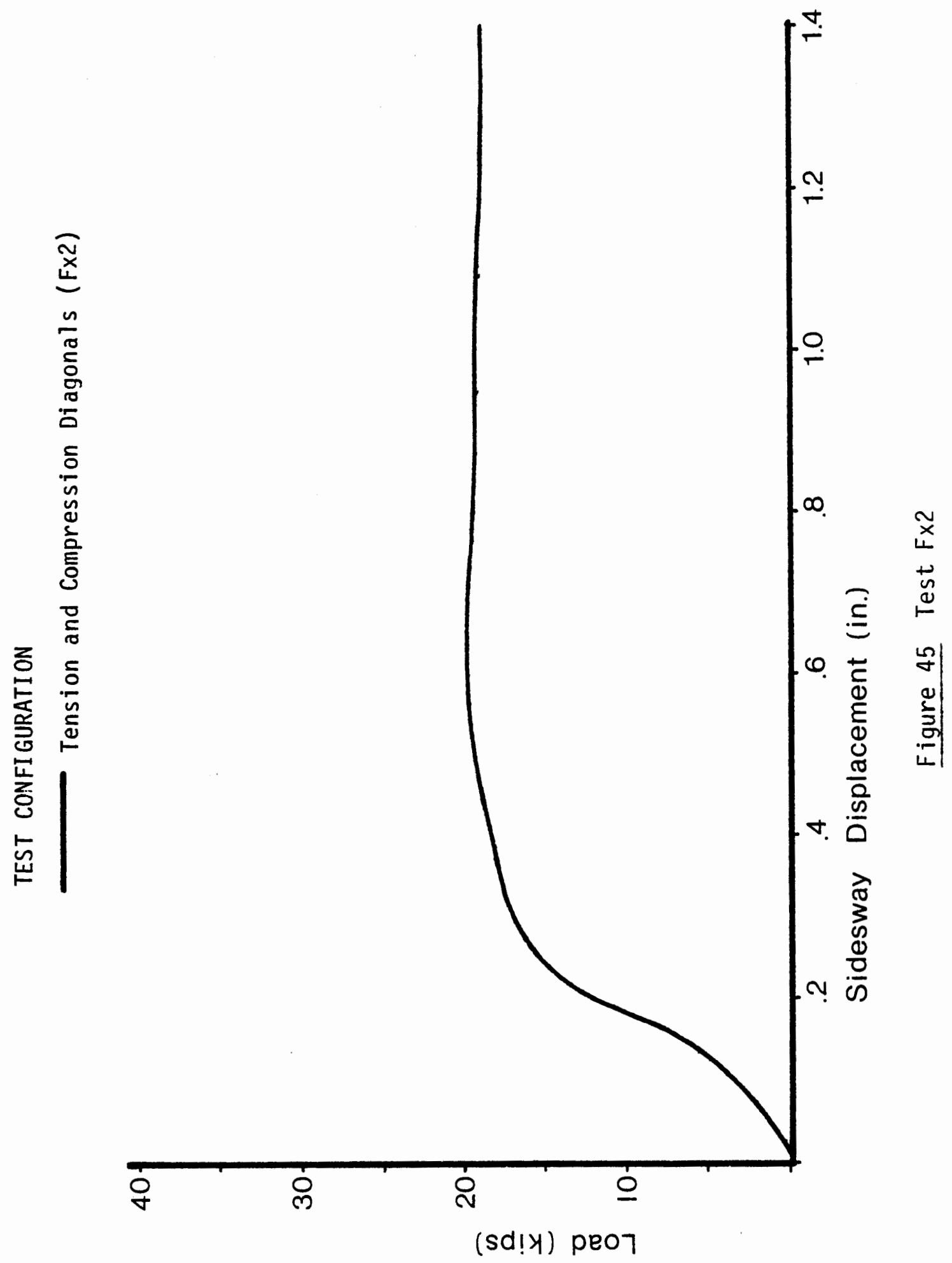




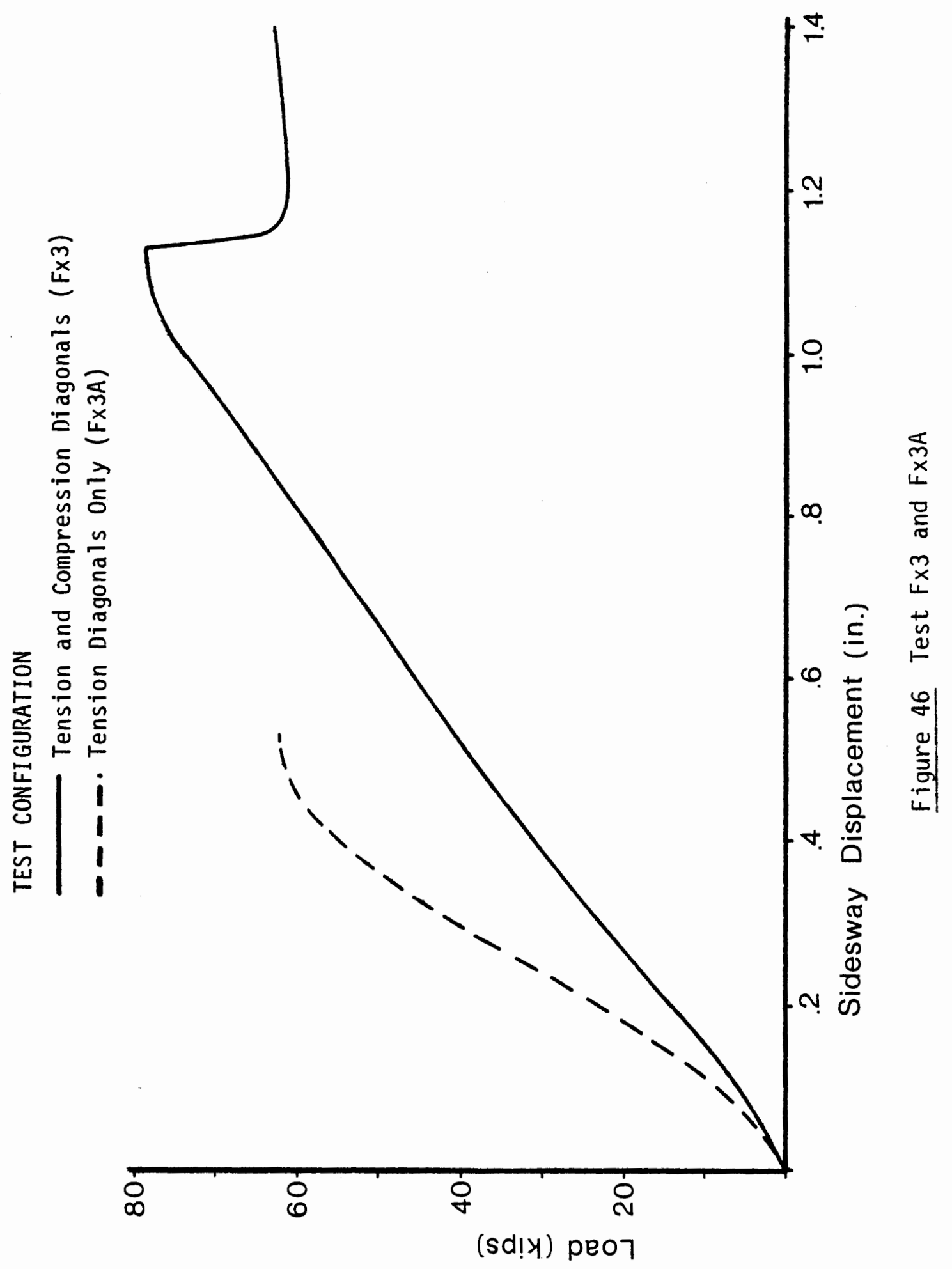




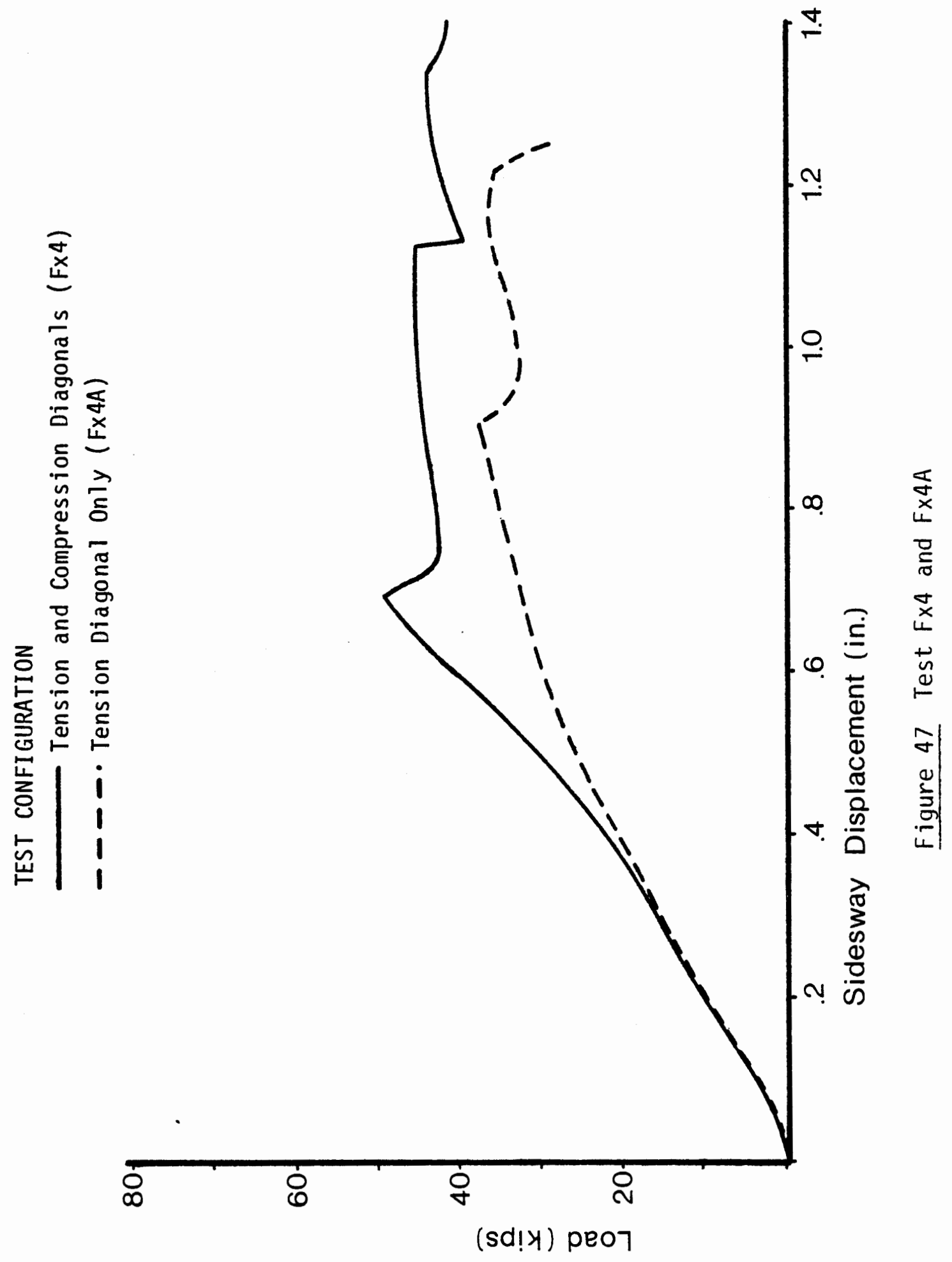




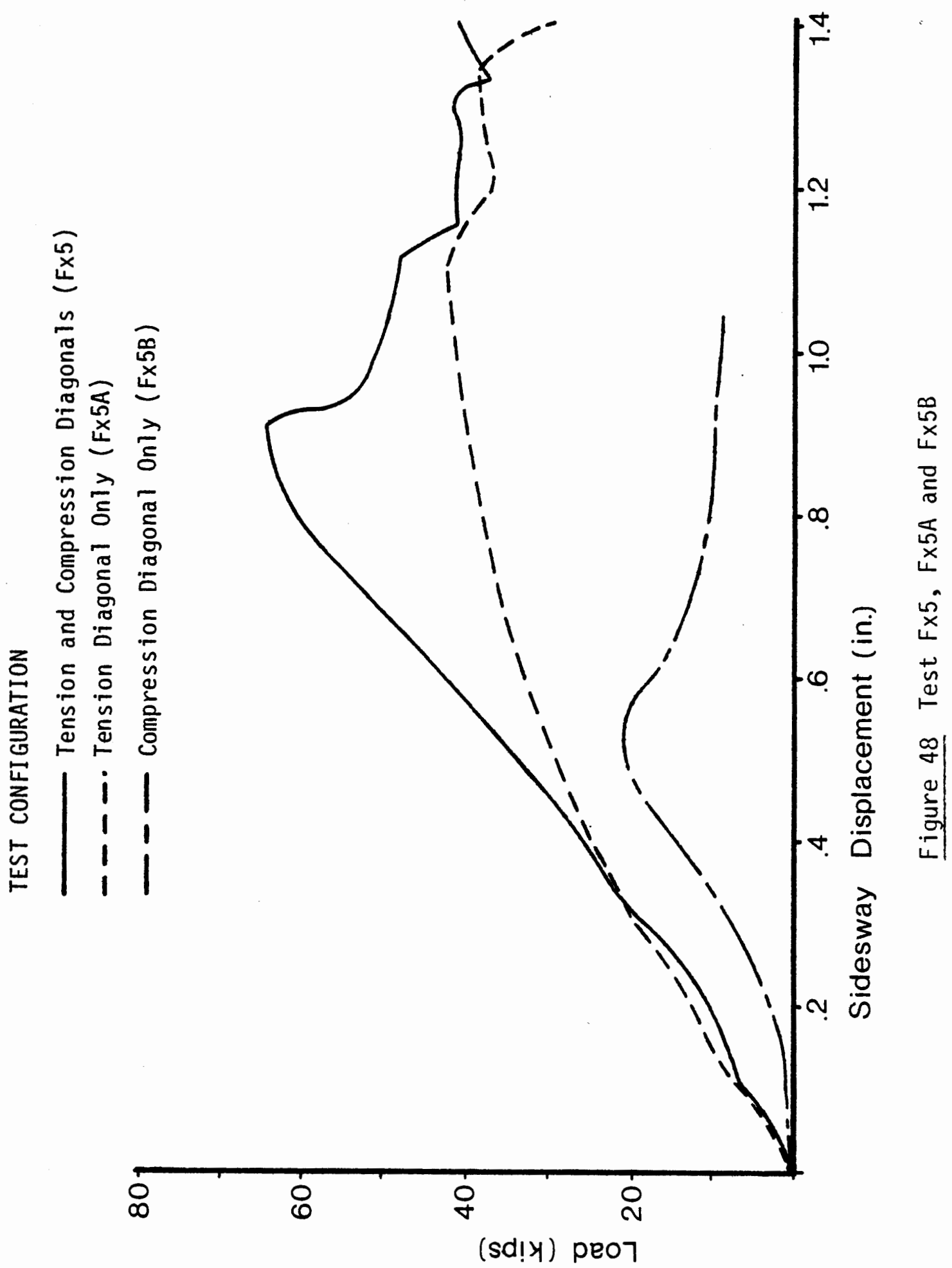




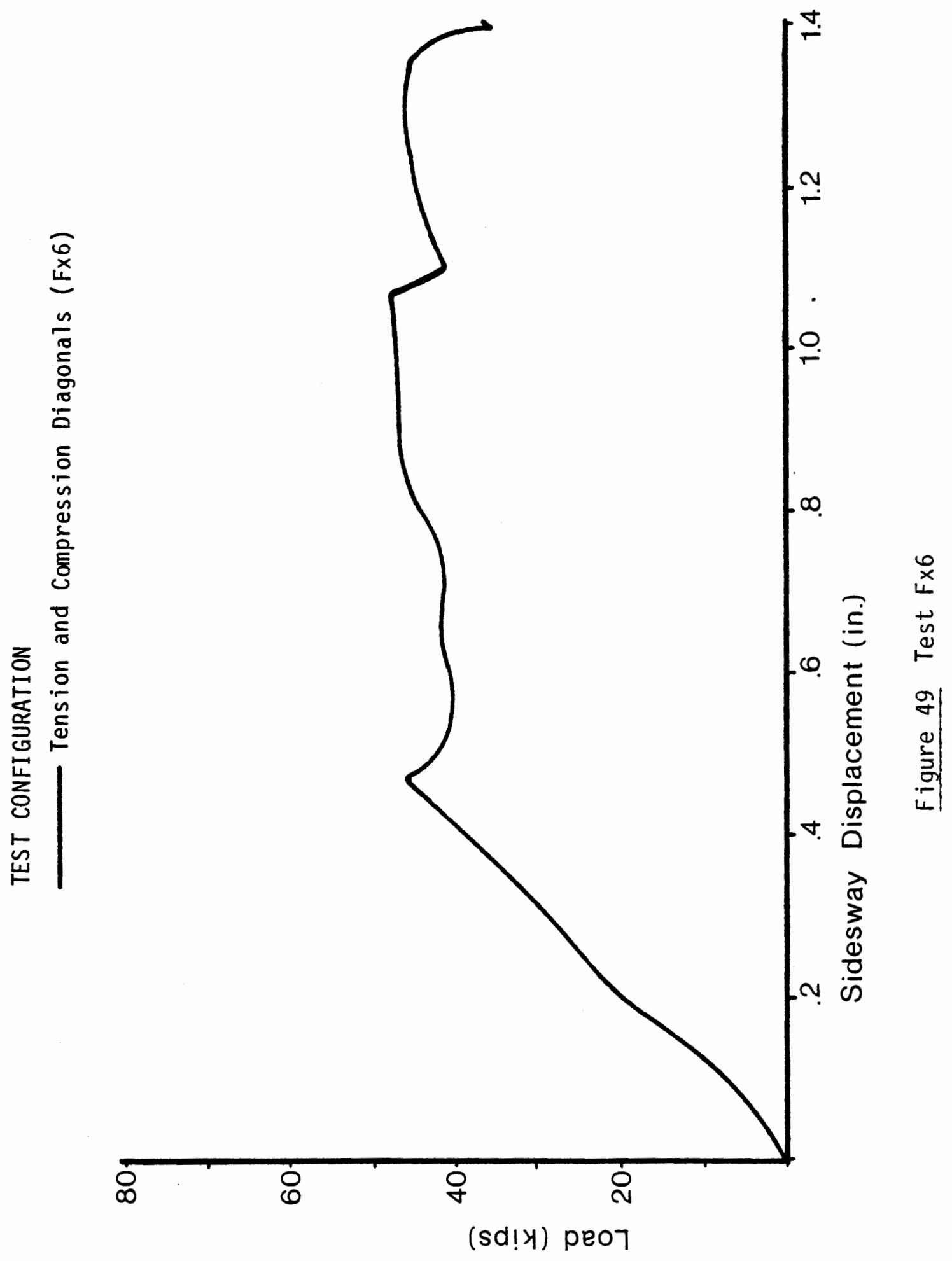



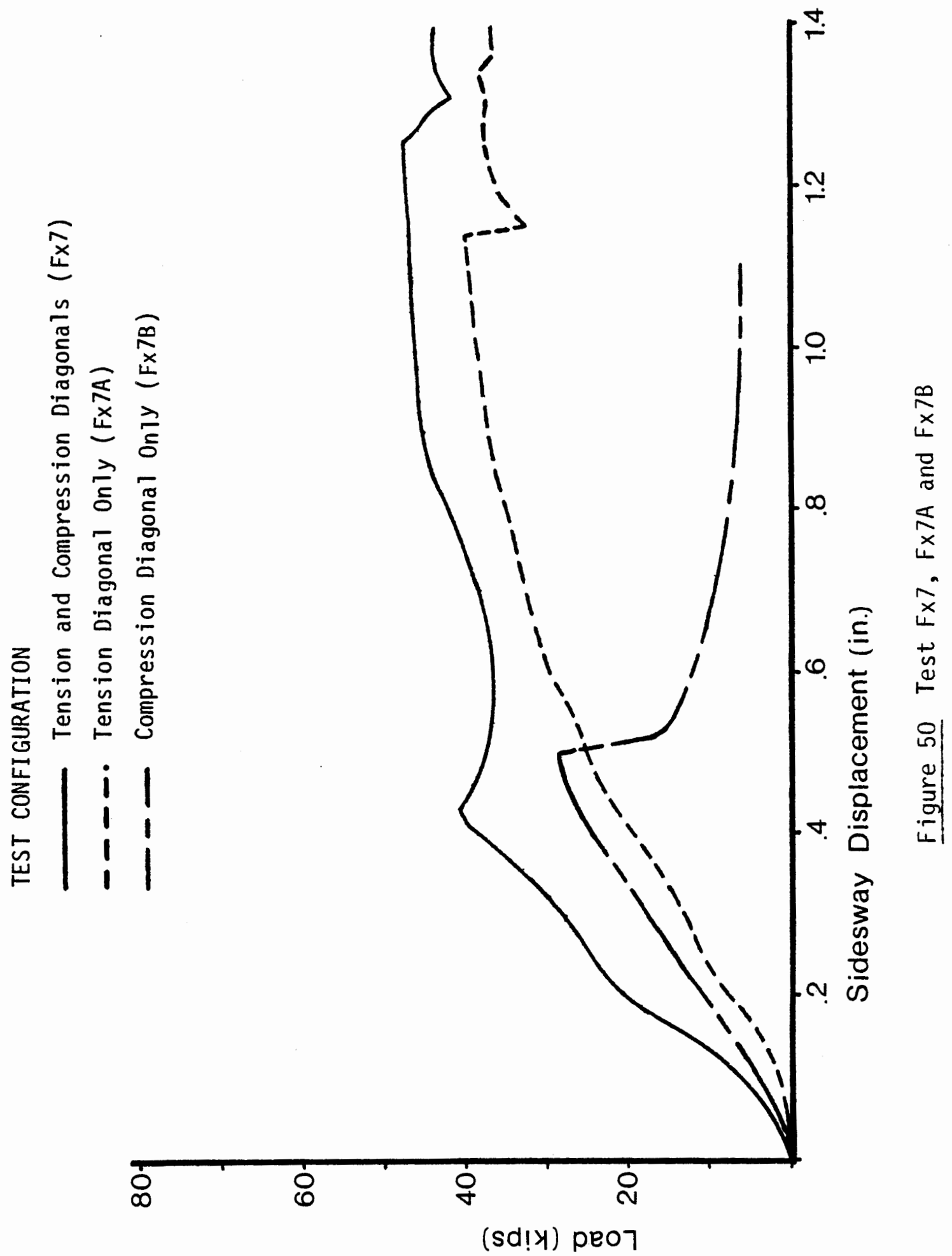


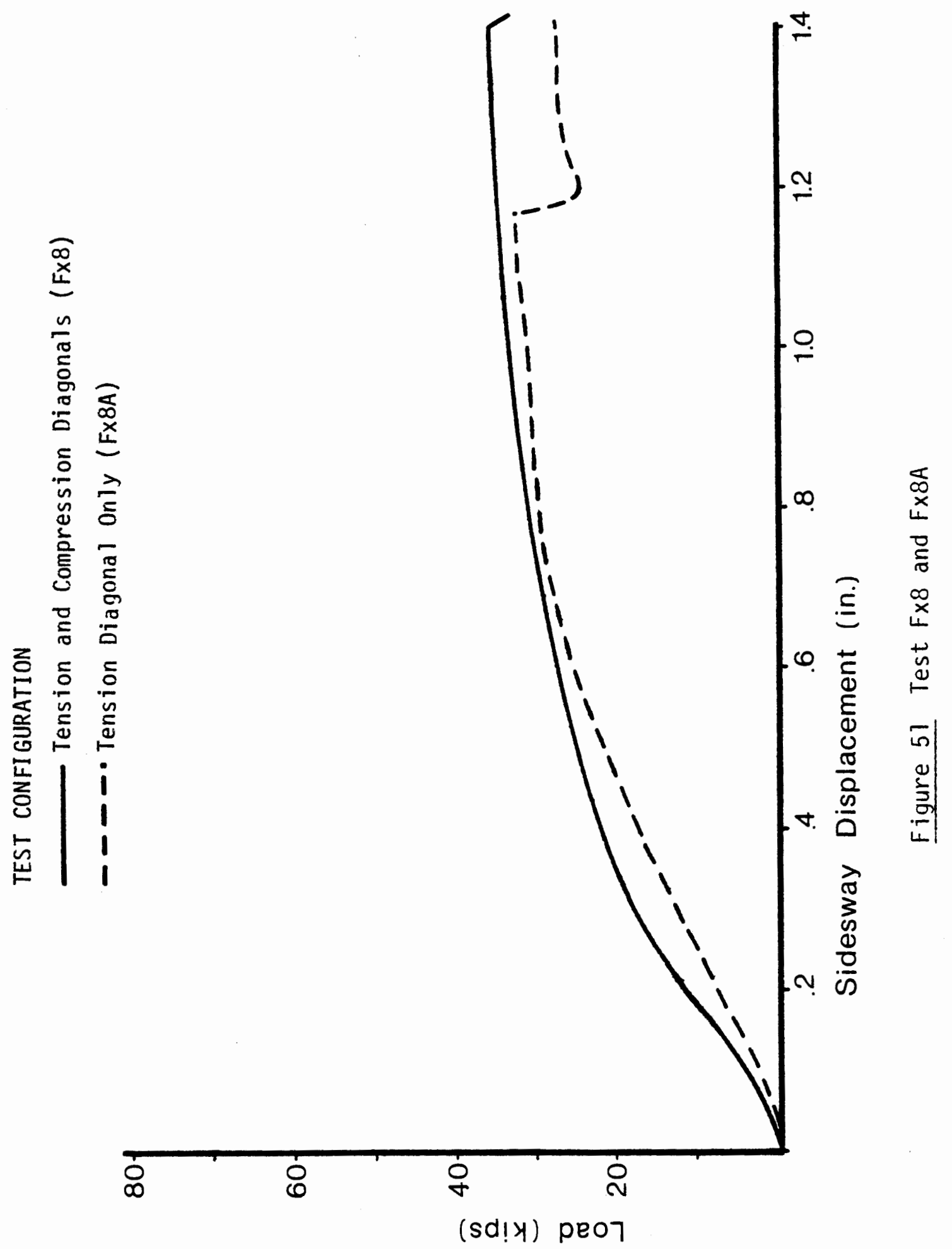




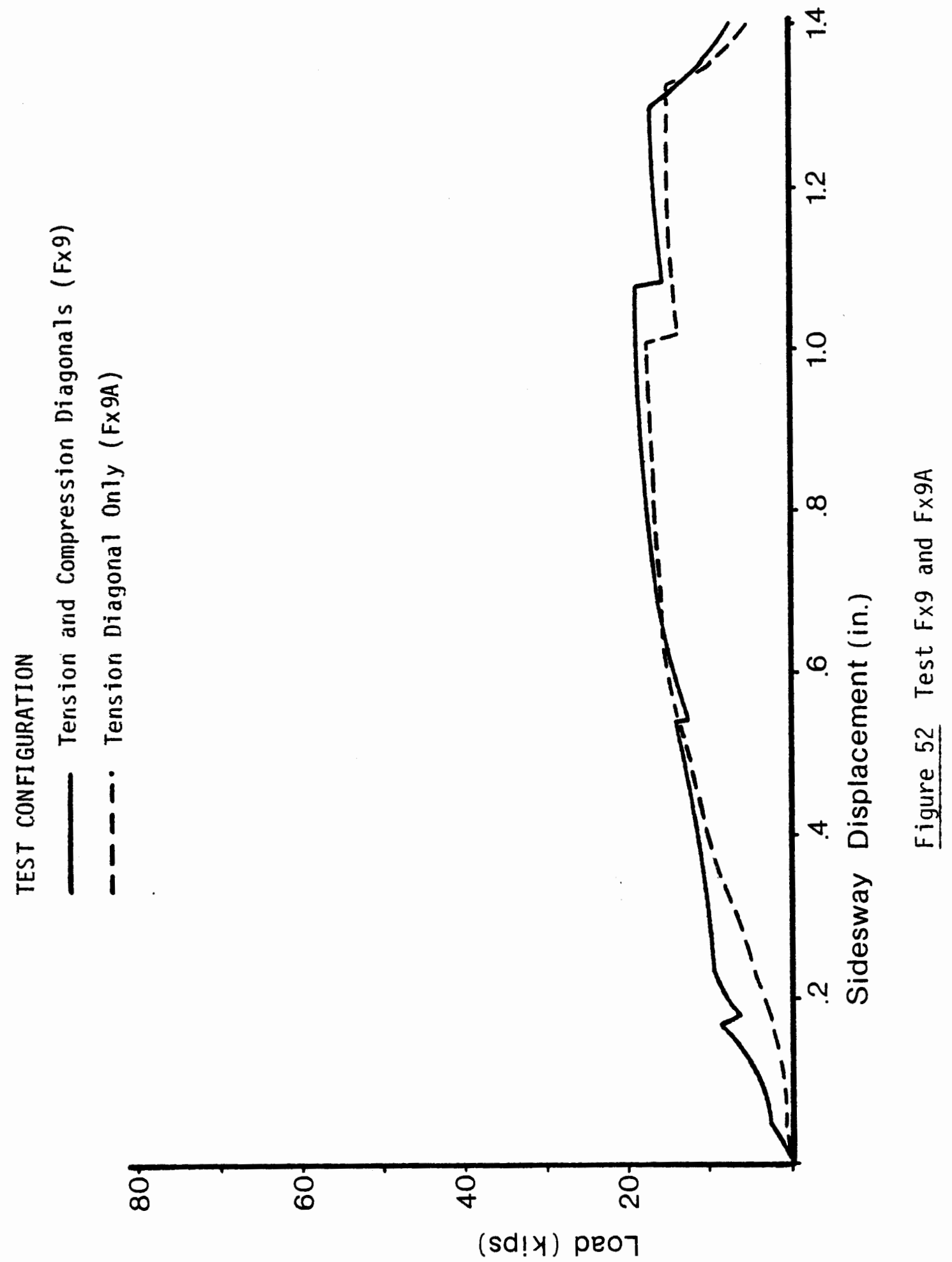


stressed to yield and the compression diagonal carries a zero load. The theoretical buckling load of a compression diagonal is the Euler Buckling load of the member assuming a pinned-pinned connection. It is assumed that the shear is equally distributed between the diagonal members before the failure of the compression member and hence the tension member carries the same load as the compression member. Hence the theoretical frame load when compression diagonal buckles listed in Table IVB is twice the component of the buckling load for the compression member in the case of the tests with two diagonals.

The experimental results are presented in Figures 44 to 52 .

The tests performed can be categorized into three as follows

(1) Tests with compression and tension diagonals

(2) Tests with tension diagonal only

(3) Tests with compression diagonal only

These three categories enable the study of the contribution of each diagonal member and both members together in sustaining the applied frame load.

Tests with compression diagonal only (Tests $F \times 5 B$ and $F \times 7 B$ ) showed a gradual increase of load capacity and a steep drop of load after the member buckles. However these tests showed that the frame had some resistance to the applied load after the compression diagonal buckles. The shape of these curves are similar to that obtained in single member tests (Figs. 48 and 50 ).

Tests with both tension and compression diagonals showed a gradual increase of load until the compression diagonal buckles and then showed a little drop in load. The structural system has the ability to sustain 
load until yielding of the tension member. This occurred at the bolt holes. It is shown in tests Fx4 and Fx5 that the load sustained in the case of tension and compression members is higher than that of tension member only tests in the post buckling region. The experimental ultimate load was shown to be 17.8 and 45.4 percent more than the theoretical frame load capacity calculated using statics. It was shown in single member tests that the compression members do sustain axial load in the post buckling region. This post buckling strength was instrumental in increasing the frame load capacity above the expected in the idealized situation. When the compression member looses load, it transfers to the tension member thus enabling the system to sustain an increase in load. 
CHAPTER IV

\section{CONCLUSIONS AND RECOMMENDATIONS}

Basically the experimental results obtained in the single member tests verified the analytical computer program of Ref. 7. The load spike for members with no eccentricity was an important observation made in this study. These members pretend to show a higher ultimate load but a little disturbance causes sudden drop in load carrying capacity.

Experimental results of this investigation as well as the analytical computer model of Ref. 7 verifies that members with large length to radius of gyration ratio possess a wider plateau in the post buckling region. Hence these long members would be able to sustain the ir maximum load capacity for additional deformation. The implications of this on a Limit State Analysis of a three dimensional truss is that long members would allow the redistribution of loads to other parts of the structural system. Long member performance may conceivably be modeled as a bi-linear load-deflection curve. Members with a small length to radius of gyration ratio showed an unloading immediately after the ultimate load was reached. These short members could not sustain the ir maximum load for additional deformations. This suggests that a Limit State Analysis technique may be required to be able to account for member performance depicted by load-deflection curves other than bilinear. This refinement should account for any unloading which exists after the ultimate load is passed. The secant stiffness approach could be used in this case. It assumes a lower stiffness of the member in the post ultimate region. This secant stiffness approach is independent 
of the shape of the load deflection curve of the member and hence ideally suitable.

Eccentricity of the member tends to provide a greater plastic plateau but a lower ultimate load of the member. This makes a shorter member with large eccentricity of loading perform like a longer member with no eccentricity.

The non compact long members tested showed that they were not susceptible to local buckling even though their width to thickness ratio was much greater than that of compact sections. This is because these members being long are not subjected to a high enough stresses to cause local buckling. This shows that the load carrying capacity of long members with larger width to thickness ratios is rot affected by the fact that they are not compact.

This study of single member tests provides a foundation to formulate axial load vs axial displacement curves for various parameters of members. These curves are needed to obtain the modified stiffness of members (secant stiffness) to use in Limit Analysis of Trusses such as transmission towers.

The preliminary truss tests conducted supports the fact that the buckled compression member aids in the load carrying capacity of the indeterminate truss by transferring loads to other members in the structural system. When the compression members reach the ir ultimate load and it through large deflections, the structure is able to redistribute it and resist higher structural loads by utilizing the reserve strength inherent in the indeterminate truss.

The bolt slippage of members was a cause for considerable axial displacement. It is recommended that further study of this bolt slippage 
be undertaken to ascertain its effect on member performance. This investigation was not concerned with the effect of intermediate supports of compression members. It is also recommended that testing of single angle members with intermediate supports and diagonal members connected at their common point in the case of indeterminate trusses be undertaken This will yield further data as to how various members behave in this type of situation. 


\section{REFERENCES}

1. Beedle, L. S., "Plastic Design of Steel Frames," John Wiley and Sons, Inc., 1958.

2. Wang, C., "Matrix Methods of Structural Analys is," American Publishing Co., 2nd edition, 1970.

3. Lee, J.W. and Jensen, H. G., "Limit Truss Analysis by Linear Programming Technique," Preprint No. 80-006, 1980 ASCE National Convention, Portland, Oregon, Aprit 1980.

4. Smith, E. A. and Epstein, H. I., "Progressive Collapse in the Hartford Space Truss," Preprint No. 80-062, 1980 ASCE National Convention, Portland, Oregon, April 1980.

5. Schmidt, L. C. and Hanaor, A., "Force Limiting Devices in Space Trusses," ASCE Journal of the Structural Division, May 1979.

6. Khan, L. F. and Hanson, R. D., "Inelastic Cycles of Axially Loaded Steel Members," ASCE Journal of the Structural Division, May 1976.

7. "Study of Limit State on Ultimate Load Behavior of Steel Columns," Portland State University - Bonneville Power Administration Contract 79-80BP24005, October 1981.

8. "Manual of Steel Construction," American Institute of Steel Construction, Inc., 8th Edition, 1980.

9. "1975 Annual book of ASTM Standards, Part 10," American Society for Testing and Materials. 
APPENDIX A

COMPUTATION OF AXIAL DISPLACEMENT USING THE DATA

OBTAINED IN SINGLE MEMBER TESTS FOR THE

HINGED-HINGED CONF IGURATION

Derivation of Equations

Definition of symbols used in this Appendix are as follows

Symbol

$X \emptyset(N)$

$N=1$ to 8

$X(N)$

$N=1$ to 8

$B_{n}$

$n=1$ to 2

$a_{n}$

$n=1$ to 2

$\mathrm{R}_{H}$
Description

Gage reading at location N (Fig. 55) at preload

Gage reading at location $N$ after member is loaded

Distance between concentric gages at member end $n$

Rotation about $y$ axis (Fig. 54)

Distance from the hinge to the end plate

In this Hinged-Hinged configuration the end plates are free to rotate about the $y$ axis and free to translate in the $Z$ direction (Fig. 53). $X \emptyset(1), X \emptyset(2), X \emptyset(3)$ and $X \emptyset(4)$ are the initial gage readings at locations $1,2,3$ and 4 which forms a square of size B1. $X(1), X(2), X(3)$ and $X(4)$ are the gage readings after displacements.

When a load is applied through the actuator the end plate translates a distance $0_{1} \mathrm{O}_{2}$ in the $Z$ direction ( $\mathrm{Fig} .54$ ) and rotate an angle $\alpha_{1}$ about the $y$ axis. The length of the member is measured from the hinge of one end to the hinge of the other end. Hence the displacement 


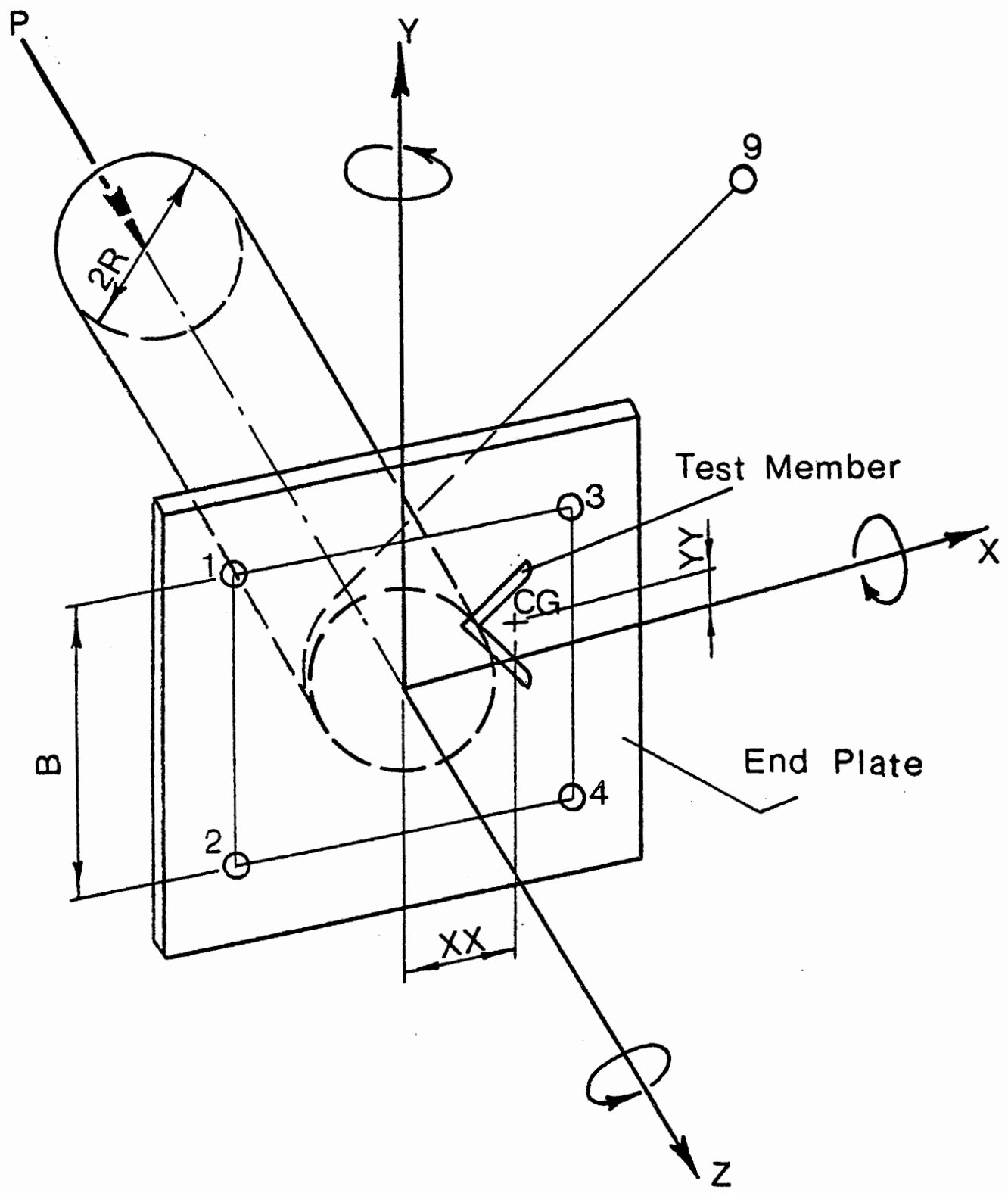

Figure 53 The end plate and gage layout at one end of the test member 
86

of the member at one end is given by $\mathrm{O}_{7} \mathrm{O}_{2}$ in $\mathrm{Fig} .54$.

The sum of displacements at both ends gives the total axial displacement for the member.

It follows that in Fig. 54 .

$$
\begin{aligned}
& 0_{1} A_{1}=O_{2} A_{2}=R_{H} \\
& C_{1} C_{3}=G_{2}=\frac{X(1)+X(2)-X \phi(1)-X \phi(2)}{2} \\
& B_{1} B_{3}=G_{1}=\frac{x(3)+x(4)-x \emptyset(3)-x \phi(4)}{2} \\
& D C_{1}=B_{3} B_{1}=G_{1} \\
& \operatorname{Tan} \alpha_{1}=\frac{G_{1}+G_{2}}{B_{1}} \\
& \text { In triangle } \mathrm{EC}_{1} \mathrm{C}_{3} \\
& E C_{1}=C_{1} C_{3} \operatorname{Cot} \alpha_{1} \\
& E C_{1}=G_{2} \operatorname{Cot} \alpha_{1} \\
& E A_{1}=E C_{1}-B_{1} / 2 \\
& E A_{1}=G_{2} \operatorname{Cot} \alpha_{1}-B_{1} / 2 \\
& A_{1} A_{3}=E A_{1} \operatorname{Tan} \alpha_{1} \\
& A_{1} A_{3}=\left(G_{2} \operatorname{Cot} \alpha_{1}-B_{1} / 2\right) \operatorname{Tan} \alpha_{1} \\
& O_{2} A_{3}=R_{H} \operatorname{Sec} \alpha_{1} \\
& A_{2} A_{3}=O_{2} A_{3}-R_{H} \\
& =R_{H}\left(\operatorname{Sec} \alpha_{1}-1\right)
\end{aligned}
$$




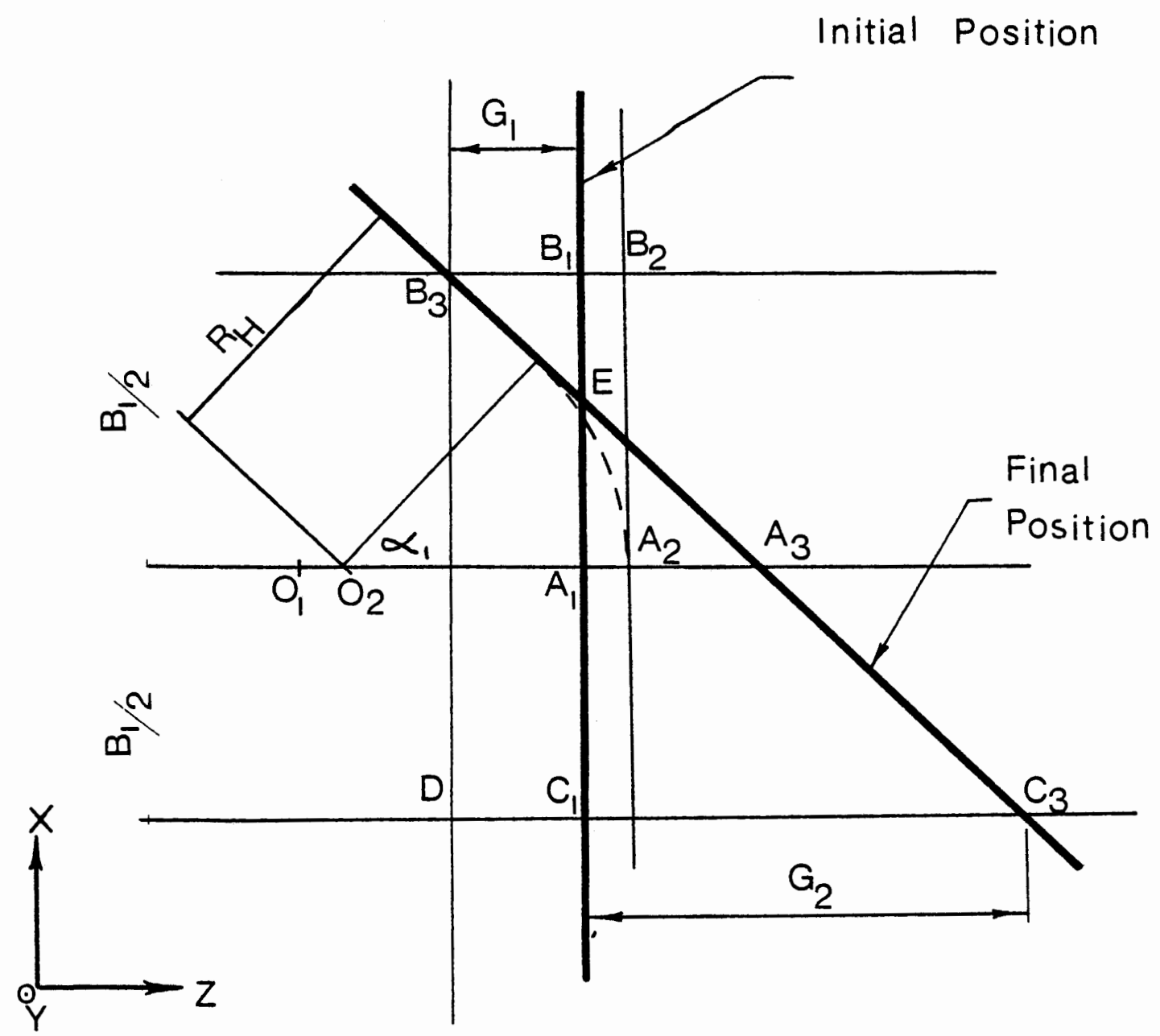

Figure 54 Translation of the end plate and rotation about the $\mathrm{y}$ axis for the hinged-hinged configuration 


$$
\begin{aligned}
A_{1} A_{2} & =A_{1} A_{3}-A_{2} A_{3} \\
& =G_{2}-(B 1 / 2) \operatorname{Tan} \alpha_{1}-R_{H} \operatorname{Sec} \alpha_{1}-R_{H} \\
& =G_{2}-(1 / 2)\left(G_{1}+G_{2}\right)-R_{H}\left(\operatorname{Sec} \alpha_{1}-1\right) \\
A_{1} A_{2} & =\left(G_{2}-G_{1}\right) / 2-R_{H}\left(\operatorname{Sec} \alpha_{1}-1\right) \\
0_{1} O_{2} & =A_{1} A_{2}
\end{aligned}
$$

The displacement at the first end $=0_{1} \mathrm{O}_{2}$

$$
0_{1} O_{2}=\frac{1}{2}\left(G_{2}-G_{1}\right)-R_{H}\left(\operatorname{Sec} \alpha_{1}-1\right)
$$

Applying proper signs to $G_{1}$ and $G_{2}$; the displacement at the first end is $=\frac{1}{2}\left(G_{2}+G_{1}\right)-R_{H}\left(\operatorname{Sec} \alpha_{1}-1\right)$

where $\operatorname{Tan} \alpha_{1}=\left(G_{2}-G_{1}\right) / B_{1}$

Similarly at the other end let the initial gage readings be $X \emptyset(5)$ $X \emptyset(6), X \emptyset(7)$ and $X \emptyset(8)$ at locations 5, 6, 7 and 8 (Fig. 55) and $X(5)$, $X(6), X(7)$ and $X(8)$ be the gage readings after displacements.

Then we can find $G_{3}, G_{4}$, and $\operatorname{Tan} \alpha_{2}$ such that

$$
\begin{aligned}
& G_{3}=(X(5)+X(6)-X \emptyset(5)-X \emptyset(6)) / 2 \\
& G_{4}=(x(7)+X(8)-X \emptyset(7)-X \emptyset(8)) / 2
\end{aligned}
$$

$\operatorname{Tan} \alpha_{2}=\left(G_{4}-G_{3}\right) / B_{2}$

Hence the displacement at the other end is $=\frac{1}{2}\left(G_{4}+G_{3}\right)-$ $R_{H}\left(\operatorname{Sec} \alpha_{2}-1\right)$

The computer program used to perform the above calculations are shown on the following pages. 

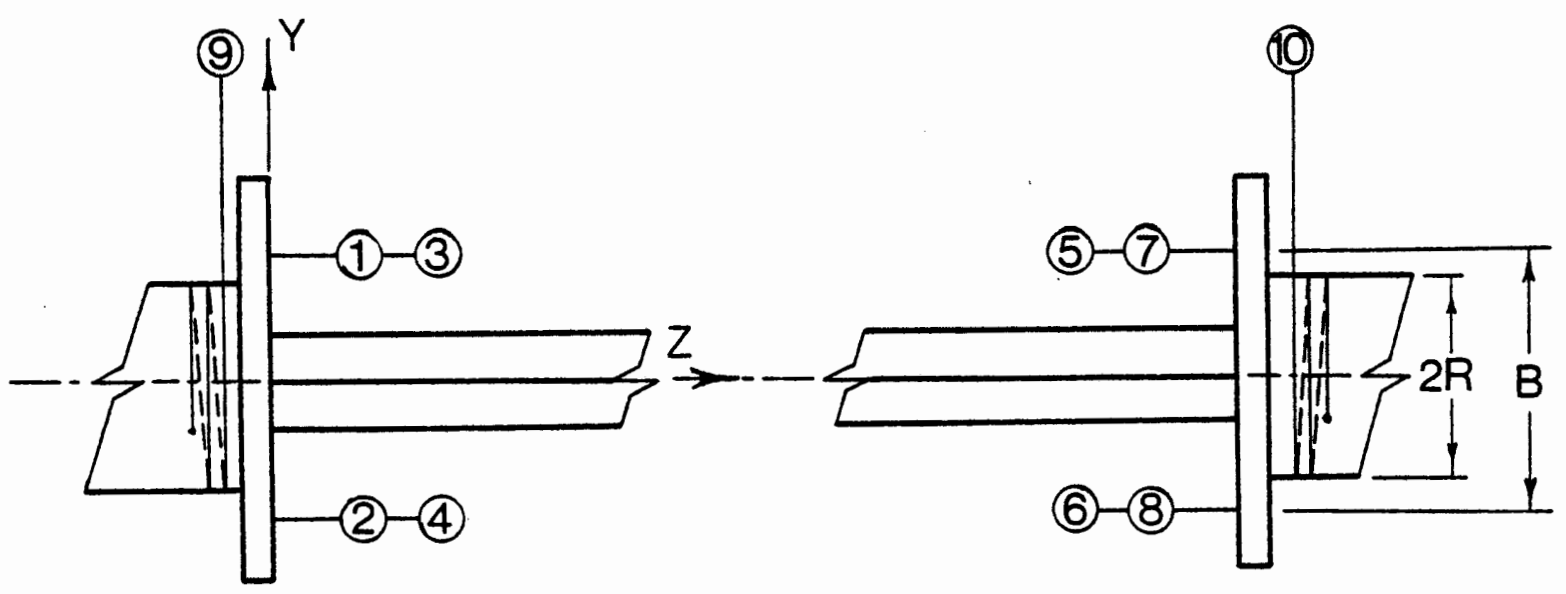

ELEVATION
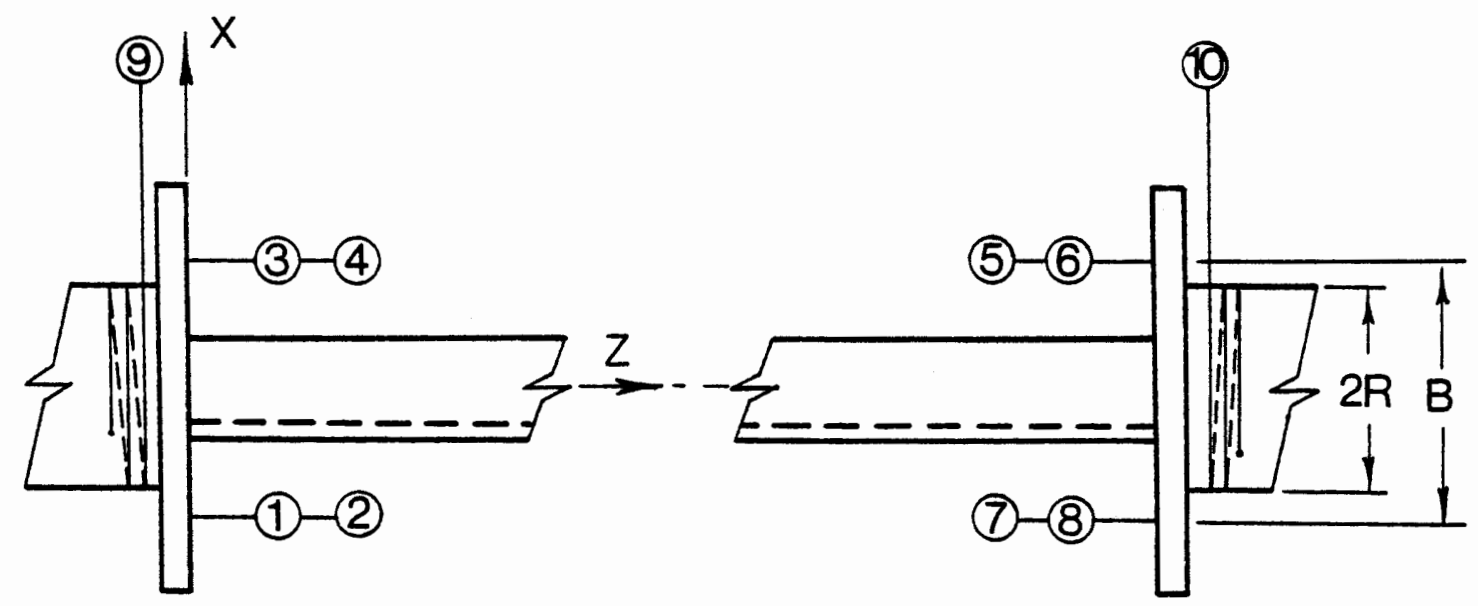

PLAN

End 1

End 2

Figure 55 Gage layout for single member tests including the rotational gages 
Input data for the computer program:

$$
\begin{aligned}
X \emptyset(N) & =\text { Gage reading at location } N(\text { Fig. } 55) \text { at preload } \\
N & =1 \text { to } 8 \\
X \emptyset(N) & =\text { Gage reading at location } N \text { after member is loaded } \\
N & =1 \text { to } 8
\end{aligned}
$$

Resetting of gages need to be done just before any of the dial gages reach their maximum range. The reading of such a gage in its current position is noted and then moved to a new position either towards or away from the end plate to facilitate further readings with the same gage. Readings of gages after resetting were taken into account for the difference.

Reset readings are input to the computer with a number 999.

The output printed is the displacement of the member at the actuator end, the displacement of the member at the reaction block end and the total axial displacement of the member. 
FLOW DIAGRAM TO CALCULATE AXIAL DISPLACEMENT FOR HINGE HINGE CONFIGURATION

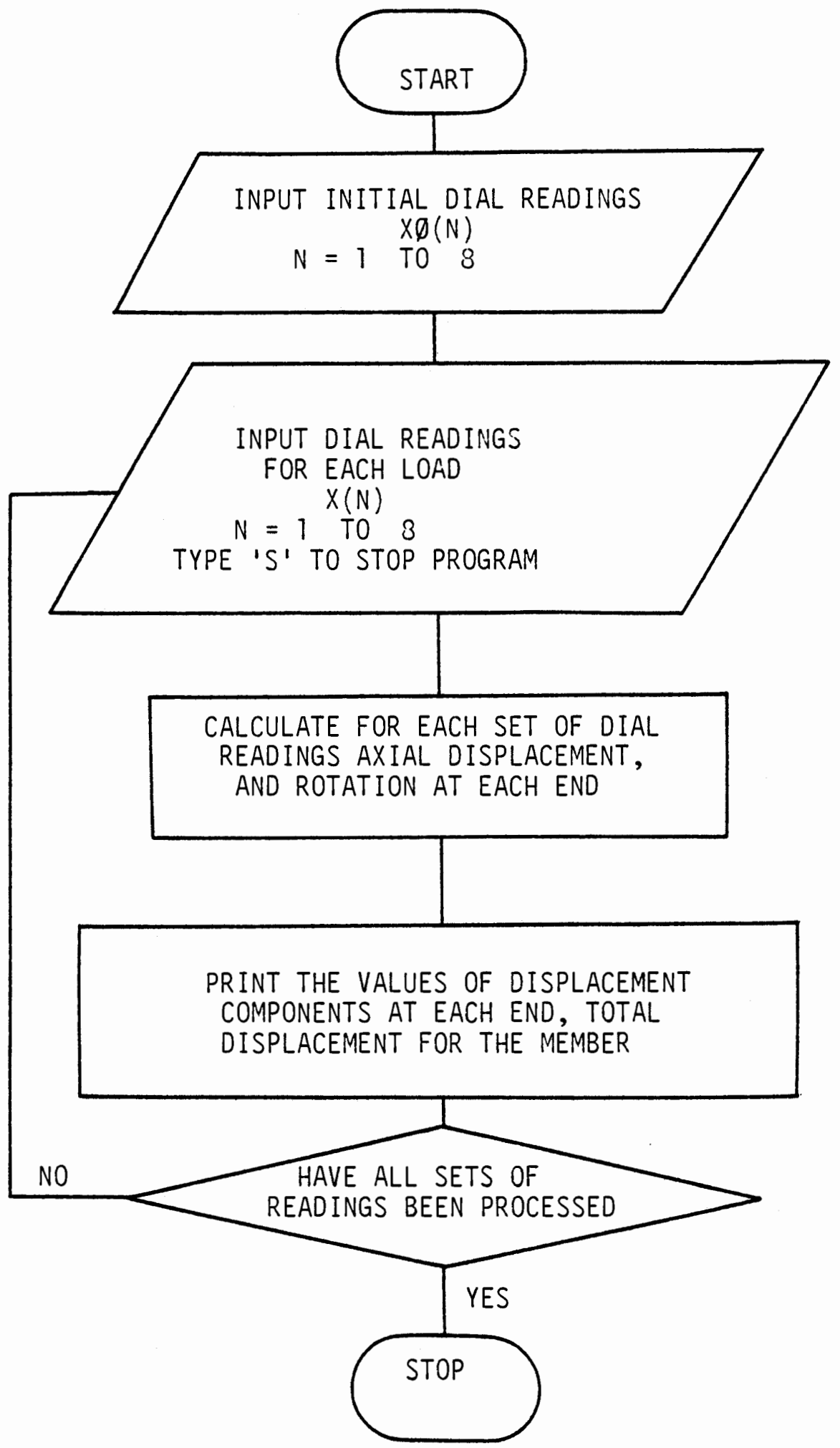


COMWUTER FFOOWAN

10 REM THIS PROGFAM WTLL RALOULATE DELTA MND END ROTATTON

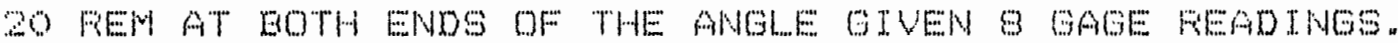

30 FEM * * TO RESET ZEFO EMTEF 999 FOF FAOM GAOE VALUW

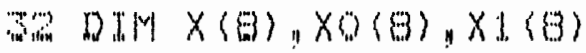

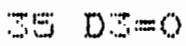

$3604=0$

$57 \quad 43=0$

380440

40 FinT

50 PRTNT

GO PRTNT "GAGE LAYOUT"

GE FINT" ACT"

70 FRTH $" x$

90 FITNT" $"$ ".

$x \quad x^{\prime \prime}$

90 FFINT

91 FIINT

92 PIINT

9.6 FINT

94 FWINT

9 FITNT"

97 FIINT

98 PFINT

IOO FFTT "TNFUT 9 ZERO FEADINGS"

D.O MAT TNEUT XO

L2O WFNT "TNFUT 3 OASE MEADINGS"

130 MAT INIFUT $X$

D.E JF $X(1) \supseteq \mathrm{E}$ "HHEN 500

140 MAT $X 1=X \ldots \times 0$

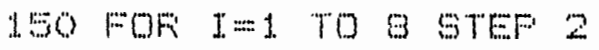

155 T. $1=5 / 2+1$

(6) $X(I I)=(X I(I)+X I(I+1)) / 2$

170 NEXXT

$175 \quad A=5.7$

$1.76 \mathrm{~B}=1.75$

$180 A 1=A T N((X(1)-X(2)) / A)+A S$

190 A2 $=A T N(X(X)+X(4)) / A)+A 4$

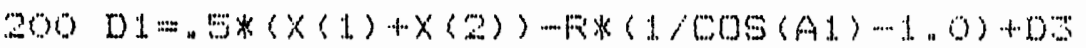

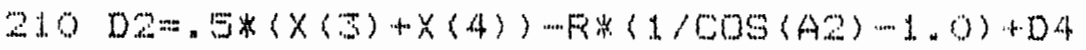

20) PRNT" DELTA (AOT) DELTASFEATT)

230 FFTNT DL, D2,DL+D2

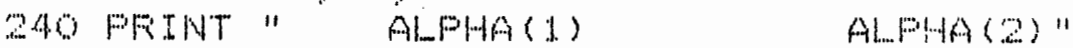

250 FINT AI "A. A

260 GOTO 120

$500 \quad 07=01$

$510 \quad 04=02$

$500=A 1$

$530 \quad A 4=A 2$

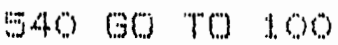

$9 \%$ END 
*EASIC

*FIUN

$\begin{array}{llll}\text { GAGE LAYOUT } & & & \\ x_{\text {ACT }} & x & x & x \\ 1 & 3 & 5 & 7 \\ & & & \\ x & x & x & x \\ 2 & 4 & 6 & 8\end{array}$

INFUT 9 ZERO READINGS

$7.452, .573, .494, .507, .491, \ldots 485, .495, .510$

INFUT 9 GAGE READINGS

7.473, , 599, .500, .519, , 477, . 468, , 495, .507

DELTA(ACT) DELTA (FEACT) DELTA

$.0159939 \quad-.0085058 \quad .0074987$

ALFFHA(1) ALPHA 2 (2)

$.0026316 \quad \quad \cdots .0024561$

INFUT 9 GAGE READINGS

$? .490, .619, .501$, . $522, .466, .455$, , 497, .511

DELTA (ACT) DELTA (FEACT)

DELTA

.0264741

$-.0125242$

ALFHA (2)

ALFHA (1)

.0054385

$-.0052631$

INPUT 8 GAGE READINGS

$7.558, .675, .437, \ldots 15, \ldots 429, .417, .525, .539$

DEL.TA $(A C T)$

.0470146

ALFHA 1 )

.016402

$$
\begin{aligned}
& \text { DELTA (FEACT) } \\
& \cdots .0174954 \\
& \text { ALFHA(2) } \\
& -.016402
\end{aligned}
$$

INFUT 8 GAGE READINGS

$7.755, .884, .470, .515, .319, .319, .621, .644$

$$
\begin{array}{lcc}
\text { DELTA (ACT) } & \text { DELTA (FEACT) } & \text { DELTA } \\
.1419965 & -.0221641 . & .1198324 \\
\text { ALFHA(1) } & \text { ALFHA(2) } & \\
.0534578 & -. .0524956 &
\end{array}
$$

INFUT 8 GAGE READINGS

$7999,999,999,999,999,999,999,999$

INFUT 8 ZEFO READINGS

$? .100, .000, .470, .515, .319, .319, .621, .644$ 
INFUT 8 GAGE FEADINGS

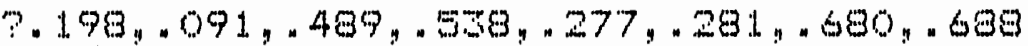

DELTA (ACT)

DELITA TFEACT"

DI: L"I"A

.1955372

$-.020273$

.17561 .42

AL..FHA(I)

ALIFHA (2)

.0663519306891

INFUT 8 GAGE READINGS

?S 


\section{APPENDIX B}

COMPUTATION OF AXIAL DISPLACEMENT USING THE DATA

OBTAINED IN SINGLE MEMBER TESTS FOR BALL-BALL CONFIGURATION

\section{Derivation of Equations}

Definition of symbols used in this Appendix are as follows

Symbol

$X \emptyset(\mathrm{N})$

$N=1$ to 10

$X(N)$

$N=1$ to 10

$E_{n}$

$n=1$ to 2

$B_{n}$

$n=1$ to 2

$\theta$

$n=1$ to 2

$\beta_{n}$

$n=1$ to 2

$\gamma_{n}$

$n=1$ to 2

$\mathrm{d}_{N}$

$N=1$ to 10

$R_{0}$

R
Description

Gage reading at location N (Fig. 55) at preload

Gage reading at location $\mathrm{N}$ after member is loaded

Displacement of the center of end plate in $Z$ direction at member end $n$

Distance between concentric gages (Fig. 53)

at member end $n$

Rotation about $X$ axis (Fig. 58) at member end

$n$

Rotation about $Y$ axis (Fig. 59)

Rotation about $Z$ axis (Fig. 57)

Gage reading at location N (Fig. 55) corrected

for the initial value

Distance from the center of end plate to center

of gravity of test member (Fig. 57)

Radius of the ball (Fig. 53) 
In this ball-ball configuration the end plates are free to rotate about $x, y$ and $z$ axes and free to translate in the $z$ direction. Figure 53 details these directions. $X \emptyset(1), X \emptyset(2), X \emptyset(3), X \emptyset(4)$ and $X \emptyset(9)$ are the initial gage readings at locations $1,2,3,4$ and 9 (Fig. 55). Locations $1,2,3$ and 4 forms a square of side $B_{1}$. Gage 9 is located perpendicular to the test member to measure rotations about $z$ axis as in Fig. 55 . $X(1), X(2), X(3), X(4)$ and $X(9)$ are the gage readings after displacements. $E_{1}$ is the translation of the center of the end plate in the $z$ direction. Layout details are given in Fig. 56.

The following define the relationship between displacements and geometry.

$$
\begin{aligned}
& x \emptyset(1)+E_{1}+(1 / 2) B_{1} \operatorname{Tan} \theta_{1}+(1 / 2) B_{1} \operatorname{Tan} \beta_{1}=x(1) \\
& x \emptyset(2)+E_{1}-(1 / 2) B_{1} \operatorname{Tan} \theta_{1}+(1 / 2) B_{1} \operatorname{Tan} \beta_{1}=x(2) \\
& x \emptyset(3)+E_{1}+(1 / 2) B_{1} \operatorname{Tan} \theta_{1}-(1 / 2) B_{1} \operatorname{Tan} \beta_{1}=x(3) \\
& x \emptyset(4)+E_{1}-(1 / 2) B_{1} \operatorname{Tan} \theta_{1}-(1 / 2) B_{1} \operatorname{Tan} \beta_{1}=x(4) \\
& \text { Adding equations } 1,2,3 \text { and } 4 \\
& x \emptyset(1)+x \emptyset(2)+x \emptyset(3)+x \emptyset(4)+4 E_{1}=x(1)+x(2)+x(3)+x(4) \\
& E_{1}=\frac{1}{4}(x(1)-x \emptyset(1)+x(2)-x \emptyset(2)+x(3)-x \emptyset(3)+x(4)-x \emptyset(4)) \\
& \text { Let } x(1)-x \emptyset(1)=d_{1} \\
& x(2)-x \emptyset(2)=d_{2} \text {, etc. }
\end{aligned}
$$

Equations 1-2

$$
\begin{aligned}
& B_{1} \operatorname{Tan} \theta_{1}=d_{1}-d_{2} \\
& \theta_{1}=\operatorname{Arc} \operatorname{Tan}\left(\left(d_{1}-d_{2}\right) / B 1\right)
\end{aligned}
$$




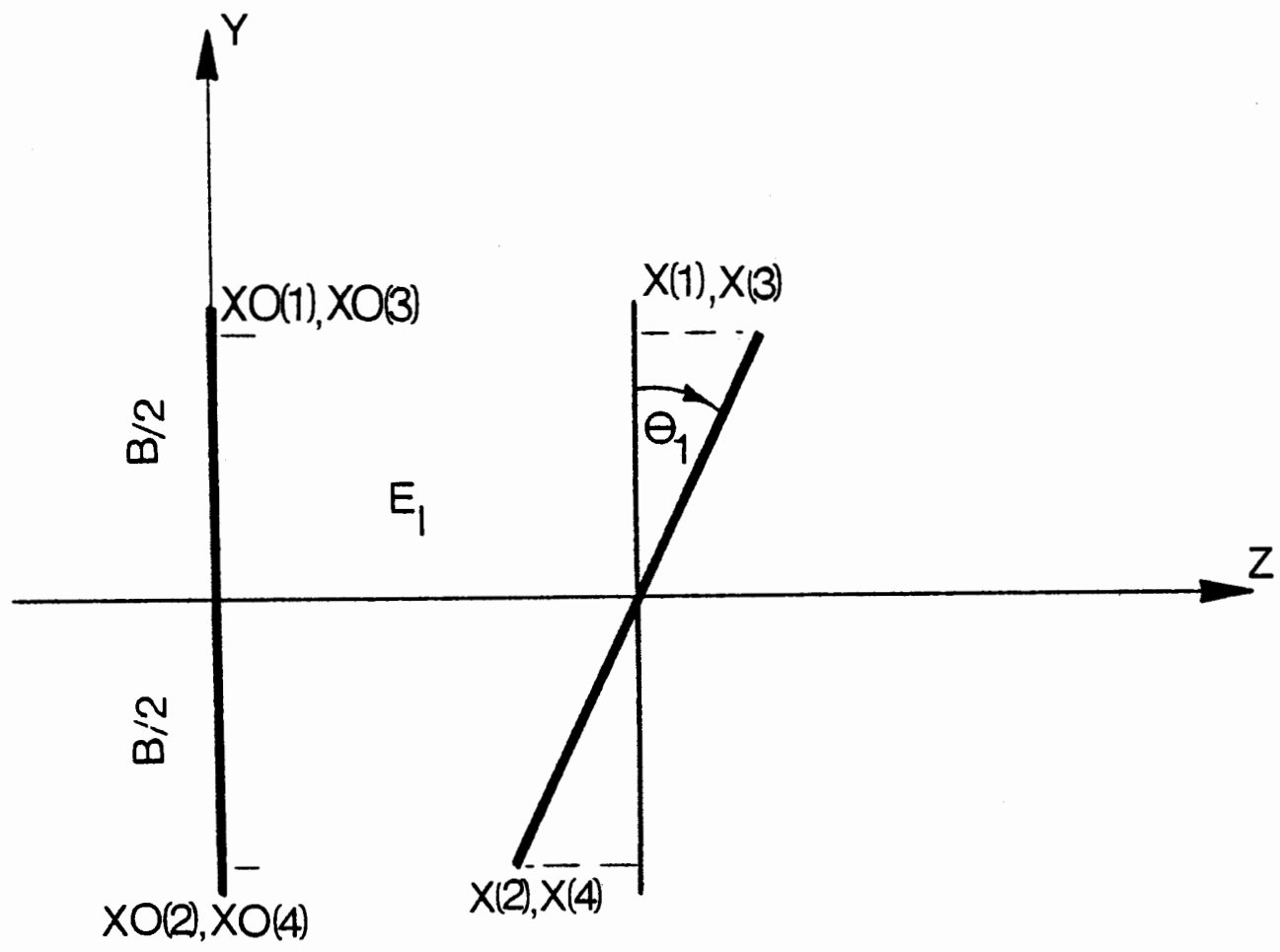

Figure 56 Translation of the end plate with rotation about the $x$ axis

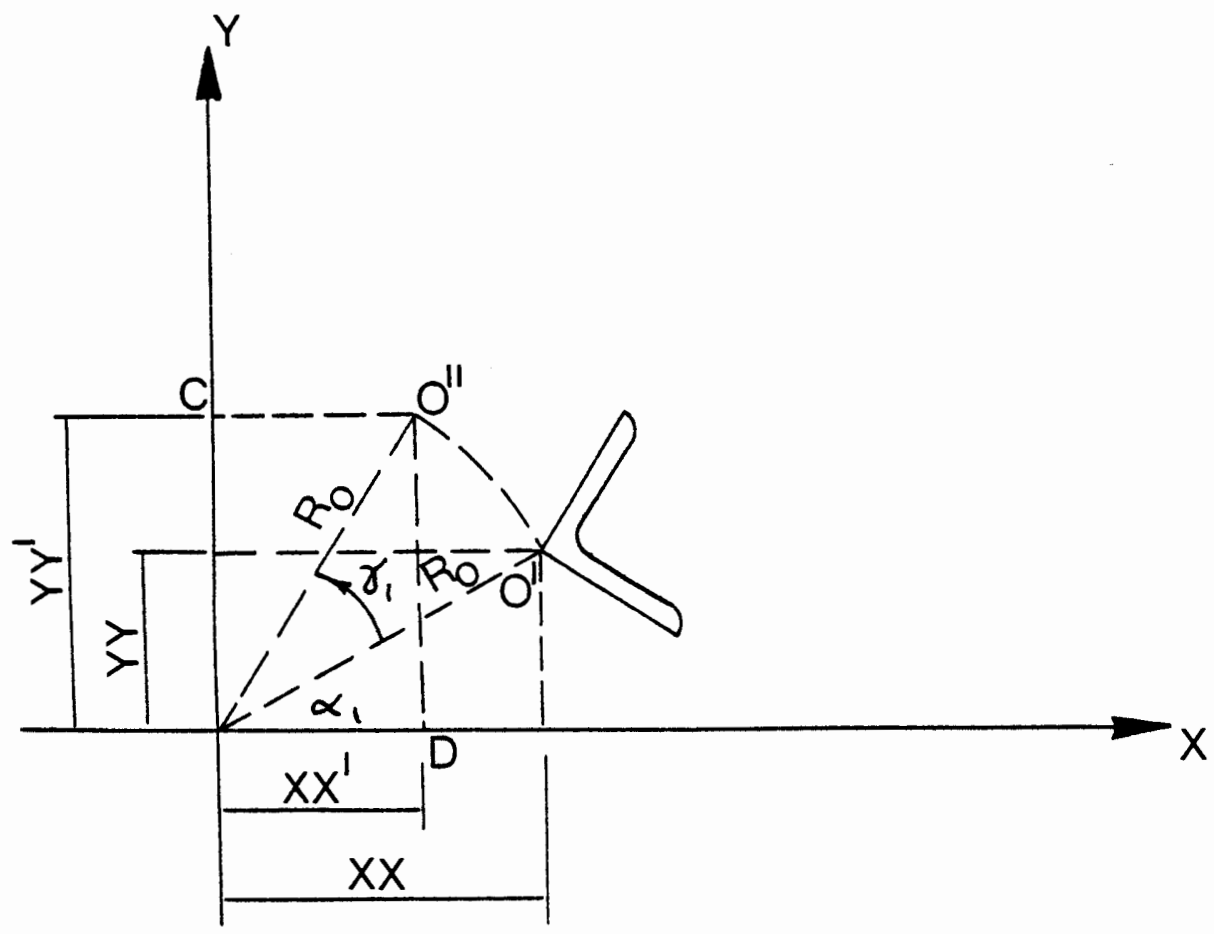

Figure 57 Rotation of the end plate about the $z$ axis 
Hence rotation about $X$ axis

$$
\theta_{1}=\operatorname{Arctan}\left(\left(d_{1}-d_{2}\right) / B_{1}\right)
$$

Equations 1-3

$$
\begin{aligned}
& B_{1} \operatorname{Tan} \beta_{1}=d_{1}-d_{3} \\
& \operatorname{Tan} \beta_{1}=\left(d_{1}-d_{3}\right) / B_{1} \\
& \beta_{1}=\operatorname{Arc} \operatorname{Tan}\left(\left(d_{1}-d_{3}\right) / B_{1}\right)
\end{aligned}
$$

Rotation about $y$ axis

$$
\beta_{1}=\operatorname{Arctan}\left(\left(d_{1}-d_{3}\right) / B_{1}\right)
$$

Equations $1+2+3+4$

$$
\begin{aligned}
& 4 E_{1}=x(1)-x \emptyset(1)+x(2)-x \emptyset(2)+x(3)-x \emptyset(3)+x(4)-x \emptyset(4) \\
& E_{1}=\frac{1}{4}\left(d_{1}+d_{2}+d_{3}+d_{4}\right)
\end{aligned}
$$

Rotation about $Z$ axis $\gamma_{1}$ is given by

$$
\gamma_{1}=(X(9)-X \emptyset(9)) / R
$$

Consider the $\gamma_{1}$ rotation about $Z$ axis (Fig. 57).

The location of the center of gravity of the angle is given by

$$
R_{0}=\left(X X^{2}+Y y^{2}\right)^{\frac{1}{2}}
$$

In Fig. 57

$$
\begin{aligned}
\text { O" } C=^{\prime} & R_{0} \cos \left(\alpha_{1}+\gamma_{1}\right) \\
O^{\prime \prime} C= & R_{0} \cos \alpha_{1} \cos \gamma_{1}-R_{0} \sin \alpha_{1} \sin \gamma_{1} \\
O^{\prime \prime} C= & \left(X X^{2}+Y Y^{2}\right)^{\frac{1}{2}} X X \cos \gamma_{1} /\left(X X^{2}+Y Y^{2}\right)^{\frac{1}{2}}-\left(X X^{2}+Y Y^{2}\right)^{\frac{1}{2}} X \\
& Y Y \sin \gamma_{1} /\left(X X^{2}+Y Y^{2}\right)^{\frac{1}{2}}
\end{aligned}
$$


$x x^{1}=O^{\prime \prime} C=x x \cos \gamma_{1}-y y \sin \gamma_{1}$

Similarly

$$
\begin{aligned}
& \text { O"D }=R_{0} \sin \left(\alpha_{1}+\gamma_{1}\right) \\
& \text { O"D }=R_{0} \sin \alpha_{1} \cos \gamma_{1}+R_{0} \cos \alpha_{1} \sin \gamma_{1} \\
& Y Y^{1}=\text { O"D }=Y Y \cos \gamma_{1}+X X \sin \gamma_{1}
\end{aligned}
$$

Now consider the rotation $\theta_{1}$ about $X$ axis (Fig. 58)

$Z Z_{1}^{\prime \prime}=Y Y^{1} \sin \theta_{1}$

$Y Y^{1}=O^{\prime \prime} D=Y Y \cos \gamma_{1}+X X \sin \gamma_{1}$

$Z Z^{\prime \prime}=\left(Y Y \cos \gamma_{1}+X X \sin \gamma_{1}\right) \sin \theta_{1}$

$Y Y^{\prime \prime}=Y Y^{1} \cos \theta_{1}$

$Y Y "=\left(Y Y \cos \gamma_{1}+X X \sin \gamma_{1}\right) \cos \theta_{1}$

$Y^{1}=Y Y^{1}-Y Y^{\prime \prime}$

$Y^{1}=\left(Y Y \cos \gamma_{1}+X X \sin \gamma_{1}\right)\left(1-\cos \theta_{1}\right)$

For rotation $\beta_{1}$ about $Y$ axis (Fig 59)

$$
\begin{aligned}
& x X^{\prime \prime}=X x^{1} \cos \beta_{1} \\
& X x^{\prime \prime}=\left(x x \cos \gamma_{1}-Y y \sin \gamma_{1}\right) \cos \beta_{1} \\
& x^{1}=\left(x x \cos \gamma_{1}-Y y \sin \gamma_{1}\right)\left(1-\cos \beta_{1}\right) \\
& Z Z_{1}^{\prime \prime}=x x^{1}\left(\sin \beta_{1}\right) \\
& Z Z_{1}^{\prime \prime}=-\left(x x \cos \gamma_{1}-Y y \sin \gamma_{1}\right) \sin \beta_{1}
\end{aligned}
$$

The new location of center of gravity of the angle at the first end is given by

$$
\begin{aligned}
& M=X X "=\left(X X \cos \gamma_{1}-Y Y \sin \gamma_{1}\right) \cos \beta_{1} \\
& N=Y Y^{\prime \prime}=\left(Y Y \cos \gamma_{1}+X X \sin \gamma_{1}\right) \cos \theta_{1}
\end{aligned}
$$




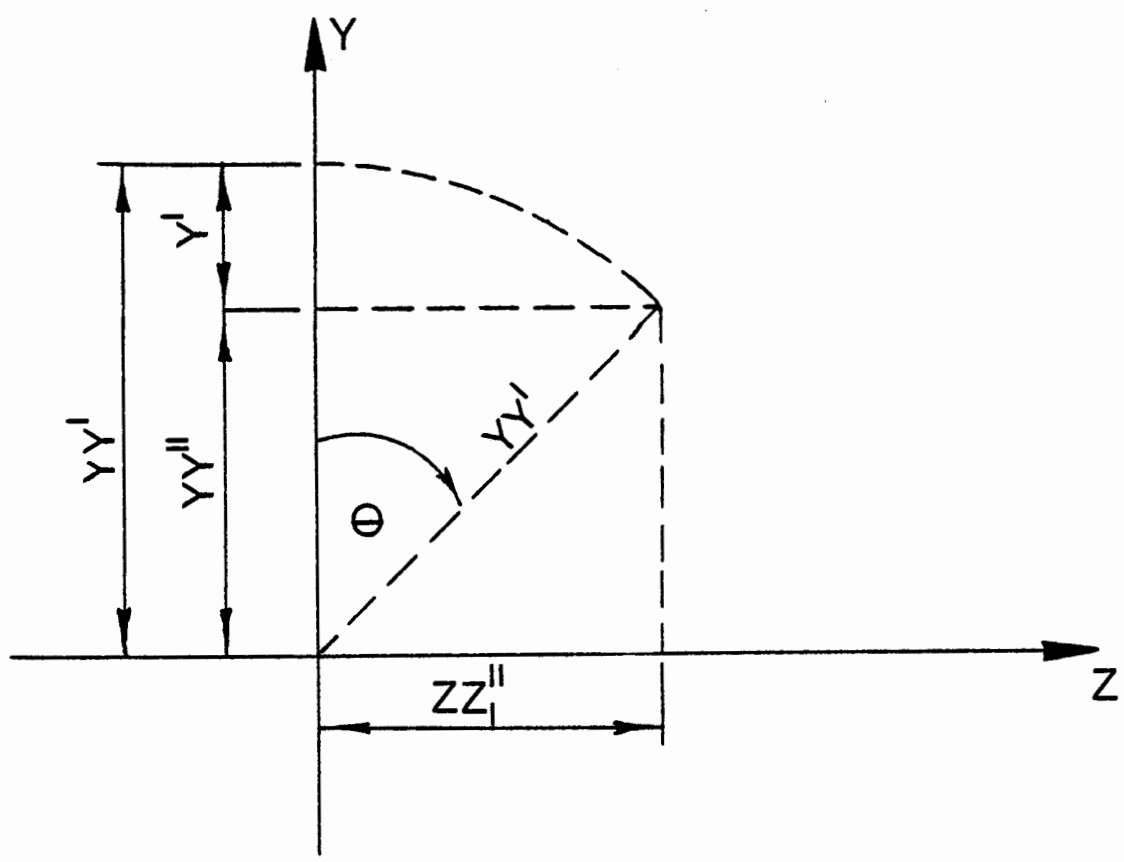

Figure 58 Rotation of the end plate about the $x$ axis

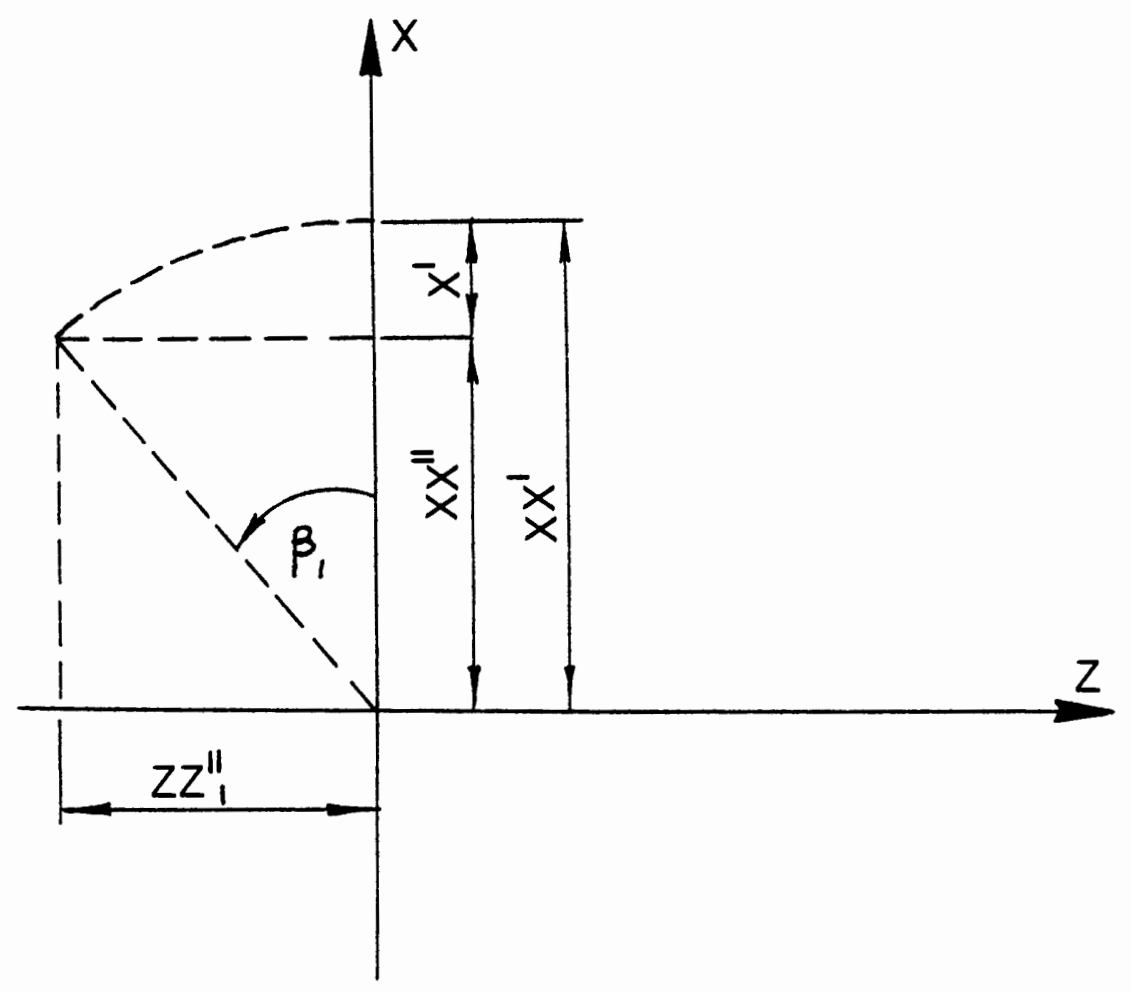

Figure 59 Rotation of the end plate about the $y$ axis 


$$
\begin{aligned}
P=E_{1}+Z Z^{\prime \prime} & =\left(Y Y \cos \gamma_{1}+X X \sin \gamma_{1}\right) \sin \theta_{1} \\
& -\left(X X \cos \gamma_{1}-Y Y \sin \gamma_{1}\right) \sin \beta_{1}+E_{1} \\
& =Y Y\left(\cos \gamma_{1} \sin \theta_{1}+\sin \gamma_{1} \sin \beta_{1}\right) \\
& +X X\left(\sin \gamma_{1} \sin \theta_{1}-\cos \gamma_{1} \sin \beta_{1}\right) \\
& +E_{1}
\end{aligned}
$$

Hence the position vector of the center of gravity of angle $v_{1}$ at the first end is given by

$$
\underline{v}_{i}=\underline{M i}+N \underline{j}+P \underline{k} .
$$

$\underline{j}, \underline{j}$ and $\underline{k}$ are unit position vectors in $x, y$ and $z$ directions respectively.

Similarly let $X \emptyset(5), X \emptyset(6), X \emptyset(7), X(8)$ and $X \emptyset(10)$ be the initial gage readings at locations $5,6,7,8$ and 10 (Fig. 55). Let $X(5), X(6)$, $X(7), X(8)$ and $X(10)$ be the gage readings after displacements. Let $E_{2}$ be the translation of the center of the end plate in the $z$ direction. Writing similar equations for the second end

$$
\begin{array}{lr}
X \emptyset(5)+E_{2}+(1 / 2) B_{2} \operatorname{Tan} \theta_{2}+(1 / 2) B_{2} \operatorname{Tan} \beta_{2}=x(5) & 5 \\
X \emptyset(6)+E_{2}-(1 / 2) B_{2} \operatorname{Tan} \theta_{2}+(1 / 2) B_{2} \operatorname{Tan} \beta_{2}=x(6) & 6 \\
X \emptyset(7)+A_{2}+(1 / 2) B_{2} \operatorname{Tan} \theta_{2}-(1 / 2) B_{2} \operatorname{Tan} \beta_{2}=x(7) & 7 \\
X \emptyset(8)+A_{2}-(1 / 2) B_{2} \operatorname{Tan} \theta_{2}-(1 / 2) B_{2} \operatorname{Tan} \beta_{2}=x(8) & 8
\end{array}
$$

Adding equations $5,6,7$ and 8 we get $E_{2}=\frac{1}{4}(X(5)-X \emptyset(5)+$

$$
x(6)-X \emptyset(6)+x(7)-X \emptyset(7)+x(8)-x \emptyset(8))
$$

Similarly we obtain location of center of gravity of the angle at the second end as follows

$$
\begin{aligned}
& R=X X_{2} "=\left(X X \cos \gamma_{2}-Y Y \sin \gamma_{2}\right) \operatorname{Cos} \beta_{2} \\
& S=Y Y_{2}^{\prime \prime}=\left(Y Y \cos \gamma_{2}+X X \sin \gamma_{2}\right) \cos \theta_{2} \\
& T=Z Z_{2}^{\prime \prime}=-Y Y\left(\cos \gamma_{2} \sin \theta_{2}+\sin \gamma_{2} \sin \beta_{2}\right)+\text { continued }
\end{aligned}
$$


$-x x\left(\sin \gamma_{2} \sin \theta_{2}-\cos \gamma_{2} \sin \beta_{2}\right)-E_{2}+L$

Position vector of the center of gravity of the angle at the second end $V_{2}$ is given by

$$
\begin{aligned}
& \underline{V}_{2}=R \underline{i}+S \underline{j}+\underline{T} \underline{ } \\
& L^{1}=\left((M-R)^{2}+(N-S)^{2}+(P-T)^{2}\right)^{\frac{1}{2}}
\end{aligned}
$$

$L^{1}$ is the distance between the center of gravity of the test member from one end to the other.

Hence the axial displacement of the test member is given by

$$
\delta L=L-L^{\top}
$$

The computer program used to perform the above calculations is as follows.

\section{INPUT DATA FOR THE COMPUTER PROGRAM}

$\begin{array}{ll}X X & =\text { Eccentricity of the test member in the } X \text { direction (Fig. } 53 \\ Y Y & =\text { Eccentricity of the test member in the } Y \text { direction (Fig 53) } \\ B & =\text { Distance between concentric gages (Fig 53) } \\ L & =\text { Length of the test member } \\ P & =\text { Load value at each increment step } \\ P_{M} & =\text { Ultimate load of the test member } \\ R & =\text { Radius of the ball } \\ X(N) & =\text { Gage reading at location } N \text { (Fig 55) } \\ N=1 \text { to } 10 & \end{array}$

Resetting of gages need to be done just before any of the dial gages reach their maximum range. The reading of such a gage in its current position is noted and then moved to a newer position either 
towards or away from the end plate to facilitate further readings with the same gage. Readings of gages after resetting were taken into account for the difference.

Reset readings are indicated to the computer by a character " $Z$ " for the load.

The output printed is axial load, gage readings and axial displacement for each load step. 
FLOW DIAGRAM TO CALCULATE AXIAL

DISPLACEMENT FOR BALL-BALL CONFIGURATION

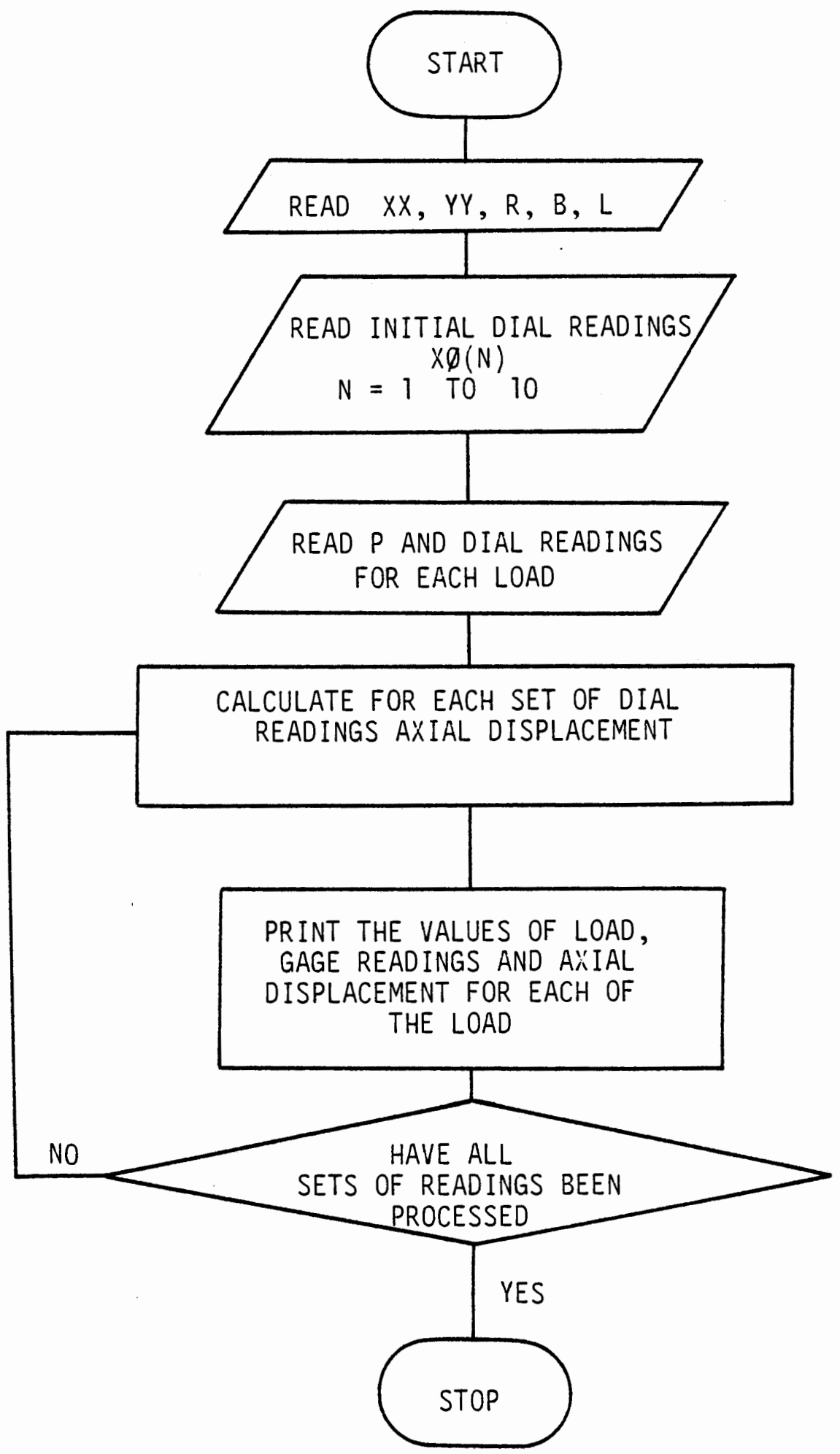


COMFUTEF FROGRAM

*!... IT

10 WEM THIS FWOOFAM CALCLLATES THE AXIAL DTSFLACEMENT FOF

20 REEM A MEMEEF WITH BALL BALL CONFTGURATIOH

2 DIM $X 0(10), X(1,0), X 1(10), L$ L

26. READ $Y 1, Y 2, R, E, L, F$

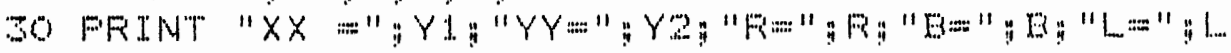

3 PRTNT "LOAD GAGE FEADINGS"

36 Aि $=0$

$37 \quad A A=0$

$\because 8 T S=0$

$39 \quad+4=0$

46) $83=0$

$41 \quad 84: 4=0$

$42 \quad 63=0$

$4364=0$

50 FOF $N=1 . T O 10$

B REEAD XO(N)

NEXT N

ES READ L.

60 IF L良="Z" BOTO 500

70 IF L

190 FOF $N=1$ TO 10

1.91 READ $X(N)$

$19 \div \quad X \|(N)=X(N) \cdots X(N)$

193 IF NO4 THEN 195

1.94 (30) 200

195 IF NC9 THEN 198

$19600 T 200$

$198 \times 1 .(N)=-\cdots .(N)$

WOO NEXT N

$210 A \mathrm{~A}=(X \mathrm{X}(1)+X 1(2)+X 1(3)+X \mathrm{X}(4)) / 4+A .5$

220 A2 $=(X 1(5)+X 1(6)+X 1(7)+X 1(9)) ; 4+44$

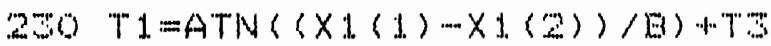

$240 \quad T 2=A T N(\langle X 1(B)+X 1(b)) / E+T 4$

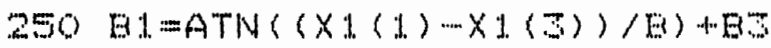

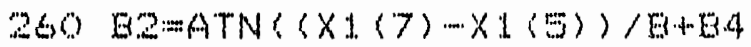

$270 \quad(31=\times 1.9) / F+B$

$275 \quad 02=\times 1(10) / 6+64$

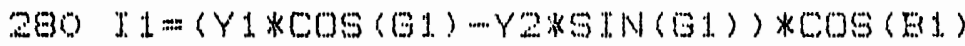

$290 \mathrm{~J} 1=(Y 2 * 005(01)+Y 1 * \operatorname{TTN}(01)) * 005(\mathrm{TH})$

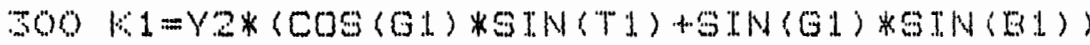

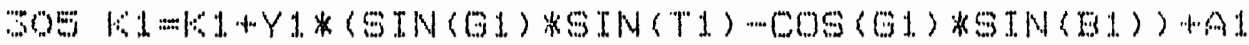

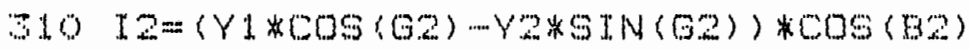




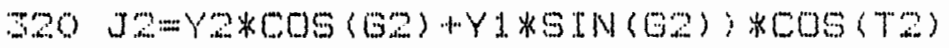

$3002=Y 2 *(009(62) * 5 I N(T 2)+9 I N(02) * 9 I N(E 2))$

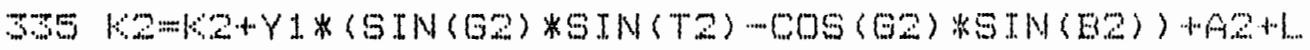

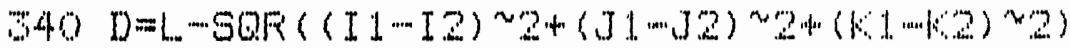

400 PFINT L得 $X(1) ; \times(2) ; \times(2) ; \times(4) ; \times(5)$

402 PRTNT $x(6) ; x(7) ; x(8)$

405 PEINT $X(9) \because X(10)\}$

410 FRINT" DELTA

420 GOTO 55

500 A $\quad=A 1$

510 A4 $=A 2$

$520 \quad B S=B 1$

$530 \quad B 4=82$

$540 \quad 73=71$

550 T4 $=72$

$560 \quad 03=61$

$570 \quad 64=02$

600 GOTO 50

3000 DATA - , $842,-, 721,2,5,7,66,25,0$

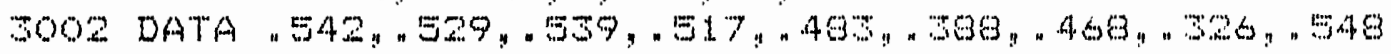
3005 DATA 561

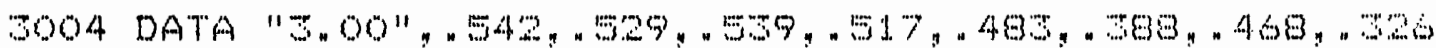

3005 DATA $.548, .561$.

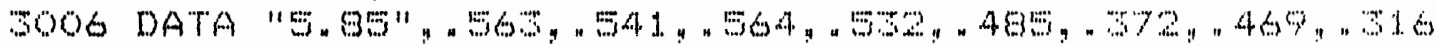

$30 \% 7$ DATA "5.48, .558

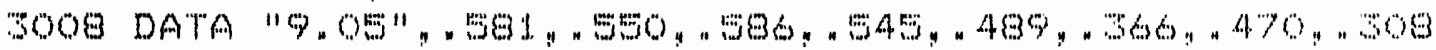

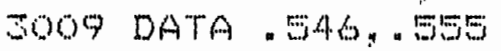

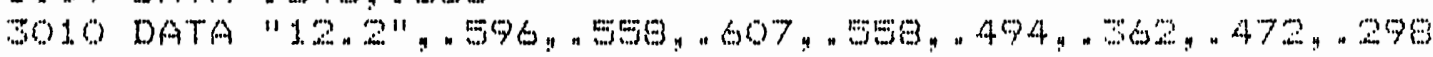

3011 DATA . $544, .55$

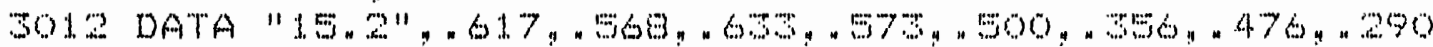

313 DATA . $542, .551$

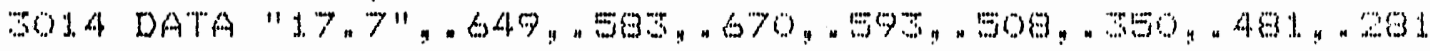

S15 DATA $5.51, .550$

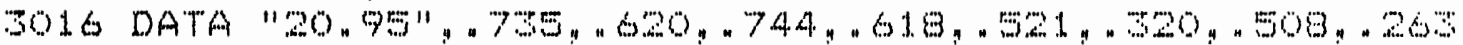

3017 DATA .55\%, "548

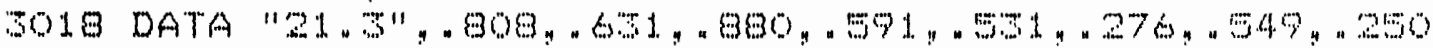

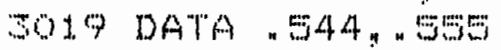

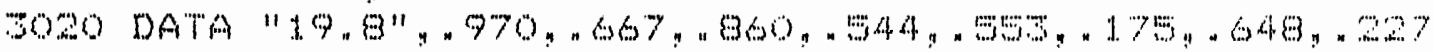

3021 DATA .595, 576

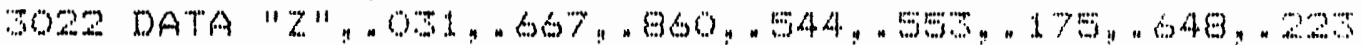

3025 DATA " 595,576

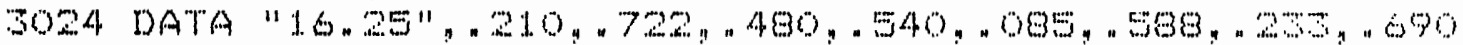

BOES DATA "606! "588

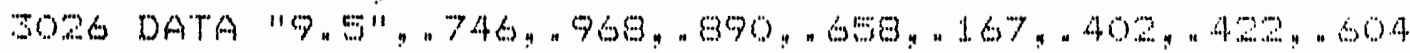

3027 DATA "607. "69\%

3030 DATA "GTF"

$40 \% \mathrm{END}$ 


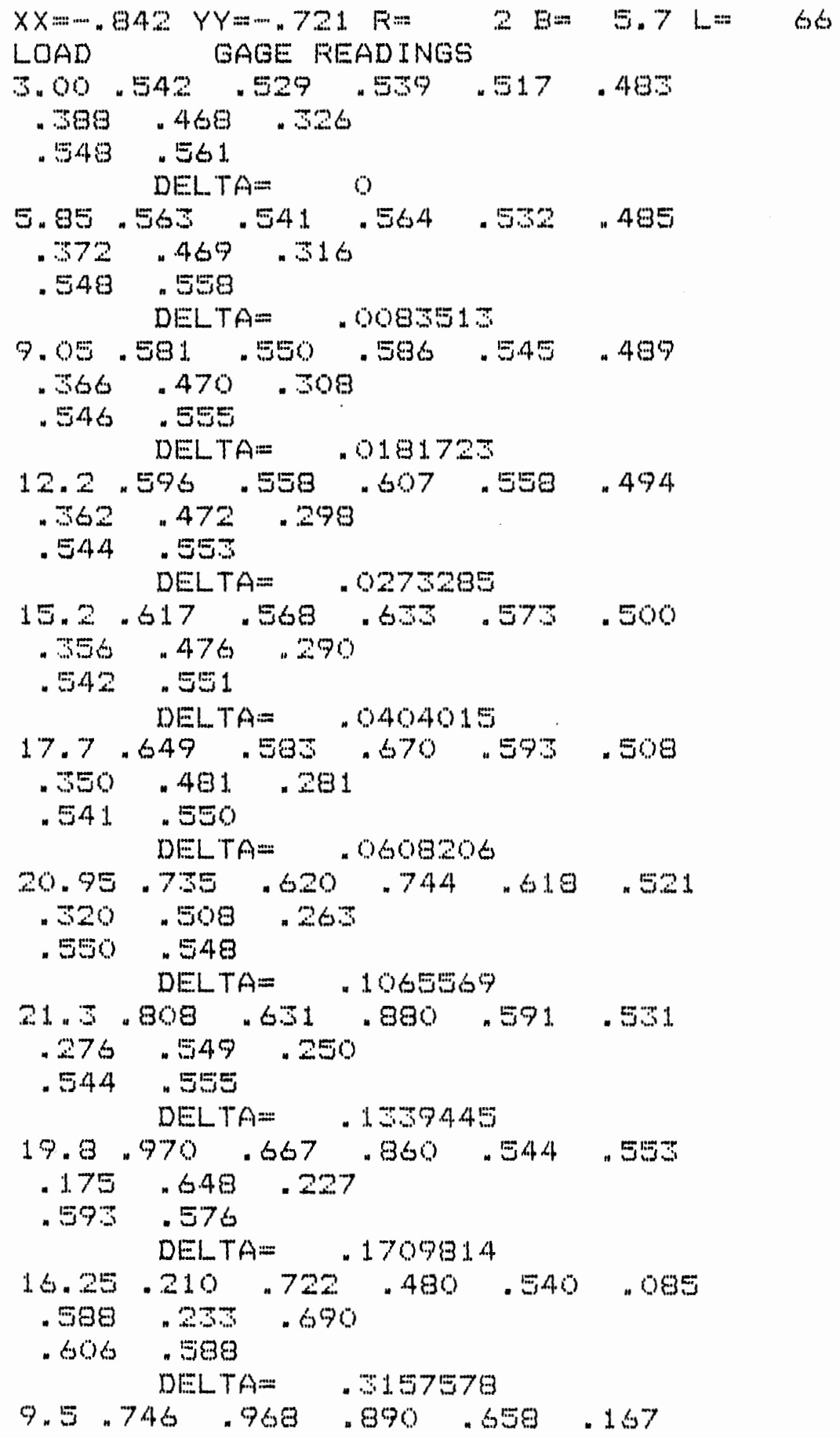


$\begin{array}{lll}.402 & .422 & .604 \\ .607 & .595 & \\ & 0 E L T A= & .6049776\end{array}$

BEADY

* 